Rochester Institute of Technology

RIT Scholar Works

Theses

$12-2004$

\title{
Analysis of production control methods for semiconductor research and development fabs using simulation
}

Vikram Ramamurthi

Follow this and additional works at: https://scholarworks.rit.edu/theses

\section{Recommended Citation}

Ramamurthi, Vikram, "Analysis of production control methods for semiconductor research and development fabs using simulation" (2004). Thesis. Rochester Institute of Technology. Accessed from

This Thesis is brought to you for free and open access by RIT Scholar Works. It has been accepted for inclusion in Theses by an authorized administrator of RIT Scholar Works. For more information, please contact ritscholarworks@rit.edu. 
Rochester Institute of Technology

\title{
ANALYSIS OF PRODUCTION CONTROL METHODS FOR SEMICONDUCTOR RESEARCH AND DEVELOPMENT FABS USING SIMULATION
}

\author{
A Thesis \\ Submitted in partial fulfillment of the \\ requirements for the degree of \\ Master of Science in Industrial Engineering
}

in the

Department of Industrial \& Systems Engineering Kate Gleason College of Engineering

by

Vikram Ramamurthi

B.E., Instrumentation Engineering, University of Mumbai, 2002

December, 2004 


\author{
DEPARTMENT OF INDUSTRIAL AND SYSTEMS ENGINEERING \\ KATE GLEASON COLLEGE OF ENGINEERING \\ ROCHESTER INSTITUTE OF TECHNOLOGY \\ ROCHESTER, NEW YORK
}

CERTIFICATE OF APPROVAL

\title{
M.S. DEGREE THESIS
}

The M.S. Degree Thesis of Vikram Ramamurthi

has been examined and approved by the thesis committee as satisfactory for the thesis requirement for the Master of Science degree Approved by:

Dr. Michael E. Kuhl, Thesis Advisor

Dr. Karl D. Hirschman

Dr. Sudhakar R. Paidy 


\section{ACKNOWLEDGEMENTS}

I am indebted to my advisor, Dr. Michael Kuhl, for his guidance and support throughout the course of the research work. I would like to thank him for his contribution and encouragement, which have seen me through the successful completion of this thesis. Heartfelt thanks go out to Dr. Karl Hirschman for his proactive contribution as a thesis committee member. His innovative approaches and ideas made the research work enjoyable. I would like to thank Dr. Sudhakar Paidy for his association with this thesis as a committee member. His suggestions and advice have been invaluable.

I would also like to take this chance to thank Dr. Jacqueline Mozrall, head of the Industrial and Systems Engineering department, Dr. Santosh Kurinec, head of the Microelectronic Engineering department and Dr. Lynn Fuller for their support. I am thankful to Marilyn Houck and Jeffrey Marshall, who have assisted me throughout my term as a graduate student. I am grateful to all the professors I took courses with. The knowledge they helped me to gain has been put to good use in this thesis. Special thanks go out to the graduate students in the Industrial and Systems Engineering department. I cherish my interactions and discussions with them.

I thank my uncle and aunt for giving me a home away from home and going out of their way to help me at all times. I thank my grandparents for believing and instilling confidence in me.

Lastly and most importantly, I would like to thank my parents and my sister. Their love and support will never go unnoticed. I dedicate this thesis to them. 


\section{ABSTRACT}

The importance of semiconductor device fabrication has been rising steadily over many years. Integrated circuit technology and innovation depends on successful research and development (R\&D). R\&D establishes the direction for prevailing technology in electronics and computers. To be a leader in the semiconductor industry, a company must bring technology to the market as soon as its application is deemed feasible. Using suitable production control methods for wafer fabrication in $\mathrm{R} \& \mathrm{D}$ fabs ensures reduction in cycle times and planned inventories, which in turn help to more quickly, transfer the new technology to the production fabs, where products are made on a commercial scale. This helps to minimize the time to market. The complex behavior of research fabs produces varying results when conventional production control methodologies are applied. Simulation modeling allows the study of the behavior of the research fab by providing statistical reports on performance measures. The goal of this research is to investigate production control methods in semiconductor $R \& D$ fabs. A representative $R \& D$ fab is modeled, where an appropriate production load is applied to the fab by using a representative product load. Simulation models are run with different levels of production volume, lot priorities, primary and secondary dispatching strategies and due date tightness as treatment combinations in a formally designed experiment. Fab performance is evaluated based on four performance measures, which include percent on time delivery, average cycle time, standard deviation of cycle time and average work-in-process. Statistical analyses are used to determine the best performing dispatching rules for given fab operating scenarios. Results indicate that the optimal combination of dispatching rules is dependent on specific fab characteristics. However, several dispatching rules are found to be robust across performance measures. A simulation study of the Semiconductor \& Microsystems Fabrication Laboratory (SMFL) at the Rochester Institute of Technology (RIT) is used to verify the results. 


\section{TABLE OF CONTENTS}

1 Introduction............................................................................................................................ 1

1.1 An Overview on Semiconductor Manufacturing ................................................ 2

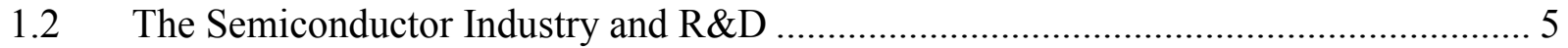

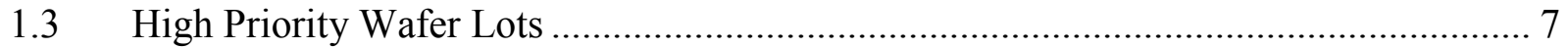

1.4 The Role of Industrial Engineers in the Semiconductor Industry.............................. 7

1.4.1 Process Improvements in Semiconductor Fabs ............................................. 8

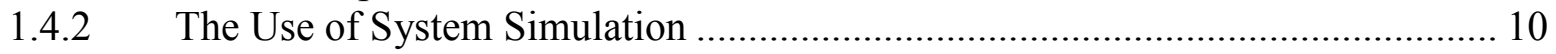

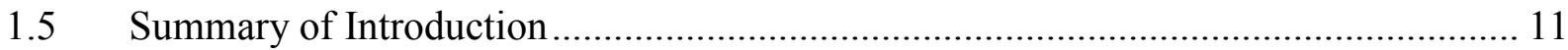

2 Problem Statement....................................................................................................................... 12

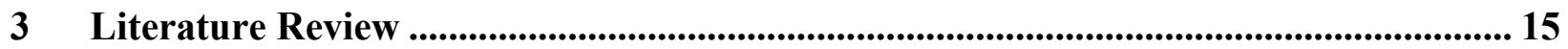

3.1 Past Research on Improvements in R\&D Fab Productivity .................................... 15

3.2 Past Research on Improvements in Production Fab Productivity............................. 18

4 Simulation of Representative Semiconductor R\&D Fabs...................................................... 26

4.1 Simulation Model Assumptions and Details......................................................... 26

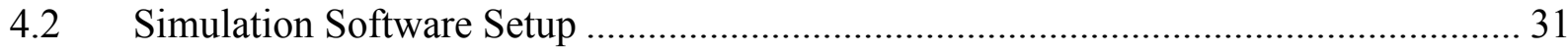

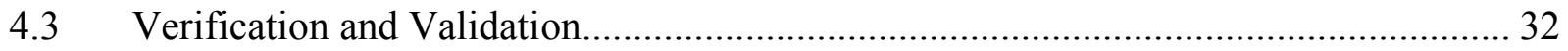

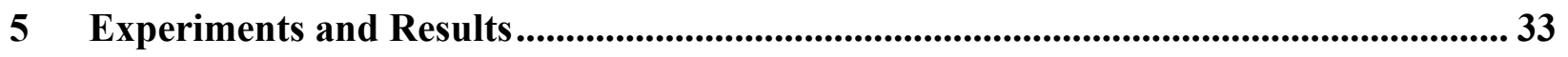

5.1 Experiment 1: The Effect of WIP on Average Cycle Time and Throughput .............. 33

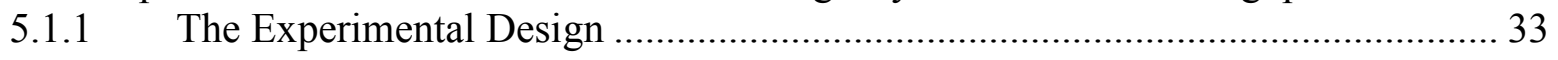

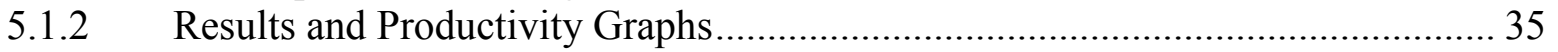

5.1.3 Conclusions of Experiment 1 1.................................................................. 37

5.2 Experiment 2: The Effects of Resource Levels and WIP on Productivity .................. 38

5.2.1 The Experimental Design ............................................................................. 38

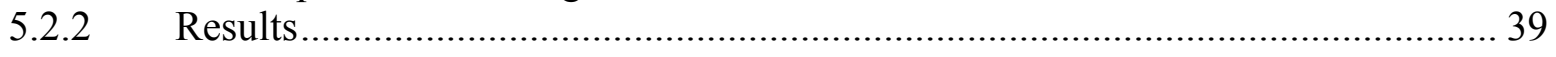

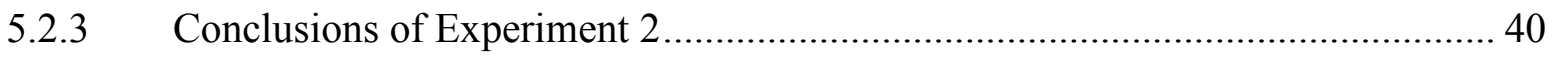

5.3 Experiment 3: Comparing Primary/Secondary Dispatching Rules ........................... 41

5.3.1 Simulation Model............................................................................ 42

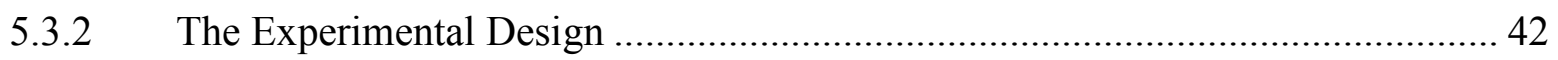

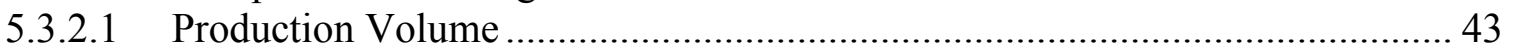

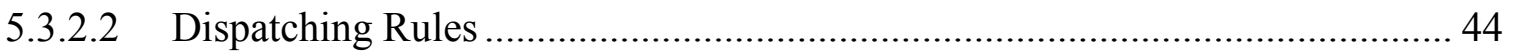

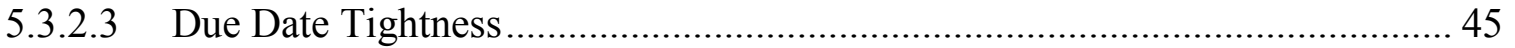

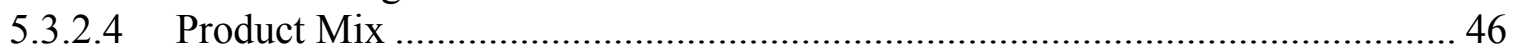

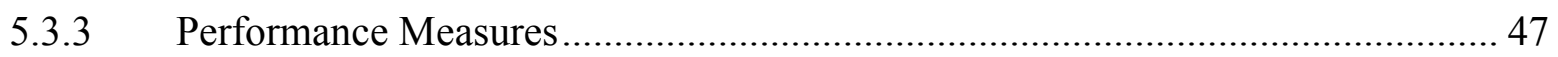

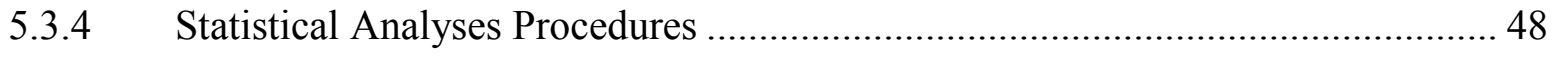

5.3.4.1 Analysis of All Factors and Their Interactions .......................................... 49 
5.3.4.2 Analysis of Dispatching Rules, Product Mix and Due Date Tightness With

Given Levels of Production Volume ............................................................................ 50

5.3.4.3 Analysis of Dispatching Rules and Due Date Tightness With Given Levels of

Production Volume and Product Mix ........................................................................... 52

5.3.4.4 Using Due Date Tightness as a Controllable Factor ...................................... 56

5.3.4.5 Performance of the Due Date Based Rules ................................................. 59

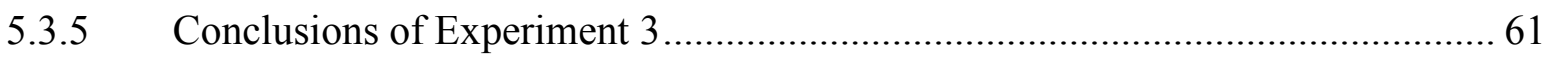

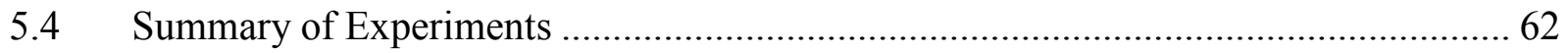

6 Semiconductor Research and Development Fab Case Study .................................... 64

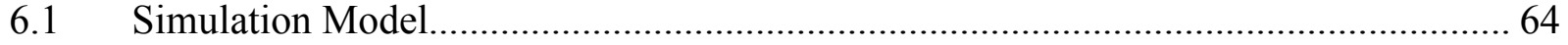

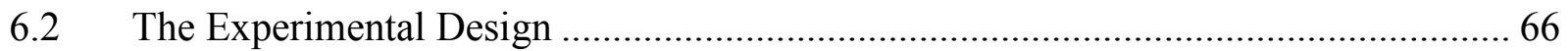

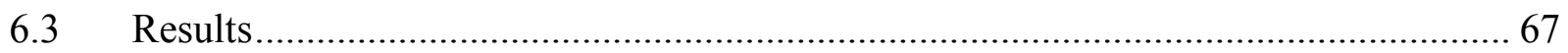

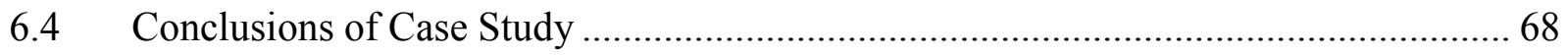

7 Conclusions and Recommendations For Future Research .............................................69

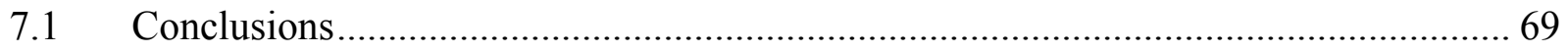

7.2 Recommendations for Future Research ........................................................... 70

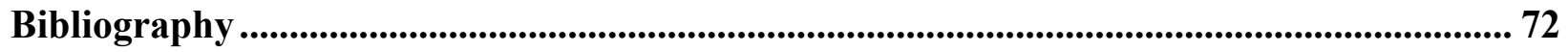

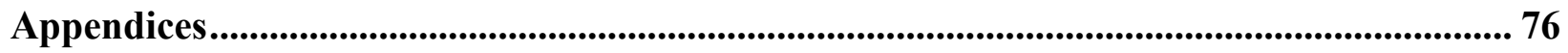

Appendix A. Data Averaged from Replications of Simulation Runs For Experiment 3......... 76

Appendix B. Four Factor ANOVA Results ................................................................... 78

Appendix C. Three Factor ANOVA Tables for Production Volume of 154 lots/year ............ 80

Appendix D. Three Factor ANOVA Tables for Production Volume of 128 lots/year ............. 82

Appendix E. Two Factor ANOVA and Tukey Tables...................................................... 84

Appendix F. Analysis of Dispatching Rules With Given Levels of Production Volume,

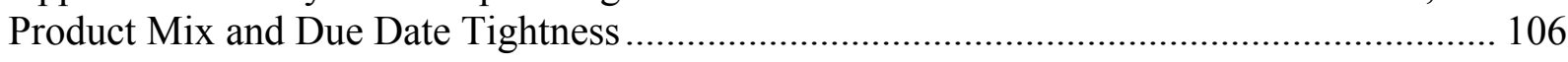

Appendix G. Simulation Models of Semiconductor Research and Development Fabs and

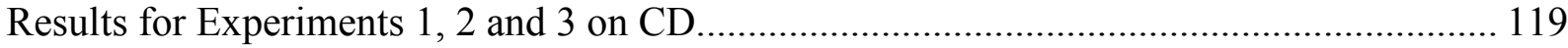




\section{INTRODUCTION}

Silicon replaced germanium in the early 1960 s as the dominant material for semiconductor device fabrication. Many factors went in favor of the use of silicon wafers for fabrication. Silicon can be oxidized easily to form silicon dioxide $\left(\mathrm{SiO}_{2}\right)$, which acts as a barrier for the diffusion steps needed in integrated circuit (IC) fabrication. Most importantly, silicon is abundantly available in nature, which makes it an inexpensive raw material (May \& Sze, 2003). The exceptional qualities of this raw material have opened the doors to radical technology that has changed the world. The use of computers, calculators, cell phones, transistors and other indispensable smart devices has become possible due to semiconductor technology.

Integrated circuits are fabricated on silicon wafers in semiconductor manufacturing facilities, also called fabs. Technology and product development are key to the success of semiconductor manufacturers. Thus, most of the industry leaders have both production fabs, where products are made for sale to the public, and research and development (R\&D) fabs, where new technologies and products are designed and tested. Although production fabs and R\&D fabs may have similar tool sets, semiconductor production fabs operate differently than R\&D facilities. These differences arise from the scales of production, lot prioritization, material handling techniques and performance parameters. Production fabs aim at increasing throughput for maximizing profits whereas $\mathrm{R} \& \mathrm{D}$ fabs concentrate on developing new technology and minimizing time to market.

Production fabs in general are characterized by a low product mix, high production volumes, established products with standardized routings and established processes. On the other hand, R\&D fabs are characterized by large product mix with unique and/or non-standard routes, prioritization of research activities, random engineering holds and mandatory testing procedures. 
While a significant body of research exists for designing, analyzing and improving the performance of production fabs, very little has been done to study the performance of R\&D fabs. This research will focus on performance improvement of $R \& D$ fabs in terms of productivity, cycle time and due date performance. In general, this research will involve conducting simulation experiments on models of $R \& D$ fabs to determine factors that significantly effect fab performance. Furthermore, this research will investigate prioritization policies that are encountered in R\&D fabs.

In the next sub-sections, the background on semiconductor manufacturing is discussed along with the role of $R \& D$ fabs and their production control strategies. Finally, the role of simulation as an analysis tool is discussed.

\subsection{An Overview on Semiconductor Manufacturing}

In 1965, Gordon Moore, founder of Intel made his famous observation in his original paper which the press called Moore's Law. In this observation, Moore concluded that the observed trend of exponential growth in the number of transistors in an integrated circuit would continue. This means that the number of transistors on a chip would double every couple of years (Jaeger, 2002). Figure 1.1 shows the evolution of microprocessors beginning with the world's first single chip microprocessor, Intel 4004 in 1970. With advent in technology, the number of transistors on the chips began to increase and this increase corresponded with the observation made by Moore. The Intel Itanium 2 processor introduced in 2003 has 410,000,000 transistors in an integrated circuit. Moore's Law is expected to hold well into the future. Semiconductor manufacturing, which is the pace setter for Moore's Law, involves four basic steps as shown in Figure 1.2. 


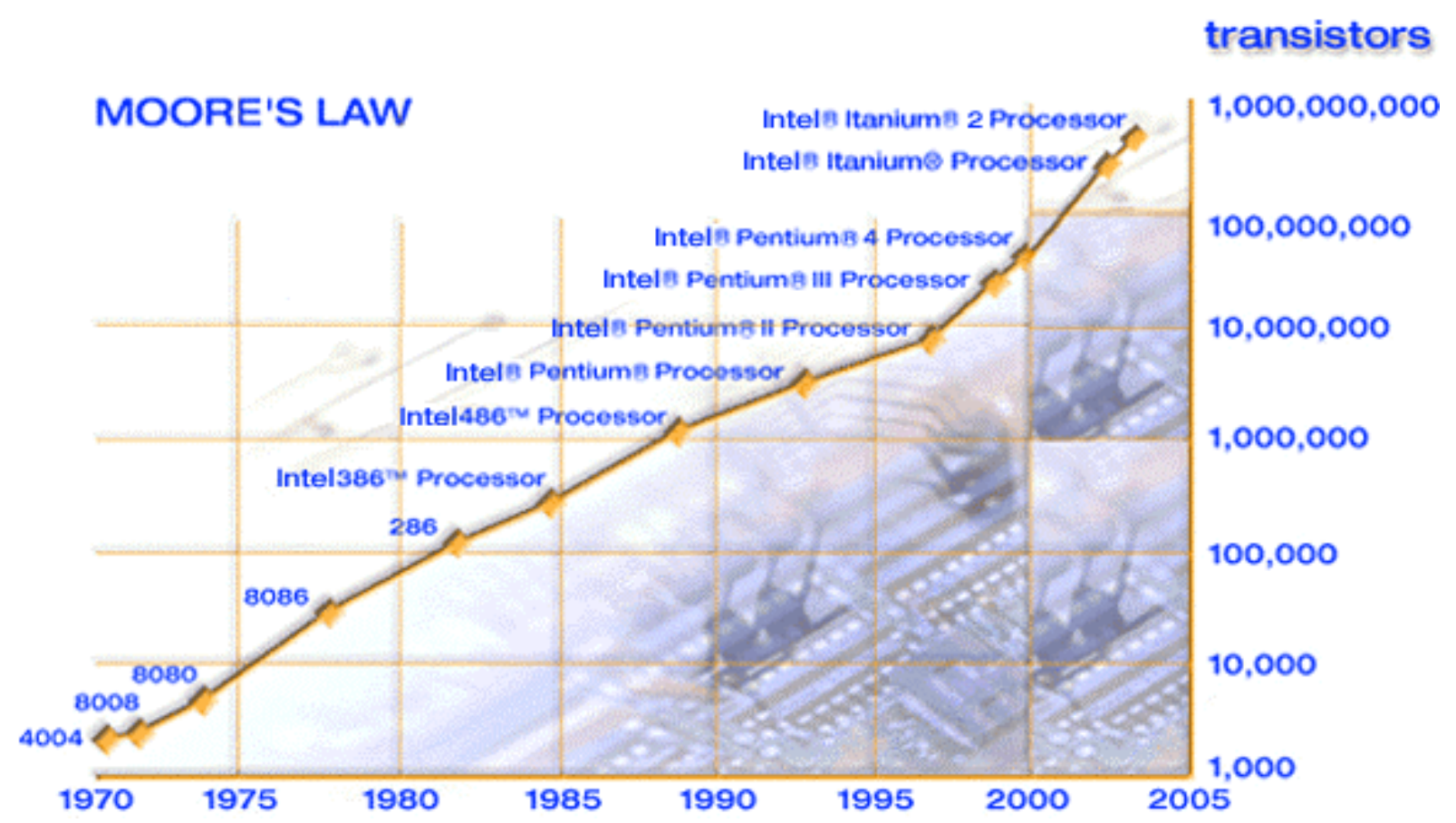

Figure 1.1: Realization of Moore's Law (http://www.intel.com/research/silicon/mooreslaw.htm)

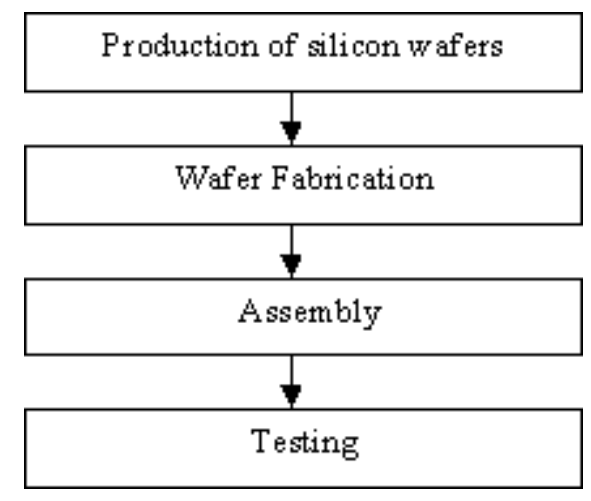

Figure1.2: Semiconductor Manufacturing Steps

The raw material, quartzite is distilled and reduced to form polycrystalline silicon and eventually single crystal silicon, in the form of ingots, using either the "Czochralski crystal growth" or the "Float Zone" method. The ingots are ground, polished and sawed according to the desired orientations to form silicon wafers (Wolf, Stanley, Tauber, \& Richard, 1986). Wafer fabrication is a process of integrating circuits on a silicon die. The first integrated circuits were fabricated at Texas instruments and Fairchild Semiconductor in the early 1960s. Simple logic 
gates and amplifier circuits were built using transistors and resistors. These were the first steps, which opened up the gates for bigger and better technology to follow. The level of integration on wafers has been doubling every two years and modern technology allows for integration of up to billions of components on a 20-mm x 20-mm die (Jaeger, 2002). Larger wafer diameters allow for simultaneous production of a large number of integrated-circuit dies. Clean room facilities these days are including tools in their layout that process wafers with a diameter of $300 \mathrm{~mm}$. Layers of integrated circuits are built on the silicon wafer in the wafer fabrication step. The integrated circuit is then assembled and packaged for use. Automatic test equipment (ATE) and test programs electrically test the assembled devices before shipment to the customer (Wolf et al., 1986).

A great amount of research has gone into optimizing the wafer fabrication process since it is the most expensive phase of semiconductor manufacturing. This stage involves the addition of layers of circuits on the silicon wafer through a sequence of 300-600 intricate steps. The process flow is highly reentrant, where many of the processing steps are repeated for every layer. Different sequences of steps are required for different circuits and some steps can include suboperations on different tools. Processing steps also vary in the quantity of wafers that are processed at one time. These quantities can be single wafers, wafer lots or batches of wafer lots. Typically a lot consists of 24-48 wafers, while a batch consists of 6 lots.

These characteristics of semiconductor manufacturing make it different from traditional manufacturing. Due to the reentrant nature of the flow, wafers at different stages of production queue up in front of the same tool a number of times. The smoothness of flow is hindered by this reentrant flow. Typical reentrant flow in a semiconductor manufacturing facility is shown in Figure 1.3. 


\subsection{The Semiconductor Industry and R\&D}

The invention of the transistor in 1947 served to make semiconductors, the leaders of the electronics revolution (Busch, 1999). An article on the top 100 R\&D spenders in the IEEE Spectrum publication ranks International Business Machines Corp., U.S. and Intel Corp., U.S., major players in the semiconductors and semiconductor equipment sector, in the top 15 (Hira, 2003). The semiconductor industry ranks behind only the automotive and communications industries in annual R\&D spending. In 2001, the industry spent $\$ 14.2$ billion on R\&D (Wolfe, 2002). This makes it a strategic industry that is vital to the financial and state security welfare and whose existence has a bearing on the economy with important forward and backward relationships through the presence of encouraging externalities. The technological progress of the semiconductor industry seen increase in productivity of fab products but has also motivated gains in industries linked to it (Green, 1996). Semiconductors form the backbone of the information age and are the roots of innovation in all electronic applications and defense mechanisms. Hence, the well being of a country's semiconductor industry is a necessary condition for competing in high technology (Busch, 1999).

The semiconductor industry is distinguished by big capital investment in $\mathrm{R} \& \mathrm{D}$, learning curves and constant enhancement. The industry falls into the category of high technology because a high proportion of $\mathrm{R} \& \mathrm{D}$ costs as a percentage of sales and also because a high number of the employees are scientists and engineers (Green, 1996). 


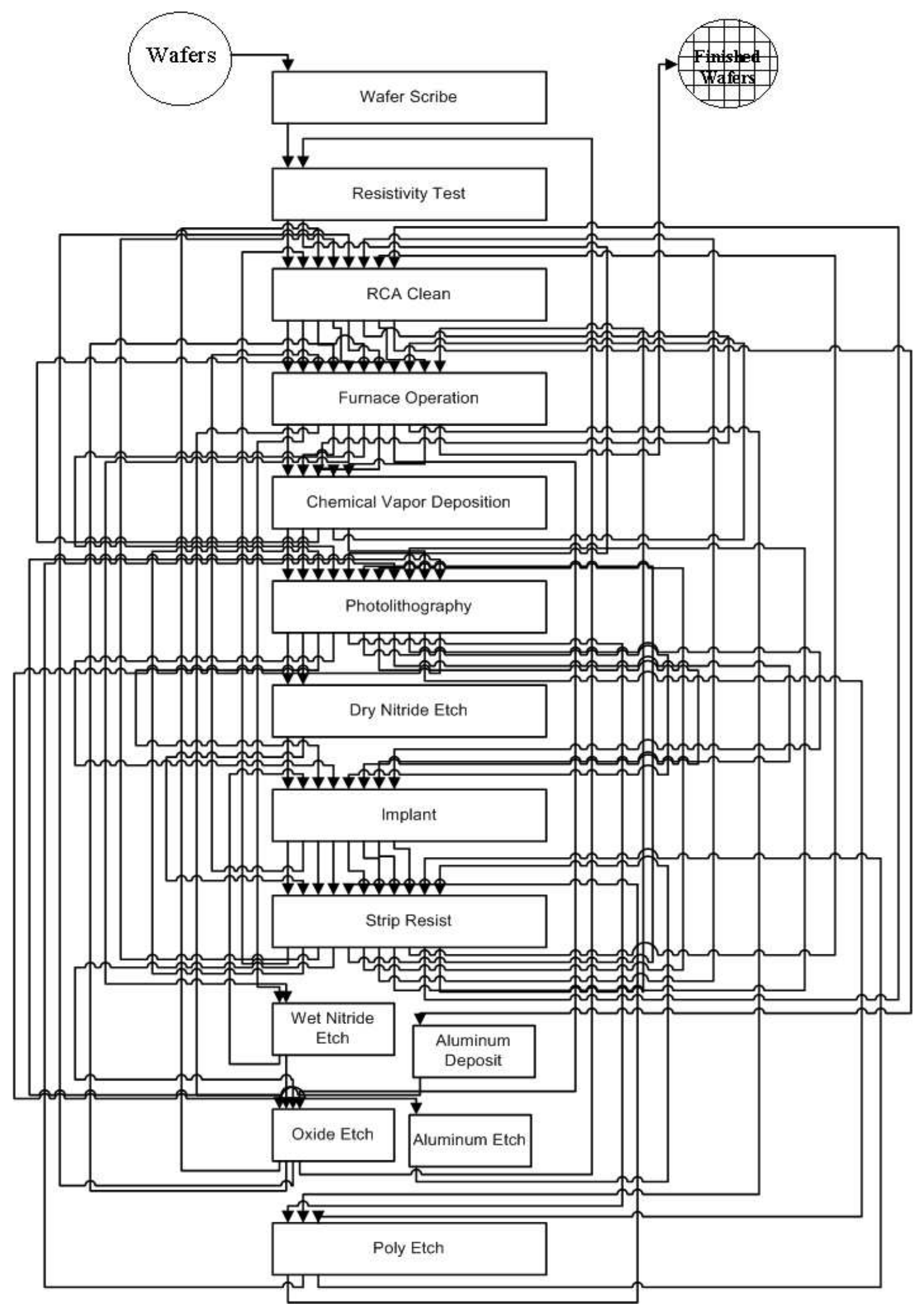

Figure 1.3: Sub-Micron CMOS Process at RIT 
Productivity is seen as an economic parameter that manifests the increase in efficiencies and outputs on the basis of present inputs. Progress in productivity has been made possible by technological advances via $R \& D$. $R \& D$ has been the biggest contributor to growth in productivity and plays a very important role in determining economic strength. Improvements in manufacturing methodologies, materials and tools are technological advances that improve productivity. This advance is essential since in the simplest terms companies can be competitive by maximizing output. It also is a big provider to growth in national income and productivity.

\subsection{High Priority Wafer Lots}

High priority lots in semiconductor research fabs are commonly referred to as 'hot lots'. Their presence in the work in process inventory has positive and negative effects. Hot lots give the management a clearer picture on delivery lead times but on the flipside, they disrupt the process flow on the fab floor (Ehteshami, Petrakian, \& Shabe, 1992). Hot lots are introduced into the system to meet marketing and business needs. These include decreasing manufacturing cycle time for the lots to decrease product delivery time and expediting the development time of a new process or product. Although hot lots have the same routes and step process times as other lots of the same product type, they get priority over regular lots for processing, which results in altered average cycle time and throughput (Narahari \& Khan, 1997 and Fronckowiak, Peikert, \& Nishinohara, 1996).

\subsection{The Role of Industrial Engineers in the Semiconductor Industry}

The semiconductor industry is a capital and technology driven industry. The R\&D, manufacture and marketing of a single chip estimates to more than $\$ 50$ million. According to the National Technology Roadmap for Semiconductors, equipment in a semiconductor manufacturing facility is close to $90 \%$ of the factory capital costs. Tools on an average cost between $\$ 500,000$ to $\$ 2,000,000$. 
It hence becomes essential to output products to the world market as soon as possible to recover invested funds and increase profits (Green, 1996). This is the only way for semiconductor companies to be competitive and gain on the learning curves.

In comparison to discrete manufacturing facilities, the unique challenges that semiconductor fabrication processes face are:

- Large number of process steps;

- Complex and reentrant process flows;

- Intermixture of lots and single wafers in tool queues;

- Batching of different lots having common processing recipes and times;

- Different rework routes for every product; and

- Regular use of metrology tools for parameter measurement and to judge the health of the wafer (Thompson, 1996).

Apart from implementing changes in the products and the fabrication procedures, improvement in productivity is achieved by increasing utilization of resources on the fab floor, reducing cycle times and effectively managing the work-in-process (WIP). This approach to increasing productivity can be achieved by the effective utilization of industrial engineering practices. The role played by industrial engineers (IEs) today, in this respect is very limited. Even though the importance of industrial engineering to this field has been realized, there still is room for industrial engineers to play a bigger role. (Padillo \& Meyersdorf, 1998)

\subsubsection{Process Improvements in Semiconductor Fabs}

A number of product and process developments have been made in recent times. These can be categorized as technology dependent. Improvement in the operation of the fab is system 
dependent and is the domain of IE. Technological advances in semiconductor manufacturing include feature size reduction, wafer size increase and better yield.

- Feature size reduction - Chips can now hold transistors that are 0.35 micron wide. These measure less than half the width of a strand of human hair. It is estimated that in another ten years the feature size will go down to 0.14 micron.

- Wafer size increase - With the use of wafers measuring $300 \mathrm{~mm}$ in diameter, more chips can be accommodated per wafer.

- Yield improvement - Yield is defined as the percentage of good die to the total number of die on a finished wafer.

Operational improvements have been historically proven to account for 7 to $10 \%$ of annual productivity rate. Most of the operational improvements have come from technology dependent developments like equipment performance, quality of raw materials and technological advances. (Padillo et al., 1998)

Optimizing the process flow on the fab floor can offset the increase in operational costs attributed to these technological advances. System dependent problems relating to flow and capacity that have consequences on performance and efficiencies will have to be tackled. IEs use diagnostic tools to evaluate policies and existing practices on issues concerning:

- Resource scheduling;

- Resource utilization;

- Fab floor layout;

- WIP; and

- Process routings and times. 
Industrial engineers play a vital role in maintaining a semiconductor firm's competitiveness in this age of short product life cycles and complex procedures. An industrial engineer effectively uses his skills to bridge the gap between production targets and actual performance levels (Padillo et al., 1998).

\subsubsection{The Use of System Simulation}

Diagnostic tools used by decision makers range from classical and traditional methods to modern computer software including system simulation, queuing theory, mathematical programming and heuristics, statistical process control and computer-aided design (CAD). Computer tools are used to account for fab floor constraints for planning and scheduling systems when crucial decisions are made. The planning process gets intricate when new constraints are introduced into the system due to design evolution.

The smooth running of the system depends on high machine utilization and short cycle times to ensure product line flexibility and good throughput rates. Process flows and data in semiconductor manufacturing systems are getting intricate by the day. The presence of too many interdependent variables in the various manufacturing disciplines of design, engineering and management become too cumbersome to handle. Many decisions made affect the future running of the system since they have a long-term effect. So, it makes it really unsafe to leave these decisions to instinct. These decisions can be modeled using simulation software and evaluated for feasibility. The best way to going about comprehending the concerned manufacturing system is to understand the layout and process flow from the simulation model.

In essence, semiconductor manufacturing facilities use simulation software in three main areas:

- Dispatch rule testing; 
- Forecasting plan, schedule and "what-if" situations; and

- Integrating the simulation software with Manufacturing Execution System software for real-time dispatching (Thompson, 1996).

Leading names in semiconductor manufacturing employ industrial engineers to use simulation software for the above purposes.

\subsection{Summary of Introduction}

The wafer fabrication process in semiconductor fabs is highly complex and reentrant. In semiconductor R\&D fabs, large product mixes with unique and/or non-standard routes, prioritization of research activities, random engineering holds and mandatory testing procedures characterize this process. Since semiconductor R\&D fabs feed technology to the production fabs, it is important to minimize the time-to-market for this technology. Industrial engineers effectively use their skills to bridge the gap between production targets and actual performance levels. For this purpose, industrial engineers use system simulation to comprehend the manufacturing system to understand the layout and process flow. 


\section{PROBLEM STATEMENT}

To gain a large share of the market, a semiconductor company needs to minimize time to market to make its technology commercially available faster than its competitors. This is essential for a company to maximize profits (Johal, 1998). Minimizing time to market can be achieved by shorter cycle times in the various stages of new product development, which include the concept design, the detailed design and the production of prototypes. This thesis investigates production control methods in semiconductor R\&D fabs. The appropriate use of which, will enable a faster transfer of technology to the production fabs. This in turn reduces the time to make the product commercially available.

The product and process development phase is one of the most complex and expensive steps in semiconductor manufacturing. With advent in technology, Very Large Scale Integration (VLSI) allows for more and more chips to be integrated into the wafer. A significant reinvestment of revenue goes into supporting $R \& D$ fabs to maintain these technological advances in the semiconductor industry. R\&D fabs operate differently than production fabs. A research fab may host several processes and products at varying WIP levels and priorities. Hindrances to process flow like random stoppages, tool reservations and lot prioritization are inherent characteristics of $R \& D$ fabs.

Past research on productivity improvement in semiconductor fabs has focused on the working of production fabs and the effective application of cycle time reduction strategies to these fabs. Very little research has gone into improving productivity of R\&D fabs and decreasing cycle times for faster transfer of technology to the production fabs. This thesis investigates methods to increase productivity and quantify the performance of semiconductor R\&D fabs considering cycle time and throughput along with the influence of hot lots or high priority lots 
using system simulation with a focus on employing production control. The objectives of this research are to:

- Construct a simulation model of a representative R\&D fab;

- Conduct a series of experiments to understand the relationship between WIP, throughput and cycle time in R\&D fabs;

- Conduct an experiment to evaluate the effects of WIP, tool redundancy and levels of technical (repair) support on productivity;

- Conduct an experiment to compare alternative dispatching rules in R\&D fabs with prioritydesignated lots based on productivity; and

- Perform a case study for the Semiconductor and Microsystems Fabrication Laboratory (SMFL) at the Rochester Institute of Technology (RIT) to validate experiments and to aid in improving productivity of the fab;

To comprehend the workings of research fabs, a simulation model of a representative R\&D fab is built with no lot priorities using a representative load to approximate production. This model is simulated to investigate factors affecting the productivity of R\&D fabs. These factors are lab shifts, scheduling policies, resource allocations, and technical support capabilities, among others. Bottleneck situations identified during this simulation run will helps identifying tools and/or resources that operate with the maximum utilizations.

A relationship between WIP, throughput and cycle time is investigated to determine the capacity of the R\&D fab. To achieve this, the simulation model is run with varying levels of WIP. Cycle time and throughput figures from each of these runs are recorded and separately graphed to determine the capacity of the fab. 
Levels set on the WIP, redundancy of the bottleneck tools in the fab and technical support capabilities will be part of formally designed experiments. The results from each run will indicate fab performance in cycle time and throughput metrics.

Wafer lots are assigned priorities for the next set of experiments. The lots have three classifications of priorities; $\mathrm{H}, \mathrm{M}$ and $\mathrm{L}$, where $\mathrm{H}$ is high priority, $\mathrm{M}$ is medium priority and $\mathrm{L}$ is low priority. The model will then be simulated with a combination of different primary and secondary dispatching rules with different lot prioritization proportions in effect. Dispatching rules like Priority, FIFO, Critical Ratio, Highest X-Theoretical Ratio First and Least Balance Ahead are used as primary and secondary rules. This covers the four classifications of dispatching strategies that are based on processing time, due dates, strategies based on neither processing time nor due date and finally a combination of the three strategies (Sha \& Hsu, 2004). This helps compare the use of employing different dispatching rules. Statistical analyses will be used to compare the performance of the different dispatching rules. Fab performance is reflected by the behavior of the performance measures, which are percent on time delivery, average cycle time, standard deviation of cycle time and average WIP.

The results from these experiments are verified by running experiments on simulation models of the Semiconductor and Microsystems Fabrication Laboratory (SMFL) at the Rochester Institute of Technology (RIT) for validation purposes. The culmination of these objectives aids in selecting the appropriate production control policies with regard to changing operational factors in $R \& D$ fabs. This helps increase the productivity of these fabs and in turn shorten the time to market. 


\section{LITERATURE REVIEW}

Literature reviewed on past research has been classified into two sub-sections. Past research on R\&D fabs and production fabs has been reviewed separately.

\subsection{Past Research on Improvements in R\&D Fab Productivity}

Janakiram (1996) discusses a theory of constraints (TOC) related to cycle time reduction.

His work involves identifying constraint equipments, evaluating constraints based on physical and procedural types and effectively implementing the listed TOC methods for cycle time reduction. His work cites training, dedication by management and committed team effort as essentials for cycle time reduction. Cycle time reduction techniques involve reducing process waste, effective scheduling of resources, using tested WIP management strategies and employing cross-functional work-teams. Some of the benefits of compressing cycle time apart from increased productivity are better utilization of resources, schedule reliability, decreased costs, adaptability to market needs and conditions. The main obstacles faced in a semiconductor research facility are changing levels of the product-mix and production volumes, random delays, the R\&D outlook, test steps and reentrant flow. The biggest hindrance is the presence of any kind of variation. The constraints in such an $R \& D$ setup, if not monitored and managed properly, can lead to misleading results.

Tullis, Mehrotra and Zuanich (1990) discuss the use of discrete event simulation at HP's Silicon Processing Laboratory (SPL), which is an R\&D fab. ManSim, a simulation software package was used to create discrete event simulation models of the flow of lots. The overall fab load was controlled either by varying lot starts or defining maximum WIP levels. Random delays were modeled between some recipe steps. Equipment breakdown (MTBF), repair times (MTTR) and preventive maintenance events were also included in the model. Operators were categorized 
into work areas, shifts and skills. Mean Cycle Time (MCT) versus WIP graphs were plotted for the base model, a model with full staffing, a model without unscheduled maintenance events and a combination of the full staffing model and the model without unscheduled maintenance. It was observed that the MCT did not change significantly between any of the dispatching rules used. The dispatching rules employed were FIFIO, SIPT (shortest processing time at next station), SRPT (shortest remaining processing time), LLNQ (least lots in next queue), CR and SLACK. The predicted cycle time was observed to be within $15 \%$ of a small sample of observed lot cycle times.

Pierce and Yost (1996) investigate metrics on cycle time in an R\&D semiconductor wafer fab. Multiples of theoretical cycle time, breakdown analysis of cycle time queue and holding time of equipment were studied and analyzed. A relationship is established between discipline cycle time and overall fab performance. The study also concludes that day-to-day fab cycle time is related to the same day of the week and not with the previous or the following day.

Liao, Chang, Pei and Chang (1996) present a paper on the development of a daily scheduling tool for an R\&D fab. The daily scheduling function is set up such that the right amount of wafer lots get processed at the right time, meeting the delivery schedule and hence reduce fabrication cycle times. The scheduling methodology consists of three parts viz. an efficient algorithm, fast rescheduling and periodic rescheduling. The daily scheduling tool, Electronic Researcher and Service Organization Fab Scheduler (ERSOFS) gives due consideration to high variety, low volume, cyclic process flow, engineering splitting and merging of wafer lots which are inherent to R\&D fabs. The solution methodology is based on Lagrangian relaxation and network flow techniques. This methodology is developed, implemented and validated. Tests have proven that ERSOFS generates high quality schedules efficiently. Fast and 
smooth adjustments of schedules by the rescheduling function of the ERSOFS help cope with the production uncertainties in an R\&D fab. It is concluded that ERSOFS can also be used in large fabs due to the nature of the algorithm.

Shiu et al. (1996) present a paper on the working of FASE, a computer-aided scheduling environment developed for semiconductor manufacturing. It is an extended version of an optimization-based scheduler for an R\&D pilot line to a production fab. FASE combines optimization-based scheduling methodologies, equi-variability graph technique, queuing analysis and GUI technique into a decision aid. It consists of a mid-term and daily scheduler, a machine variability analyzer, a what-if analysis tool and a user-friendly GUI. The objective is to generate daily production schedule with a look-ahead capacity. FASE's variability analyzer can be used for bottleneck identification, trade-off among cycle time, utilization and variability and a what-if analysis. This tool supports what-is analyses of capacity variation, machine allocation policy, output schedule and wafer start schedule.

Lu, Ramaswamy and Kumar (1994) test a new set of scheduling rules called Fluctuation Smoothing policies using simulation. 11,000 simulations were conducted on three R\&D fab lines and one production line. The fluctuation smoothing policies were developed as a special subclass of least slack (LS) policies, which give lots in queue with the least slack, the highest priority. This class of scheduling policies attempts to reduce various fluctuations in the queuing network. The class consists of 3 least slack policies. The Fluctuation Smoothing for Variance of Lateness (FSVL) policy reduces variance of lateness, the Fluctuation Smoothing Policy for Variance of Cycle Time (FSVCT) reduces the variance of cycle time and the Fluctuation Smoothing Policy for Mean Cycle Time (FSMCT) reduces the mean cycle time and also leads to a small variance of cycle time. These policies and other dispatching rules like FIFO and SRPT were tested on the 
fab models. A $22.4 \%$ reduction in the mean queuing time and a $52 \%$ reduction the standard deviation of cycle time were reported over the baseline FIFO policy.

\subsection{Past Research on Improvements in Production Fab Productivity}

Wein (1988) assesses the impact that scheduling has on the performance of semiconductor wafer fabs. The data gathering for the simulation model was done at HP's Technology Research Center Silicon fab (TRC), an R\&D fab in Palo Alto, California. The model excludes the engineering hold -times encountered at this fab as the focus was on the analysis of production facility environments. In the simulation model, coded in SIMAN, lots entering the fab visit 24 different stations with a total of 172 operations. Three versions of the simulation model with three fab configurations are used. Fab 1 and Fab 2 are 1- \& 2-bottleneck systems respectively. Fab 3 has four stations with high utilizations (near 90\%) and several other moderately utilized stations (between 60 and 77\%). The fabs are run using different combinations of input rules and lot sequencing rules. The input rules include Poisson processes, constant interarrival times, closed loop inputs and workload regulating inputs. The lot sequencing rules include FIFO and SRPT. For each rule tested, 20 independent runs are made, each representing $3 \frac{1}{2}$ years of fab operation. The runs do not include warm-up periods for steady-state specific analysis. The results from the simulation runs show that scheduling has definite and significant impacts on operations but larger improvements are seen from discretionary input control than from lot sequencing rules. Fabs that are characterized by controllable inputs can achieve improvements through strict and appropriate input control and fabs with priority-designated lots could achieve improvements in performance by using a better form of input control. There is an interaction observed between the combination of the type of the input and scheduling rules employed. It is concluded that the improvement from input control and lot sequencing depends upon factors like amount of variability in the effective processing 
times, the actual-to-theoretical ratio, the number of bottleneck and non-bottleneck stations in the fab, the amount of rework required, the amount of "hot lots" or priority-designated lots processed and whether the fab is a production or R\&D fab.

Domaschke, Brown, Robinson and Leibl (1998) investigate areas for improving productivity in production fabs with a goal to reduce cycle time by $60 \%$. A project management approach is used for this methodology. Data is verified by visits to the shop floor and consultations with the floor personnel. The data is then used for constructing a model on Factory Explorer. These efforts and some other intuitive decision making lead to the mean values of the data to fall within $10 \%$ of historical values. The model is validated and sensitivity analyses conducted whose findings and recommendations are presented. Results include a $12 \%$ decrease in back-end cycle time, reduction in inventory, efficient utilization of bottleneck tools, other reductions in cycle time due to elimination of tool dedication at bottlenecks and modifications to operator staffing. Making lot release less variable and modifying the batch size for material handling also realize significant cycle time reductions. The overall result on the cycle time due to these modifications is a $41 \%$ decrease. The actual implementation of these techniques leads to a $32 \%$ decrease in cycle time for back-end manufacturing.

Hung and Chen (1998) establish that shortest-processing-time, earliest-due-date, simulation-based and least-slack are good dispatching rules for cycle time reduction but they can result in negative effects in practice. Flow-time based decisions rather than those based on waiting times and complex look-ahead based dispatching techniques are more suited to semiconductor manufacturing facilities. Production management decisions are better made using active flow time prediction. Changes made to the SRPT rule that would also account for remaining flow time would render the rule a much better one to use. 
Sada, Yuen, Ichikawa, Yamada and Kabata (2001) describe a simple technique of achieving cycle time reduction in semiconductor fabs. Theoretical queue time is compared with actual queue times to identify opportunities for cycle time reduction. This theoretical queue time is calculated using operations research queuing theory with due weight age given to the influence of very high priority lots or "super hot lots". The average queue time increases due to the influence of the extremely high priority lots on normal processing. Equipment utilization decreases based on the number and process time of the "super hot lots". Lot transfer time is assumed to be equal for all equipment types for simplicity. Also mean process times are entered into the spreadsheet, which are calculated depending on hours per wafer or per batch. If actual queue times exceed theoretical queue times, the concerned equipment groups are candidates for productivity improvements. A process improvement in average steps/day across the fab of $24 \%$ and queue time reduction of $21 \%$ are realized by placing the responsibility on the respective process operator. A maximum number of super hot lots are calculated to keep damage to fab progress under $5 \%$.

Narahari et al. (1997) study the effects of hot lots or high priority jobs in semiconductor manufacturing systems using mean value analysis (MVA). The performance metrics considered are mean steady-state cycle time, variance of steady-state cycle time and mean steady-state throughput rates of hot lots and regular lots. The analysis method models scheduling policies such as LBFS (Last Buffer First Serve) and FBFS (First Buffer First Serve). Detailed simulations of several re-entrant lines validate and verify the analytical method and the accuracy of the performance predictions. It is found that the MVA approximation is effective and accurate in performance prediction of semiconductor manufacturing facilities in the presence of hot lots. 
Fronckowiak et al. (1996) use the semiconductor manufacturing line simulator, $\operatorname{ManSim} / \mathrm{X}$, to analyze the impact of different percentages of hot lots on the cycle times of two different products to develop rules of thumb to release high priority lots so as not to significantly alter the overall cycle time of the product. A constant work in process is maintained and the assumed lot size is 25 wafers. Cycle time graphs are generated for increasing percentages of both the products relative to base cycle time with no hot lots. Bar graphs are also generated to compare increasing cycle time for hot lots of product 1 at various percentage hot lots of product 2. Also, deviation of regular lot cycle time and hot lot cycle time due to the effects of the increased hot lots and comparison of the effects of hot lots for both products on manufacturing cycle time for regular lots are plotted. Discrete event simulation is thus used to investigate the impact of hot lots in a fab. It is concluded that the percentage of hot lots in a manufacturing line should be maintained between $10 \%$ and $20 \%$.

Ehteshami et al. (1992) talk about object oriented simulation experiments on a wafer fabrication model to study the impact of hot lots on the cycle time of other lots in the system. The simulation experiments are setup to maintain a constant WIP even though this release strategy has proven to be inferior to other rules like the bottleneck starvation avoidance policy. In reality, a factory manager is provided with a maximum number of hot lots that can be in the system at any time. The use of the constant WIP release strategy means that a certain classification of lots will not be started into the facility unless the same type came out at the other end. Hot lots are given priority over regular lots with no interruption of current service. Lots of same classes are prioritized by the FIFO rule. The model is run at different WIP levels with a constant lot size of 50 wafers. The number of hot lots changed for each of five scenarios for each level ranging from $0 \%$ to $16.7 \%$, which corresponds to findings in industry. With a constant WIP 
for each of the two classifications of lots, the system's throughput rate is larger than the ratio of the respective WIP levels. This conclusion is derived using the equation $L=\lambda w$, where $L$ is the average WIP in the system, $\lambda$ is the average throughput rate and $w$ is the average cycle time. The simulation results show that the overall cycle time and equipment utilization levels remain constant as the proportion of hot lots in the fab varies. The overall variance of cycle time distribution increases dramatically when more hot lots are introduced in the system, given a constant WIP level. As more and more hot lots are introduced in the WIP, the average and standard deviation of cycle time for these lots will become large.

Lee at al. (2000) in their paper, "Super-Hot-Runs Management System" create a system which can make sure that cycle time of push lots can be kept under 0.8 days/layer and keep the average cycle time in manageable proportions. Cycle time is subdivided into running time, holding time and queue time. It is concluded that reducing queue times is the only opportunity to improve push lots' cycle times. Reasonable queue times must be identified to meet customers' required deadlines. The formula of reasonable step queue time is (Required days - Theoretical process time)/Total step no. When a new push lot is introduced in the system, operators are made aware of its presence and the production team is equipped to track the path. A pre-announcement is made to preempt regular lots from processing on machines 5 steps downstream. Certain operating disciplines, rules and procedures are followed by the operators, which are the keys to cycle time reduction. The status of the lot can be checked to see if it will be delayed or is ahead of time. If the slack for a lot is negative, it implies that the lot will be delayed. Remaining processing time in days is given by Due date - Current time in system (in days). Demand cycle time is given by Remaining Layers * Cycle Time goal ( 0.8 days per layer). If Due Date $>$ Demand cycle time, the slack is positive and the super-hot-lot can be completed on time. The 
forecast system, the current status and event history also give lot status. This enables the analysis of the root cause of any delay. Data collection in a database system can be used to analyze performances and make new strategies. Hence using the PDCS (Plan, Do, Check, Action) concept, the cycle time goals of 0.8 days/layer for super-hot-lots and one day/layer for pilot lots are achieved. These improvements have a positive impact on queue time percentage of cycle time also.

Chikamura, Nakamae and Fujioka (1999) evaluate the effect of express lots on production dispatch rule testing and cost in VLSI manufacturing final test process. The FIFO and WEIGHT+RPM rules are used and compared in the assignment of express lots. The simulation model has two queues set for each station - one for regular lots and the other for express lots. The three production rules applied to each stage and station are FIFO, JIG and WEIGHT+RPM. The JIG rule enables the lot in queue with the least preparation time to process on a free machine. The WEIGHT+RPM rule considers time for jig and temperature exchanges, the remaining process time of the machine in use and the lot waiting time in queue. If a machine becomes free, an optimum combination of the machine and lot in queue is selected using the following equation:

$$
\mathrm{W}=(\text { preparing time })-\mathrm{K} * \text { (waiting time in queue })
$$

where $\mathrm{K}$ is the constant to consider the waiting time in queue and is estimated roughly from the number of past tested lots per month and their test flows. 100 replications of a six-month run time simulation are executed. Assumptions made are the regular lots have a due date of one week after they arrive at the final test facility and every express lot must be processed as soon as possible. The proportion of express lots in the total planned lots is varied from $0 \%$ to $100 \%$. When using the FIFO rule, the number of total processed lots decreases with an increase in the 
number of express lots. When using the WEIGHT+RPM rule, the decrease in number of total processed lots is very small even for $50 \%$ of the WIP accounting for express lots. The average test turnaround time (TAT) of regular lots increases when WIP content of express lots exceeds $10 \%$ for FIFO rule but does not increase for up to express lot content of $30 \%$ for the WEIGHT+RPM rule. Also, tool efficiency and test cost per wafer also show the same trends for both rules. When using the WEIGHT+RPM rule express lot tolerance (ELT), defined as the maximum content of express lots which permit the deterioration of the system characteristics by $5 \%$ is thrice as high as ELT when using the FIFO rule.

DeJong and $\mathrm{Wu}(2002)$ present a paper describing a modeling approach to study the behaviors of priority lots and to quantify their impact to manufacturing. An integrated discrete event simulation modeling approach is used to evaluate the impact to performance metrics by factory components. The fab capacity model methodology has two key attributes specific to priority lots. The model can comprehend the different levels of priority assigned to the lots. P1, P2, P3 and NP are the priorities, where P1 has the highest priority, P2 has the second highest priority, P3 has the third highest priority and NPs are non-priority lots. The model also has the ability to model complex rules based on the priority of the lot. Lot priorities also affect AMHS (Automated Material Handling System) rules and classes. The model can track throughput time, WIP turns, units out, tool starvation rates and waiting times. The baseline model with no high priority lots is simulated. The model report shows that the throughput target is met. The model report also tracks the fastness of WIP movement through the line. An immediate impact to the non-priority lot is felt once a high priority lot is introduced. With increased amount of priority lots, the downstream machines are held idle to wait for these lots. Even though overall weekly 
outs are not significantly impacted, the NP lot velocity and factory outs are significantly reduced with increasing proportion of high priority lots. 


\section{SIMULATION OF REPRESENTATIVE SEMICONDUCTOR R\&D FABS}

This thesis investigates methods to increase productivity and quantify the performance of semiconductor R\&D fabs considering cycle time and throughput along with the influence of hot lots or high priority lots using system simulation with a focus on employing production control. Hence the research is operations based and narrows in on testing controllable parameters at different levels. The other techniques to improve productivity, which the research does not touch on are design, process and yield improvements among other technological enhancement possibilities.

Models of representative semiconductor $R \& D$ fabs are built and analyzed as part of three different experiments. The sub-sections in this chapter detail the modeling assumptions, description of the setup of the simulation software package to be used for the simulation and the methodology. The modeling assumptions include the considered constraints, operator actions and tool certifications for technicians. The capabilities and working of the simulation software are described in the setup section.

\subsection{Simulation Model Assumptions and Details}

The Complementary Metal Oxide Semiconductor (CMOS) recipe is chosen as the routing for the representative wafer lots. This recipe comes closest to matching the average tool usage in the SMFL. This ensures that the routing loads the fab like the actual tool usage in the fab. The constraints that stop these lots from processing on the tools are:

- Tool reservations;

- Down events;

- PM events;

- Off shift events; and 
- Waiting times.

Tools are reserved for researchers with specific requests. Other researchers can use tools and other fab facilities during reserved hours. Shift calendars dictate the availability of fab personnel.

A researcher spends 8 hours in the fab, Mondays through Fridays, from 8 am to $4 \mathrm{pm}$. The model also has preemption provisions. The researcher will not put a lot on his worklist unless he has sufficient time on hand to process the lot. For e.g. the LPCVD tool requires a total processing time of $220 \mathrm{~min}$ and a lot has the LPCVD operation in the next step of its route. The researcher will not process the lot unless he has the full $220 \mathrm{~min}$ available before his shift ends. The simulation software package used, AutoSched AP, does not have the required preemption options, as is described above. To model such an event, control resources are added to the operator and station files. Every station and operator has a corresponding control station and control operator. These do not in any way affect the performance and statistics of interest related to the stations and workers. Each lot has to visit a control station each time it needs to be processed or re-processed on a given station. A control operator mans every control station. With the LPCVD control station in place, the lot has to visit the control station before being processed or placed in queue at the LPCVD station. The first lot in queue at the control station seizes both the control operator and the LPCVD operator and the control station for a processing time of 0 seconds. This means that all three resources have to be available for the lot to seize them. The control operator and control stations are then released and the LPCVD operator processes the lot at the LPCVD station. The transfer time from the control station to the LPCVD station is 0 seconds. These actions are shown in Figure 4.1. Now, the LPCVD operator cannot process a lot at the LPCVD station unless he has sufficient time before the end of his shift to complete all 
processing the wafer lot. In this case, that time is 220 minutes. The control operator is thus made unavailable 220 minutes before the LPCVD operator ends his shift. This ensures that no lots go through for processing to the LPCVD station, since the control operator is not available to be seized by the lot at the control station for 220 minutes. This also ensures that the LPCVD operator does not process any lots at the LPCVD station for which there is not a sufficient enough time window for processing before his shift ends.

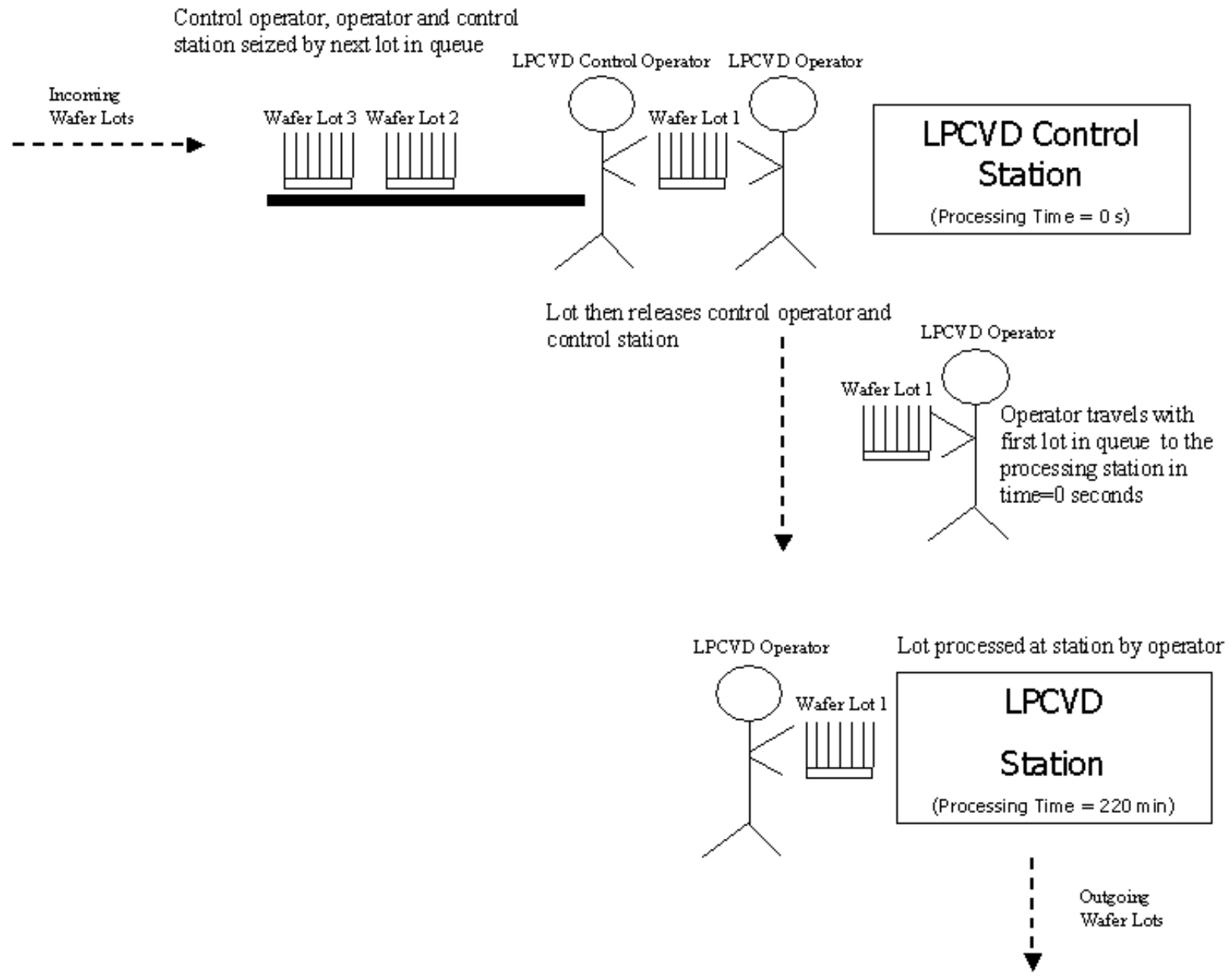

Figure 4.1: Resource Actions When LPCVD Operator Has Sufficient Time to Process a Lot Before End of Shift 


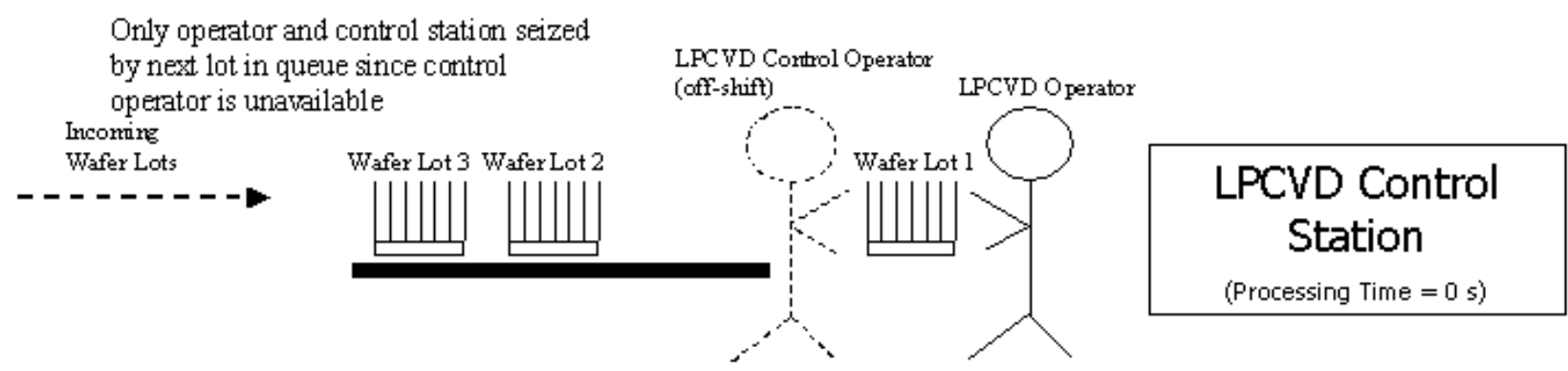

Control operator unavailable after 220 minutes before LPCVD operator's shift ends. Hence, no processing possible at LPCVD station

\section{LPCVD}

\section{Station}

(Processing Time $=220 \mathrm{~min}$ )

Figure 4.2: Resource Actions When LPCVD Operator Has Insufficient Time to Process a Lot Before End of Shift

Action lists in the model provide sets of instructions or actions for task performance by the schedulable entity. Steps in the route either require a researcher to be present:

- for setup only

- $\quad$ for setup and processing

Custom action lists are made and associated with the steps in the route, according to their need for researchers as above.

Technical operators are dedicated to PM events and down times for tools. These operators are available Mondays through Fridays from 8:30 a.m. to 4 p.m. The model has a total of 5 technical operators with different certifications. The certifications are shown in Table 4.1. Tools undergo PM events or are forced down by lots whose processing time is equal to the time distribution for the PM event or the downtime of the tool. Order files are used to trigger these lots. PM events are deterministic events whereas downtimes are stochastic. Hence the interarrival time of the lots that cause the tools to go down is the mean time between failure (MTBF) 
and the processing times for these lots as well as those that cause PM events is the mean time to repair (MTTR). When any one of these lots seizes a station, it also seizes a primary or a secondary technician, if specified, with the required certification. Order files are used to trigger PM events and downtimes because AutoSched AP does not have the provision for multiple technician certifications. Hence technicians have to use certifications, normally given to operators.

Table 4.1: Tool Certifications for Technicians

\begin{tabular}{|c|c|c|}
\hline $\begin{array}{c}\text { Technical } \\
\text { Support }\end{array}$ & Tool Certification & $\begin{array}{l}\text { Processing } \\
\text { Efficiency }\end{array}$ \\
\hline \multirow{4}{*}{$\begin{array}{c}\text { Tech. } \\
\text { Worker } 1\end{array}$} & ASM LPCVD & 1.00 \\
\hline & Branson Asher & 0.66 \\
\hline & Drytek RIE & 1.00 \\
\hline & Bruce furnace tubes & 0.66 \\
\hline \multirow{3}{*}{$\begin{array}{c}\text { Tech. } \\
\text { Worker } 2\end{array}$} & LAM 490 Plasma etch & 1.00 \\
\hline & Varian 350D Implanter & 1.00 \\
\hline & CVC-601 Sputter & 1.00 \\
\hline \multirow{3}{*}{$\begin{array}{c}\text { Tech. } \\
\text { Worker } 3\end{array}$} & RCA Clean & 1.00 \\
\hline & Canon \& GCA Steppers & 1.00 \\
\hline & Bruce furnace tubes & 1.00 \\
\hline \multirow{3}{*}{$\begin{array}{c}\text { Tech. } \\
\text { Worker } 4\end{array}$} & RCA clean & 0.66 \\
\hline & Branson Asher & 1.00 \\
\hline & Varian 350D Implanter & 0.66 \\
\hline \multirow{4}{*}{$\begin{array}{l}\text { Tech. } \\
\text { Worker } 5\end{array}$} & RCA clean & 0.66 \\
\hline & Drytek RIE & 0.66 \\
\hline & LAM 490 Plasma etch & 0.66 \\
\hline & Varian 350D Implanter & 0.66 \\
\hline
\end{tabular}

The primary technician has a higher processing efficiency than the secondary technician. The secondary technicians operate at $2 / 3$ times the efficiency as the primary technicians on the concerned tools. The secondary technician works on the tool only if the primary technician is busy or unavailable. PM events never interrupt a resource from processing a wafer lot. The scheduled PM comes into effect once the resource finishes processing on the lot. All resources in 
the fab including the technical operators have a capacity of 1 . This means that they can process only one entity at a time.

Data used for modeling the fabs for Experiments 1, 2 and 3 and the assumptions made are detailed in the workbooks on the $\mathrm{CD}$ attached to the back cover of the bound thesis. The contents of the spreadsheets are briefly described in Table G.1 of Appendix G.

\subsection{Simulation Software Setup}

The representative semiconductor R\&D fab is simulated using Brooks Automation's Autosched AP (ASAP), a discrete-event simulation software package. Autosched AP, a finite capacity planning and scheduling tool is used to model the working of factories. The factory's real system terms are translated into model terms

ASAP uses worksheets to allocate stations, routes, orders, parts and storage. The categories of data essential for model creation are resources, products and demands. These data sets can be imported from other databases or from the shop floor control system. (Phillips, 1998). Autosched AP models systems using the following:

- Calendars;

- $\quad$ Random Distributions;

- $\quad$ ASAP Extensions;

- $\quad$ ASAP Action Lists; and

- $\quad$ ASAP Dispatch Rules.

ASAP supports constant, normal, exponential, weibull, uniform, lognormal, triangular and gamma distributions. Standard extensions can be employed to use other distributions. Extensions in ASAP are dynamic linked libraries that enhance the features of the model. Actions lists allow users to choose how they want to model resource behavior and data access. Process 
and preempt are the two types of action lists used. Dispatch rules are standard for all resources. The same rule engine is used to dispatch stations, operators and resources. The dispatch rules determine lot queue ranking, lot selection and batching of lots. (Phillips, 1998)

\subsection{Verification and Validation}

Once the simulation model is built, verification is done to ensure that the AutoSched AP model runs as is intended. The software package includes a message file that can be read at the end of every simulation run. Events are traced in the message file and this allows for the user to conduct verification steps such as walkthroughs and checking for errors. This message file feature is used to authenticate the modeling of end of shift effects, technician certification and tool downtime and PM events.

After the verification process, the model is validated to ensure that it adequately represents a semiconductor R\&D fab. Discarding outliers and suspicious entries and walkthroughs with experts validates data on stations, routings, process and setup times, pulled from the Camstar Manufacturing Execution System Application (MESA) database at RIT. Information on down times, preventive maintenance (PM) events and statistics on distributions for these events are obtained by compiling empirical data from the MESA. All the data and the information are validated as exclusive to typical semiconductor R\&D fabs. The specific characteristics may differ from fab to fab but essential characteristics like down times, PM events, single shifts and the representative product load that are built into the model are representative of semiconductor $R \& D$ fabs. 


\section{EXPERIMENTS AND RESULTS}

As mentioned in the problem statement (Chapter 2), this thesis investigates production control methods to quantify the performance of semiconductor R\&D fabs. This chapter details the methodology and the results obtained, of the experiments carried out. The following are the experiments conducted, which have been detailed in the subsequent sections:

- Experiment 1: The Effect of WIP on Average Cycle Time and Throughput

- Experiment 2: The Effect of Resource Levels and WIP on Productivity

- Experiment 3: Comparing Primary/Secondary Dispatching Rules

\subsection{Experiment 1: The Effect of WIP on Average Cycle Time and Throughput}

This experiment is conducted to comprehend the effects of change in WIP to average cycle time and throughput in semiconductor R\&D fabs. Little's law in equation form is, $\mathrm{L}=\lambda * \mathrm{~W}$. Little's law equates the average number of jobs in the system (L) to the product of the average arrival rate of the jobs $(\lambda)$ and the average time a job spends in the system (W). Little's law is used in queuing theories and is applied to areas such as manufacturing and logistics, among others. In this case of the simulation model of the representative R\&D fab, Little's Law equates WIP to the product of average cycle time and throughput. Hence, WIP $=$ Average Cycle Time * Throughput. WIP, in this experiment is used as the independent variable and the average cycle time and throughput are recorded at different levels of WIP. The goal of this experiment is to investigate the changes of WIP to the average cycle time and throughput in the confines of Little's law.

\subsubsection{The Experimental Design}

A simulation model of a representative $R \& D$ fab is built (For details see section 4 : Simulation of Representative Semiconductor R\&D Fabs). Typical characteristics of 
semiconductor R\&D fabs are modeled, which include end of shift effects, different levels of certifications for technicians, a representative product routing, random tool breakdowns and preventive maintenance events. The queuing discipline chosen is FIFO. A representative CMOS routing is used where every wafer lot accounts for a full time equivalent (FTE) researcher. This representative routing is chosen as it approximates tool usage in the fab. As mentioned earlier, WIP is used as the independent variable. The WIP levels tested range from 1 to 30 with increments of 1. For e.g., at a WIP level of 6 , there are 6 lots in process in the system and a lot enters the system, only, each time a lot in process traverses all the steps in the representative product routing. This is essentially a pull system. Every lot in the WIP is a research project carried out by a FTE researcher. An assumption is made that with the given number of tools in the fab and the steps in the representative product routing, not more than 30 researchers can be present in the fab at any given time. The replication/deletion method is used to run the simulations. Each run has a warm-up period of to bring the model into the steady state and five replication runs of 6 years each. This replication deletion method ensures that the replications are independent of the initial warm-up period. Multiple replications are conducted to ensure that each replication is independent and identically distributed. It is sufficient to conduct five replications to minimize variation between these replications. Table 5.1 shows that at a WIP of 12, the average cycle time is approximately 1296 hours with a very small half-width value, which is within $1 \%$ of this cycle time.

Table 5.1: Average Cycle Time Values by Replication for WIP $=12$ lots

\begin{tabular}{|c|c|c|c|c|c|c|c|}
\hline \multicolumn{4}{|c|}{$\begin{array}{c}\text { Average Cycle Time (hours) by } \\
\text { replication }\end{array}$} & $\begin{array}{c}\text { Average } \\
\text { Cycle } \\
\text { Time } \\
\text { (hours) }\end{array}$ & $\begin{array}{c}\text { Standard } \\
\text { Deviation } \\
\text { (hours) }\end{array}$ & $\begin{array}{c}\text { Half- } \\
\text { Width } \\
\text { at 95\% CI }\end{array}$ \\
\hline Rep. 1 & Rep. 2 & Rep. 3 & Rep. 4 & Rep. 5 & & \\
\hline 1284 & 1304 & 1299 & 1286 & 1306 & 1295.8 & 10.2 & 12.7 \\
\hline
\end{tabular}




\subsubsection{Results and Productivity Graphs}

The graphs in Figure 5.1 and Figure 5.2 plot WIP vs. Average Cycle Time and WIP vs. Throughput respectively. The average cycle time and throughput values are average values from the five replication runs for each level of WIP. The graphs indicate that at a certain WIP level, production reaches a maximum level. Increasing the WIP level from here on increases the cycle time without significant increase in throughput. As the WIP increases from 1 to 12 , the throughput goes up from 12 to 81 lots/year with a cycle time increase from 1000 total hours to 1590 total hours. Increasing the WIP beyond this point until 30 results in no increase in throughput, whereas cycle time progressively increases to a high of 3250 total hours.

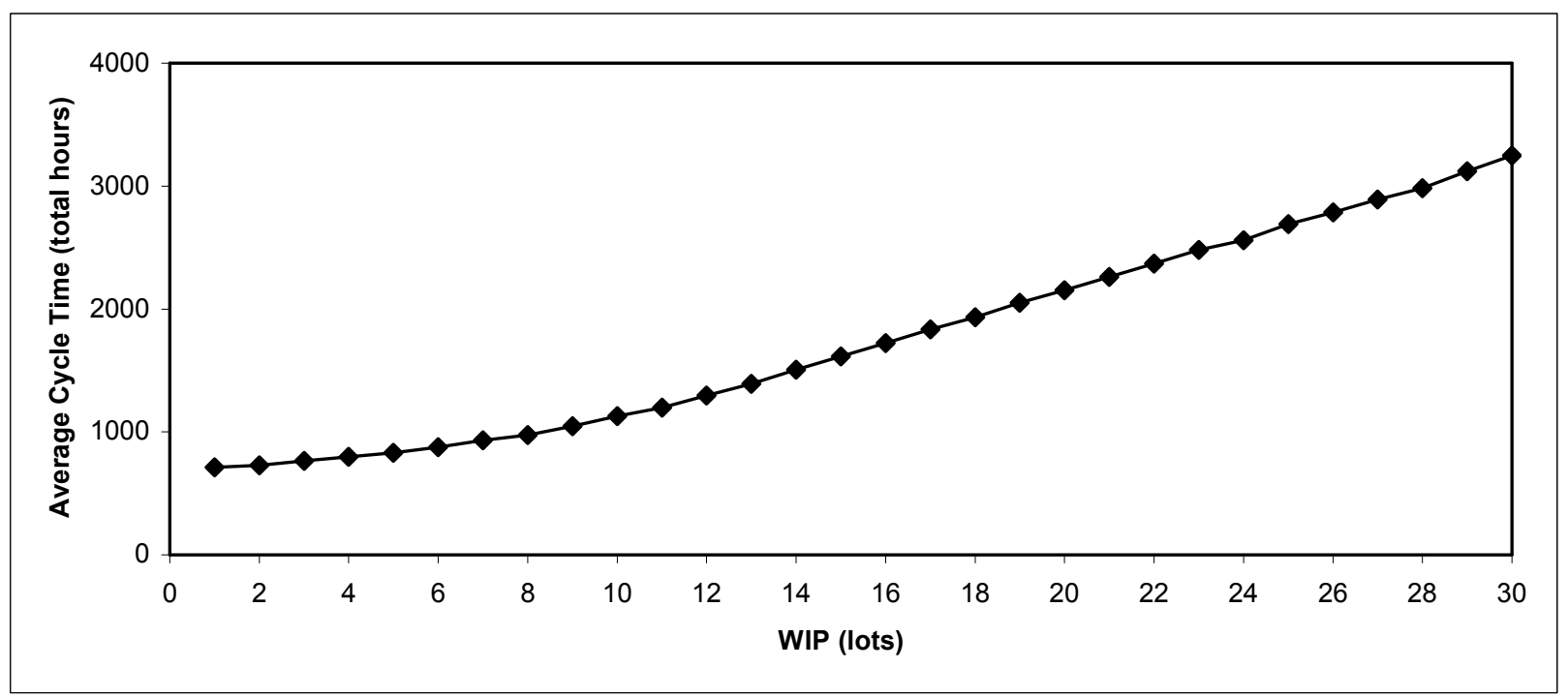

Figure 5.1: WIP vs. Average Cycle Time 


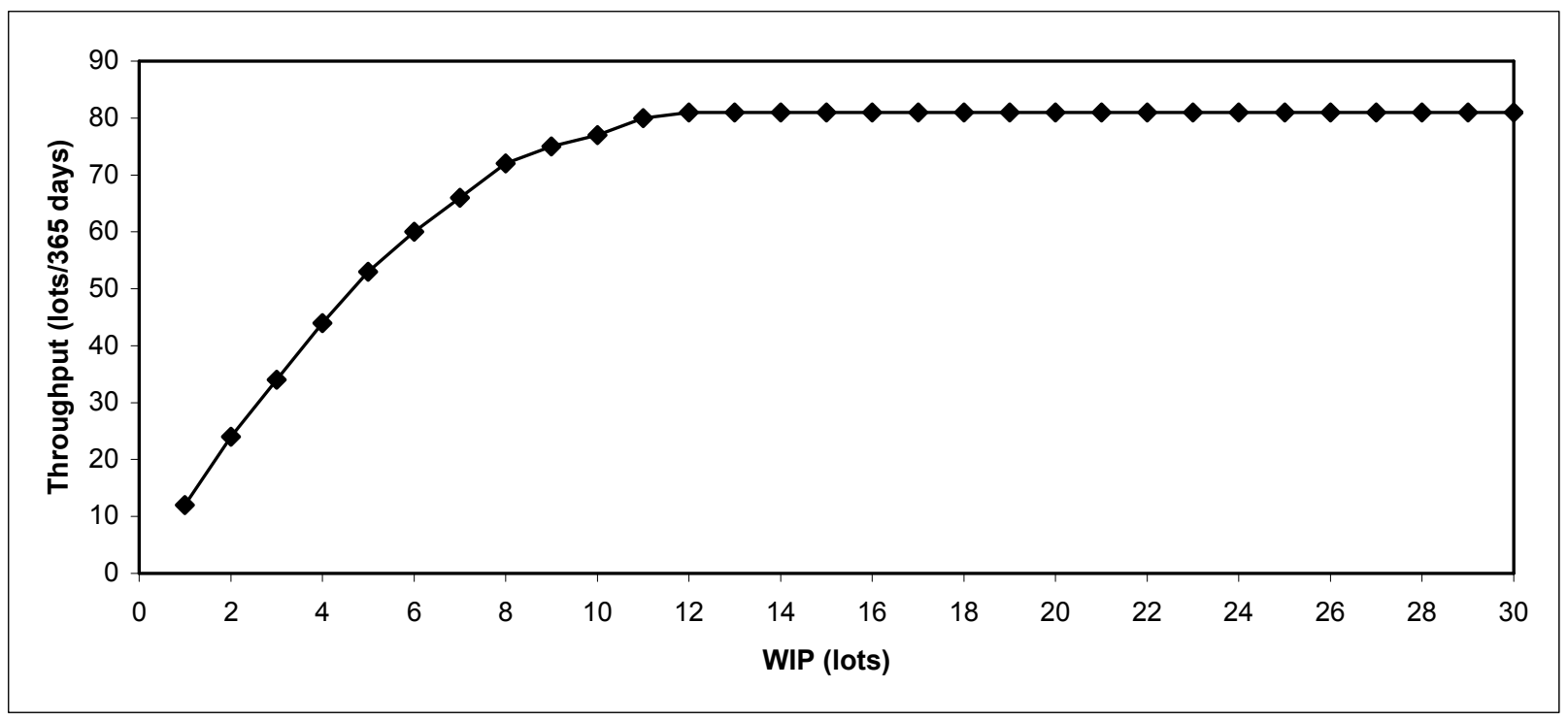

Figure 5.2: WIP vs. Throughput

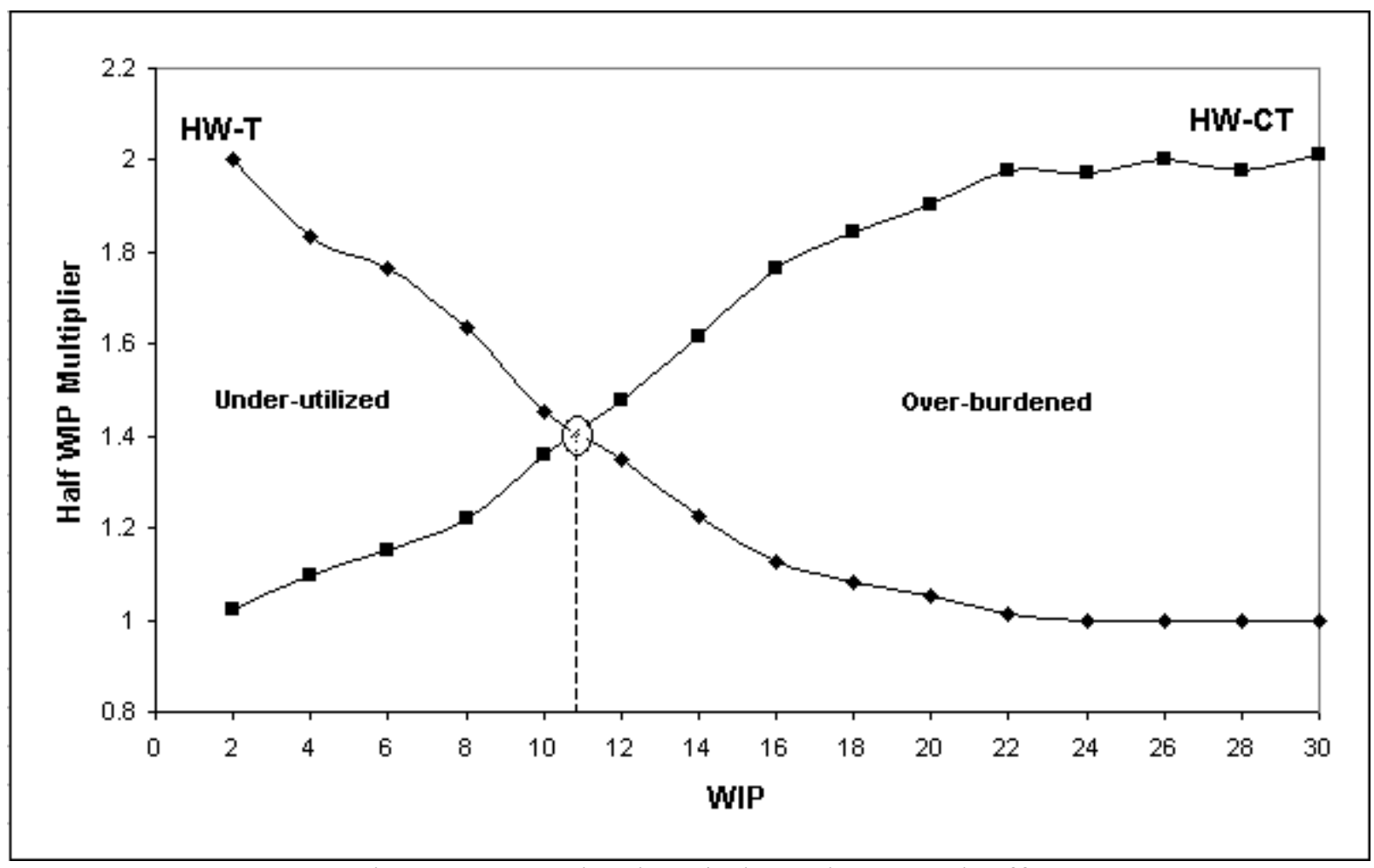

Figure 5.3: Cycle Time / Throughput Tradeoff 
Figure 5.3 is a cycle time/throughput tradeoff graph. This graph plots WIP vs. a HalfWIP multiplier. For a given WIP, the Half WIP Multiplier (HWx) graph compares throughput (T) and cycle-time (CT) metrics to those at half the WIP level. Extremes in performance are observed as follows:

- T-HWx $\sim 2$ AND CT-HWx $\sim 1$ (fab resources underutilized)

- $\mathrm{T}-\mathrm{HWx} \sim 1$ AND CT-HWx $\sim 2$ (fab resources overloaded)

The intersection of both HWx curves suggests a nominal fab load considering the following tradeoffs:

- Decreasing the WIP below this level leads to lower cycle times for the researchers but underutilization of fab resources; and

- Increasing the WIP beyond this level can provide some increase in throughput, however researchers experience a large increase in cycle time.

Based on the plots from Figure 5.1 and Figure 5.2, the HWx curves (Figure 5.3) are found to intersect at a WIP level of close to12 and a HW of 1.4. This suggests that a compromise of $40 \%$ on cycle time and an increase of $40 \%$ on throughput may represent a nominal tradeoff. The underutilized region is not self-supporting, i.e. throughput is too low. This means that the revenue will be affected. The overburdened region has high throughput, however researchers can't get their project done due to high cycle times.

\subsubsection{Conclusions of Experiment 1}

A simulation model of a representative R\&D fab is modeled, which incorporates typical characteristics of semiconductor $R \& D$ fabs. The experiment is conducted to record the effects of changing WIP levels to average cycle time and throughput, in the confines of Little's law, given the production uncertainties associated with semiconductor R\&D fabs. The results indicate that 
beyond a certain WIP level, average cycle time progressively increases with no increase in throughput. The simulation model of a given fab enables a fab manager to investigate possibilities to increase the capacity of the fab. This means achieving better average cycle time and throughput values at increased WIP levels as compared to the results obtained from simulating the base model of the fab. One of the ways this can be done is to increase resources in the fab. The resources can be tools, operators or technicians.

\subsection{Experiment 2: The Effects of Resource Levels and WIP on Productivity}

This experiment is conducted to quantify the effects of added resources to the fab layout to two levels of WIP. The previous experiment involves simulating a base model of a representative semiconductor $R \& D$ fab to comprehend the effects to average cycle time and throughput with increasing levels of WIP. This experiment enables a fab manager to evaluate the fab performance in terms of average cycle time and throughput with increased resources. Any increase in capacity due to added resources is the ability to accommodate more researchers in the fab, which in this case is the ability to accommodate more representative wafer lots as part of the WIP. The added resources in this case are tools and technicians.

\subsubsection{The Experimental Design}

A design of experiments is conducted with 2 levels on factors including WIP, number of tools and technical support. The performance measures are average cycle time and throughput. The simulation model for this experiment is the same as the one Experiment 1 uses, only with changes to the WIP and resource levels as described below. The queuing discipline stays as FIFO. From the results obtained in the previous section, a WIP of 12 is the recommended operating point for the fab with a nominal tradeoff between cycle time and throughput. This is chosen as one level for the WIP. A WIP of 16 is chosen as the higher level to test the capacity of the fab at the different levels of number of tools and technical support. A WIP of 16 as this level 
allows the model to be tested with four additional researchers in the fab. From the initial runs of the base model, it is seen that the furnace and the LPCVD tool have the highest utilizations. The first level of the number of tools factor is the same as the base model, with no redundancy on these tools. In a steady state system, the bottleneck tools have the maximum utilization. Increasing the number of bottleneck tools leads to increased capacity. Hence, the higher level has 2 furnaces and 2 LPCVD tools. The technicians in the base model have different levels of certifications. These certifications dictate their performance on the tools that they can fix. The first level of the technical support factor has 5 technicians with primary and secondary certifications (See Table 4.1). The higher level of this factor sees the addition of a fully crosstrained technician with primary certifications on all tools. Table 5.2 shows the factors and their levels.

Table 5.2: Design of Experiments on Factors to Test R\&D Fab Productivity

\begin{tabular}{|c|c|c|}
\hline Factor & 12 & 16 \\
\hline WIP & \multicolumn{2}{|c|}{ Level } \\
\hline $\begin{array}{c}\text { Number of } \\
\text { Tools }\end{array}$ & $\begin{array}{c}\text { Same number of } \\
\text { tools as in base } \\
\text { model }\end{array}$ & $\begin{array}{c}\text { Added furnace and } \\
\text { LPCVD tools }\end{array}$ \\
\hline $\begin{array}{c}\text { Technical } \\
\text { Support }\end{array}$ & $\begin{array}{c}5 \text { technicians with } \\
\text { different levels of } \\
\text { certifications }\end{array}$ & $\begin{array}{c}\text { Added cross-trained } \\
\text { technician }\end{array}$ \\
\hline
\end{tabular}

\subsubsection{Results}

Table 5.3 shows throughput and average cycle time values at all tested levels. At a WIP of 16, with tool redundancy and additional technical support, 126 lots per year are completed at an average cycle time of 1108 total hours. This translates to a $56 \%$ increase in throughput (compared to Experiment 1) with a marginal increase in cycle-time. Increase in resources (tools 
and/or technical support) must be justified by the projected increase in throughput, as increased throughput means increased revenue.

Table 5.3: Run by Run Results of the Performed Experiment

\begin{tabular}{|c|c|c|c|c|}
\hline WIP & $\begin{array}{l}\text { Number of } \\
\text { Tools }\end{array}$ & $\begin{array}{l}\text { Technical } \\
\text { Support }\end{array}$ & $\begin{array}{c}\text { Throughput } \\
\text { (lots/year) }\end{array}$ & $\begin{array}{c}\text { Average } \\
\text { Cycle Time } \\
\text { (hours) }\end{array}$ \\
\hline 16 & $\begin{array}{l}\text { Added furnace } \\
\text { and CVD tool }\end{array}$ & $\begin{array}{l}\text { Added cross- } \\
\text { trained technician }\end{array}$ & 126 & 1108 \\
\hline 12 & $\begin{array}{l}\text { Same number } \\
\text { of tools as in } \\
\text { base model }\end{array}$ & $\begin{array}{l}5 \text { technicians with } \\
\text { different levels of } \\
\text { certifications }\end{array}$ & 81 & 1296 \\
\hline 12 & $\begin{array}{l}\text { Added furnace } \\
\text { and CVD tool }\end{array}$ & $\begin{array}{l}5 \text { technicians with } \\
\text { different levels of } \\
\text { certifications }\end{array}$ & 112 & 939 \\
\hline 16 & $\begin{array}{l}\text { Same number } \\
\text { of tools as in } \\
\text { base model }\end{array}$ & $\begin{array}{c}5 \text { technicians with } \\
\text { different levels of } \\
\text { certifications }\end{array}$ & 81 & 1722 \\
\hline 12 & $\begin{array}{l}\text { Same number } \\
\text { of tools as in } \\
\text { base model }\end{array}$ & $\begin{array}{l}\text { Added cross- } \\
\text { trained technician }\end{array}$ & 89 & 1180 \\
\hline 16 & $\begin{array}{c}\text { Same number } \\
\text { of tools as in } \\
\text { base model }\end{array}$ & $\begin{array}{l}\text { Added cross- } \\
\text { trained technician }\end{array}$ & 90 & 1541 \\
\hline 16 & $\begin{array}{l}\text { Added furnace } \\
\text { and CVD tool }\end{array}$ & $\begin{array}{c}5 \text { technicians with } \\
\text { different levels of } \\
\text { certifications }\end{array}$ & 123 & 1133 \\
\hline 12 & $\begin{array}{l}\text { Added furnace } \\
\text { and CVD tool }\end{array}$ & $\begin{array}{l}\text { Added cross- } \\
\text { trained technician }\end{array}$ & 113 & 928 \\
\hline
\end{tabular}

\subsubsection{Conclusions of Experiment 2}

A simulation model of a representative semiconductor $R \& D$ fab is run as part of a formally designed experiment to check for increased fab capacity. The different levels of resources and WIP in the designed experiment test capacity in terms of average cycle time and throughput. The results show improvements in average cycle time and throughput for the levels with added resources as compared to the results from Experiment 1. The dispatching rule for the lots is FIFO. Semiconductor R\&D fabs employ various dispatching rules. Often times, these fabs 
have lots with certain processing priorities in the product mix. The simulation model of the representative semiconductor $\mathrm{R} \& \mathrm{D}$ fab allows for the testing of different dispatching rules. Fab performance in such cases can be quantified by performance measures including percent on time delivery, average cycle time, standard deviation of cycle time and average WIP.

\subsection{Experiment 3: Comparing Primary/Secondary Dispatching Rules}

This experiment tests different levels of production volume, primary/secondary dispatching rules, due date tightness and product mix. Fab performance is quantified by performance measures including percent on time delivery, average cycle time, standard deviation of cycle time and average WIP. Running a simulation model of a semiconductor R\&D fab with different levels of pertinent factors enables fab managers to use the best dispatching rules to minimize time-to-market.

"Hot Lots" or priority-designated lots as they are termed in this research are labeled as a factor causing capacity loss in semiconductor manufacturing. The other capacity loss factors that are pertinent to this research are Tool Dedication, End-of-Shift effects, Operator Cross-Training, Operator Availability, Preventive Maintenance, Reentrant Flow, Dispatch/Sequencing, Order Release, WIP Control and lack of Tool Redundancy (Robinson, Fowler, \& Neacy, 2003).

The objective of this research is to find out which of the dispatching rules tested are the most robust. This means that they can be applied to a given semiconductor R\&D fab, without a huge cycle time/on time delivery trade off. Also certain dispatching rules may perform better than others according to the prevalent operating conditions of the fab. The analysis of the results give a clear picture as to what rules can be applied for different scenarios.

This experiment is conducted to check if the effect of the application of different dispatching strategies has statistical significance on percent on time delivery, average cycle time, standard deviation of cycle time and average WIP. 


\subsubsection{Simulation Model}

The literature review summarizes papers on the effects of "hot lots" to performance of production fabs. There is a need to study and analyze the effects to performance of R\&D fabs due to the presence of priority-designated lots.

To model semiconductor R\&D fabs it is important not to overlook what sets it apart from production fabs. The Simulation of Representative Semiconductor R\&D Fabs chapter (Chapter 4) details the simulation model. An extra Chemical Vapor Deposition (CVD) tool is added to increase fab capacity. Tech. Worker 5 is given secondary certification on the CVD tool. The results from the initial design of experiments on tool redundancy and technical support justify these modifications (See 5.2 Experiment 2: The Effects of Resource Levels and WIP on Productivity). Priority-designated lots are introduced into the fab. These lots have three different classifications viz. $\mathrm{H}, \mathrm{M}$ and $\mathrm{L}$ lots. These lots follow the same product routing.

\subsubsection{The Experimental Design}

A formally designed experiment is run with the factors being production volumes (PV), dispatching rules (DR), due date tightness (DDT) and product mix (PM). Table 5.4 shows the factors and their levels.

Table 5.4: The Design of Experiments

\begin{tabular}{|c|c|c|c|c|c|c|c|}
\hline Factors/Levels & $\mathbf{1}$ & $\mathbf{2}$ & $\mathbf{3}$ & $\mathbf{4}$ & $\mathbf{5}$ & $\mathbf{6}$ & $\mathbf{7}$ \\
\hline $\begin{array}{c}\text { Production Volume } \\
\text { (PV) }\end{array}$ & $\begin{array}{c}154 \text { lots } \\
\text { per year }\end{array}$ & $\begin{array}{c}128 \text { lots } \\
\text { per year }\end{array}$ & - & - & - & - & - \\
\hline $\begin{array}{c}\text { Dispatching Rules } \\
\text { (DR) }\end{array}$ & P/FIFO & FIFO & CR/FIFO & HXT/FIFO & P/CR & P/HXT & LBA/FIFO \\
\hline $\begin{array}{c}\text { Due Date Tightness } \\
\text { (DDT) }\end{array}$ & $10,15,20$ & $15,20,25$ & - & - & - & - & - \\
\hline $\begin{array}{c}\text { Product Mix } \\
\text { (PM) }\end{array}$ & $25-25-50$ & $15-15-70$ & $5-5-90$ & - & - & - & - \\
\hline
\end{tabular}


Production volumes are in lots started in the fab per year, dispatching rules consist of primary and secondary rules, in the format primary/secondary, due date tightness is in the format $\mathrm{H}, \mathrm{M}, \mathrm{L}$ and the numbers for $\mathrm{H}, \mathrm{M}$ and $\mathrm{L}$ represent the flow factors, multiples of raw processing time, for high, medium and low priority lots respectively and the Product Mix which is the ratio of high, medium and low priority lots is given in the format H-M-L.

\subsubsection{Production Volume}

Production volume (PV) is used as a factor in the experimental design to control the lot starts into the fab. Semiconductor R\&D fabs are characterized by varying levels of production volumes. It is important to vary the levels of the volumes to test for significance of this factor.

Having lots enter the fab at constant average interarrival rate levels of 57 hours and 68.4 hours controls the production volume. At a constant average interarrival rate of 57 hours, the bottleneck tool has a utilization of between $95 \%$ and $99 \%$. The total lot starts amount to 154 lots/year. A constant interarrival rate of 68.4 hours sees a reduction in lot starts by $20 \%$ and this will indirectly ease the bottleneck utilization. Here, the number of lot stars amount to 128 lots/year.

Table 5.5: Inter-arrival Rates for Lots

\begin{tabular}{|c|c|c|c|c|c|c|c|c|c|}
\hline \multirow{3}{*}{$\begin{array}{l}\text { Production } \\
\text { Volume }\end{array}$} & \multicolumn{9}{|c|}{ Product Mix } \\
\hline & \multicolumn{3}{|c|}{ Level 1} & \multicolumn{3}{|c|}{ Level 2} & \multicolumn{3}{|c|}{ Level 2} \\
\hline & $50 \% \mathrm{~L}$ & $25 \% \mathrm{M}$ & $25 \% \mathrm{H}$ & $70 \% \mathrm{~L}$ & $15 \% \mathrm{M}$ & $15 \% \mathrm{H}$ & $90 \% \mathrm{~L}$ & $5 \% \mathrm{M}$ & $5 \% \mathrm{H}$ \\
\hline $\begin{array}{c}\text { Level } 1 \\
\text { (57 hour } \\
\text { interarrival } \\
\text { average) }\end{array}$ & $\begin{array}{c}114 \\
\text { hours }\end{array}$ & $\begin{array}{c}228 \\
\text { hours }\end{array}$ & $\begin{array}{c}228 \\
\text { hours }\end{array}$ & $\begin{array}{c}81.426 \\
\text { hours }\end{array}$ & $\begin{array}{c}380 \\
\text { hours }\end{array}$ & $\begin{array}{c}380 \\
\text { hours }\end{array}$ & $\begin{array}{c}63.333 \\
\text { hours }\end{array}$ & $\begin{array}{l}1140 \\
\text { hours }\end{array}$ & $\begin{array}{l}1140 \\
\text { hours }\end{array}$ \\
\hline $\begin{array}{c}\text { Level } 2 \\
\text { (68.4 hour } \\
\text { interarrival } \\
\text { average) }\end{array}$ & $\begin{array}{l}136.8 \\
\text { hours }\end{array}$ & $\begin{array}{l}273.6 \\
\text { hours }\end{array}$ & $\begin{array}{l}273.6 \\
\text { hours }\end{array}$ & $\begin{array}{c}97.714 \\
\text { hours }\end{array}$ & $\begin{array}{c}456 \\
\text { hours }\end{array}$ & $\begin{array}{c}456 \\
\text { hours }\end{array}$ & $\begin{array}{c}76 \\
\text { hours }\end{array}$ & $\begin{array}{l}1368 \\
\text { hours }\end{array}$ & $\begin{array}{l}1368 \\
\text { hours }\end{array}$ \\
\hline
\end{tabular}

Table 5.5 lists the interarrival rates depending upon the desired product mix on the fab floor. The lot start rates for the different classification of priority-designated lots always average 
to the desired level of the production volume. For e.g. for a product mix of $50 \% \mathrm{~L}$ lots, $25 \% \mathrm{M}$ lots and 25\% $\mathrm{H}$ lots, the lots start rates are 114 per hour, 228 per hour and 228 per hour respectively. This means that in a time window of 228 hours, 4 lots enter the fab with a constant average interarrival rate of 57 hours.

\subsubsection{Dispatching Rules}

Dispatching rules (DR) are used to rank wafer lots in resource worklists according to chosen lot attributes. These attributes may be time, due date or priority based or any combination of these. The dispatching rules used in this research are FIFO, Priority-based, Critical Ratio, Highest X-Theoretical Ratio first and Least Balance Ahead. The FIFO, Critical Ratio and Highest X-Theoretical Ratio rules are also used in conjunction with the Priority-based rule as secondary dispatching rules. Secondary dispatching rules break a possible tie between lots ranked by the primary dispatching rule.

Here is a brief description of the dispatching rules used in this research:

- The Priority Dispatching Rule (P): This rule ranks lots in resource worklists according to the processing priority associated with the lot. Higher priority lots are ranked ahead of lots with lower priorities. When the priority based rule is applied, the $\mathrm{H}$ lots get the highest priority in resource worklists and are ranked ahead of $\mathrm{M}$ and L lots, with the $\mathrm{M}$ lots having the second-highest priority and L lots having the least priority.

- First-In-First-Out (FIFO): This rule ranks lots according to their order of arrival on resource worklists. It treats lots on a first come first serve basis.

\section{- Critical Ratio (CR):}

$$
\text { Critical Ratio }=\frac{\text { time until due }}{\text { remaining processing time }}
$$


This rule ranks lots according to the lowest Critical Ratio first. A lot is late if it's critical ratio is less than zero. The ratio is between one and zero when the lot's remaining processing time is greater than the time until its due date. The ratio is greater than one when the lot has more time for processing before it is due.

\section{- Highest X-Theoretical Ratio First (HXT):}

$$
\mathrm{X} \text {-Theoretical Ratio }=\frac{\text { total time in system }}{\text { theoretical processing time }}
$$

This rule ranks lots according to the highest X-Theoretical Ratio first. The theoretical processing time is calculated by adding up the mean processing times for the steps in the route. The X-Theoretical value reflects the queue times. A ratio of one indicates that the queue time is zero. Lots with high $\mathrm{X}$-theoretical ratios have been delayed longer than the ones with lower ratios.

- Least Balance Ahead (LBA): This rule ranks lots that have the least number of lots of the same part type in the next step in the route.

\subsubsection{Due Date Tightness}

Flow factors, which are multiples of the raw or theoretical processing times, are used to lay down due date tightness (DDT) levels. Flow factor multiplied by the raw processing time gives the target cycle time or lead time (Rose, 2002). The simulation software used, then calculates the due date for every lot by the estimated lead-time entered for the product. This due date critically affects the behavior of the $\mathrm{CR}$ rule, which is a due date based rule. The raw processing time for a wafer lot in the representative CMOS route is 83 hours. Two levels of target cycle times or due dates for each priority classification are tested. The first level employs due date tightness at 20,15 and 10 times that of the raw processing time for low, medium and 
high priority lots respectively. The second level tests these lots for on time delivery at 25, 20 and 15 times the raw processing time. These levels have been set taking into consideration the priorities of the lots and the urgency associated with these priorities.

\subsubsection{Product Mix}

In semiconductor R\&D fabs, the definition of priority-designated lots may tend to differ. Ehteshami et al. (1992), in their paper tested the effects of these lots in ranges varying from $0 \%$ to $16.7 \%$. While, this is true for semiconductor production fabs, this proportion may be exceeded in $R \& D$ fabs. In $R \& D$ fabs, high priorities may be assigned to lots based on the urgency and nature of the research and the lots' path in the product development cycle. This research assumes that the proportion of priority lots in the route may go up to $50 \%$ of total lots in the system. These lots, by way of applying dispatching rules, are given priority in queue at stations over those lots that have a lower level of urgency associated with them. Priority-designated lots follow the same routes as regular lots but are set apart due to the upgrade in priority. This research assumes that the priority-designated lots, apart from following the same representative product route, have the same number of wafers and belong to the same product type. The overall average cycle time essentially remains the same but due to the presence of variability in operations of R\&D fabs, an overwhelming presence of priority-designated lots may cause this overall cycle time to increase.

Priority-designated lots are introduced in a fab to prove innovations. Various levels of priorities are run in the fab with pre-determined targets for completion that are multiples of theoretical cycle time. Targets are assigned so that these lots can be tested and revised so that new products can be introduced to the market at the earliest possible (Hillis, \& Robinson, 2002). 
Three levels of lot start percentages are used in order to vary the product mix (PM) on the fab floor. The L lots are tested at levels of $50 \%, 70 \%$ and $90 \%$ of the total lots with the remaining proportion being equally distributed between $\mathrm{M}$ and $\mathrm{H}$ lots.

\subsubsection{Performance Measures}

The performance measures analyzed in this study are the average cycle time, standard deviation of cycle time, percentage on time delivery and average WIP. These parameters reflect fab behavior and have been used widely for that purpose. The literature review section discusses papers that have used these parameters before.

The semiconductor R\&D fab modeled as part of this research operates in one shift per weekday. The length of this shift varies from 8 to 10 hours per day. This means that all the above performance measures include the shelf times or the non-operational times of the fab. This is one reason that the flow factor is high as compared to those used for conventional production fabs. For e.g. if the fab shuts at $4 \mathrm{pm}$ on a Monday and opens on 8 am on Tuesday, the lot cycle time will include the time spent by the lot in the state between the $4 \mathrm{pm}$ on Monday and 8 am on Tuesday. It is important not to exclude this time from the performance measures since a characteristic of semiconductor R\&D fabs is non-contiguous shifts.

The lot cycle time is hence defined as the total time taken by the lot to traverse from the lot start to the end of the product route. The Average Cycle Time averages the cycle times of the lots that make it out of the fab. The percentage on time delivery depends on the lots abiding by the set due dates (See 5.4.2.3 Due Date Tightness). The average WIP is the number of lots in process or on the worklist of resources at any given time in the fab during the simulation run length. 


\subsubsection{Statistical Analyses Procedures}

The goal of this research is to determine which dispatching rules, due date tightness and combinations of the two are most suited to different levels of production volumes and production mixes. To come up with these results, detailed statistical analyses are required. The analyses are done using the statistical software program MINITAB after compiling the simulation results. See Appendix A for the data averaged from the replications of the simulation experiments.

Based on previous research, it is expected that the factors tested in this research are significant. An ANOVA (Analysis of Variance) test is conducted on all the four factors to determine whether the main effects and the interaction effects are significant. The p-value given in the ANOVA table established the statistical significance of the factors and their interactions. The level of confidence for the factor significance is set at $95 \%$. Hence, a p-value of 0.05 or smaller makes the factor or an interaction significant. All the factors and their interactions are expected to be significant. This leads to a three factor investigation of dispatching rules, due date tightness and product mix for each of the two levels of product mix. These factors and their interactions are again expected to be significant. This leads to a two factor analyses which tests dispatching rules and due date tightness at every combination of production volume and product mix level. These analyses are especially important since the results will show the best combination of dispatching rules and due date tightness for a given R\&D fab. The results are particularly useful when the due dates are not a controllable factor in fabs. The fab manager can instantly decide a production control strategy if the determination of due dates is beyond his control. Depending on whether the two factor interactions or the main effects are significant, Tukey pairwise comparison tests are done to determine which factor levels are statistically significant from each other. The Tukey family error rate is set at $5 \%$. This test evaluates confidence intervals generated for the mean values for each performance measure at each level. 
If the confidence interval limits span zero for the difference between a pair in the group, it can be concluded that the members of the pair are not statistically different from each other; else the members are statistically different from each other. After the two factor analyses and Tukey Tests are done, it becomes possible to list the combination of dispatching rules and due date tightness that perform the best for each level of product mix at each level of production volume.

The last set of analyses will test the performance of dispatching rules by using production volume, product mix and due date tightness as controlling factors. Again, ANOVA tables are analyzed for the significance of the main effect and Tukey Tests are conducted. A summary table gives the top group of dispatching rules for each fab type.

\subsubsection{Analysis of All Factors and Their Interactions}

All the experiments from the formally designed set of experiments are run. An ANOVA is conducted on all four factors under consideration. This analysis will determine the factors that significantly affect the performance measures. The performance measures chosen for analyses here are overall performance measures. The chosen level of confidence for the ANOVA is $95 \%$. Most of the factors and their interactions are seen to be significant at this confidence level. Table 5.6 shows that all the factors and interactions for the percentage on time delivery performance measure are found to be significant. The ANOVA tables for percentage on time delivery are shown here to reflect the most important performance measure of the ones chosen in this research. ANOVA tables for the other performance measures can be seen in Appendix B. In the ANOVA table, single effects of the production volume (PV), dispatching rule (DR), due date

tightness (DDT), and product mix (PM) and their interactions are shown. Table 5.7 summarizes the factors and/or interactions from the analyses of all the performance measures. $\mathrm{S}$ and $\mathrm{N}$ are abbreviations for significant and non-significant respectively. 
Table 5.6: Analysis of All Factors and Interactions for \% On Time Delivery

\begin{tabular}{|c|c|c|c|c|c|c|}
\hline Source & DF & Seq SS & Adj SS & Adj MS & $\mathbf{F}$ & $\mathbf{P}$ \\
\hline PV & 1 & 54166.7 & 54166.7 & 54166.7 & 55634.0 & 0.000 \\
\hline DR & 6 & 22321.7 & 22321.7 & 3720.3 & 3821.1 & 0.000 \\
\hline DDT & 1 & 8321.8 & 8321.8 & 8321.8 & 8547.3 & 0.000 \\
\hline PM & 2 & 17005.1 & 17005.1 & 8502.6 & 8732.9 & 0.000 \\
\hline PV*DR & 6 & 31966.2 & 31966.2 & 5327.7 & 5472.0 & 0.000 \\
\hline PV*DDT & 1 & 1678.9 & 1678.9 & 1678.9 & 1724.4 & 0.000 \\
\hline PV*PM & 2 & 10407.9 & 10407.9 & 5204.0 & 5344.9 & 0.000 \\
\hline$D R^{*} \mathrm{DDT}$ & 6 & 1217.0 & 1217.0 & 202.8 & 208.3 & 0.000 \\
\hline DR*PM & 12 & 15021.8 & 15021.8 & 1251.8 & 1285.7 & 0.000 \\
\hline DDT*PM & 2 & 2736.0 & 2736.0 & 1368.0 & 1405.1 & 0.000 \\
\hline PV*DR*DDT & 6 & 2452.3 & 2452.3 & 408.7 & 419.8 & 0.000 \\
\hline$P V * D R * P M$ & 12 & 16546.0 & 16546.0 & 1378.8 & 1416.2 & 0.000 \\
\hline PV*DDT*PM & 2 & 1696.7 & 1696.7 & 848.4 & 871.3 & 0.000 \\
\hline $\mathrm{DR}^{*} \mathrm{DDT}^{*} \mathrm{PM}$ & 12 & 5526.0 & 5526.0 & 460.5 & 473.0 & 0.000 \\
\hline$P V^{*} D R^{*} D D T * P M$ & 12 & 4855.2 & 4855.2 & 404.6 & 415.6 & 0.000 \\
\hline Error & 168 & 163.6 & 163.6 & 1.0 & & \\
\hline Total & 251 & 196082.9 & & & & \\
\hline
\end{tabular}

Table 5.7: Summary of Factors and Interactions for All Performance Measures for the Four Factor ANOVA (S-Significant, N-Not Significant, at $\alpha=0.05$ )

\begin{tabular}{|c|c|c|c|c|}
\hline $\begin{array}{l}\text { Effects and } \\
\text { Interactions }\end{array}$ & $\begin{array}{c}\% \text { On } \\
\text { Time } \\
\text { Delivery }\end{array}$ & $\begin{array}{c}\text { Average } \\
\text { Cycle } \\
\text { Time }\end{array}$ & \begin{tabular}{|} 
Std. Dev. \\
Of Cycle \\
Time
\end{tabular} & $\begin{array}{c}\text { Average } \\
\text { WIP }\end{array}$ \\
\hline PV & $S$ & $\mathrm{~S}$ & $\mathbf{S}$ & S \\
\hline$\overline{D R}$ & S & $\mathbf{S}$ & $\mathbf{S}$ & $\mathbf{S}$ \\
\hline DDT & S & $\mathrm{N}$ & $\mathrm{N}$ & $\mathrm{N}$ \\
\hline PM & $\mathbf{S}$ & $\mathrm{S}$ & $\mathrm{S}$ & $\mathrm{S}$ \\
\hline PV*DR & S & $\mathbf{S}$ & $\mathbf{S}$ & $\mathrm{S}$ \\
\hline PV*DDT & S & $\mathrm{N}$ & $\mathrm{N}$ & $\mathrm{N}$ \\
\hline PV*PM & S & $\mathbf{S}$ & $\mathbf{S}$ & $\mathbf{S}$ \\
\hline DR*DDT & S & $\mathrm{N}$ & $\mathrm{N}$ & $\mathrm{N}$ \\
\hline$D R^{*} P M$ & $\mathbf{S}$ & $\mathrm{S}$ & S & $\mathrm{S}$ \\
\hline \begin{tabular}{|l|} 
DDT*PM \\
\end{tabular} & S & $\mathrm{N}$ & $\mathrm{N}$ & $\mathrm{N}$ \\
\hline PV*DR*DDT & S & $\mathrm{N}$ & $\mathrm{N}$ & $\mathrm{N}$ \\
\hline PV*DR*PM & $\mathbf{S}$ & $\mathbf{S}$ & S & $\mathbf{S}$ \\
\hline PV*DDT*PM & S & $\mathrm{N}$ & $\mathrm{N}$ & $\mathrm{N}$ \\
\hline \begin{tabular}{|l|}
$\mathrm{DR}^{*} \mathrm{DDT}{ }^{*} \mathrm{PM}$ \\
\end{tabular} & $\mathbf{S}$ & $S$ & $S$ & $S$ \\
\hline PV*DR*DDT*PM & $\mathbf{S}$ & $\mathbf{S}$ & $\mathbf{S}$ & $\mathbf{S}$ \\
\hline
\end{tabular}

\subsubsection{Analysis of Dispatching Rules, Product Mix and Due Date Tightness With Given Levels of Production Volume}

Once the four factor analyses have been complete, it is important to determine if the Dispatching Rules, Due Date Tightness and Product Mix and their interactions are significant for each level of production volume viz. 154 lots/year and 128 lots/year. For this purpose, an 
ANOVA is conducted again. For the percent on time delivery response, Tables 5.8 and 5.10 shows that all the factors and their interactions are significant at a confidence level of $95 \%$. The other ANOVA tables can be seen in Appendix C and Appendix D. Tables 5.9 and 5.11 summarize the factors and/or interactions for all performance measures.

Table 5.8: Three Factor ANOVA Table for \% On Time Delivery in the Fab with PV=154 lots/year

\begin{tabular}{lrrrrrr}
\hline Source & DF & Seq SS & Adj SS & Adj MS & F & P \\
\hline DR & 6 & 53187.5 & 53187.5 & 8864.6 & 4870.0 & 0.000 \\
DDT & 1 & 8738.2 & 8738.2 & 8738.2 & 4800.6 & 0.000 \\
PM & 2 & 27005.9 & 27005.9 & 13503.0 & 7418.3 & 0.000 \\
DR*DDT & 6 & 2624.4 & 2624.4 & 437.4 & 240.3 & 0.000 \\
DR*PM $^{*}$ & 12 & 31215.2 & 31215.2 & 2601.3 & 1429.1 & 0.000 \\
DDT*PM $^{*}$ & 2 & 4044.9 & 4044.9 & 2022.4 & 1111.1 & 0.000 \\
DR*DDT*PM $^{*}$ & 12 & 10049.0 & 10049.0 & 837.4 & 460.1 & 0.000 \\
Error & 84 & 152.9 & 152.9 & 1.8 & & \\
\hline Total & $\mathbf{1 2 5}$ & $\mathbf{1 3 7 0 1 8 . 0}$ & & & & \\
\hline
\end{tabular}

Table 5.9: Summary of Factors and Interactions for All Performance Measures for the Three Factor ANOVA with PV=154 lots/year (S-Significant, N-Not Significant, at $\alpha=0.05$ )

\begin{tabular}{|c|c|c|c|c|}
\hline $\begin{array}{l}\text { Effects and } \\
\text { Interactions }\end{array}$ & $\begin{array}{c}\% \text { On } \\
\text { Time } \\
\text { Delivery }\end{array}$ & $\begin{array}{c}\text { Average } \\
\text { Cycle } \\
\text { Time }\end{array}$ & $\begin{array}{l}\text { Std. Dev. } \\
\text { Of Cycle } \\
\text { Time }\end{array}$ & $\begin{array}{c}\text { Average } \\
\text { WIP }\end{array}$ \\
\hline PV & $\mathrm{S}$ & $\mathbf{S}$ & $\mathbf{S}$ & $\mathbf{S}$ \\
\hline$\overline{D R}$ & S & $\mathbf{S}$ & $\mathbf{S}$ & $\mathbf{S}$ \\
\hline DDT & S & $\mathrm{N}$ & $\mathrm{N}$ & $\mathrm{N}$ \\
\hline PM & $\mathbf{S}$ & $\mathbf{S}$ & $\mathbf{S}$ & $\mathbf{S}$ \\
\hline PV*DR & $\mathbf{S}$ & $\mathbf{S}$ & $\mathbf{S}$ & $\mathbf{S}$ \\
\hline PV*DDT & $\mathbf{S}$ & $\mathbf{S}$ & $\mathbf{S}$ & $\mathrm{S}$ \\
\hline PV*PM & $\mathbf{S}$ & $\mathbf{S}$ & $\mathbf{S}$ & $\mathbf{S}$ \\
\hline DR*DDT & $\mathbf{S}$ & $\mathrm{N}$ & $\mathrm{N}$ & $\mathrm{N}$ \\
\hline $\mathrm{DR}^{*} \mathrm{PM}$ & $\mathbf{S}$ & $\mathbf{S}$ & $\mathbf{S}$ & $\mathbf{S}$ \\
\hline DDT*PM & $\mathbf{S}$ & $\mathrm{N}$ & $\mathrm{S}$ & $\mathrm{N}$ \\
\hline PV*DR*DDT & $\mathbf{S}$ & $\mathbf{S}$ & $\mathbf{S}$ & $\mathbf{S}$ \\
\hline$P V^{*} \mathrm{DR}^{*} \mathrm{PM}$ & $\mathbf{S}$ & $\mathbf{S}$ & $\mathbf{S}$ & $\mathbf{S}$ \\
\hline PV*DDT*PM & $\mathbf{S}$ & $\mathbf{S}$ & $\mathbf{S}$ & $\mathbf{S}$ \\
\hline \begin{tabular}{|l|} 
DR*DDT*PM $^{*}$ \\
\end{tabular} & $\mathbf{S}$ & $\mathbf{S}$ & $\mathbf{S}$ & $\mathbf{S}$ \\
\hline PV*DR*DDT*PM & $\mathbf{S}$ & $\mathbf{S}$ & $\mathbf{S}$ & $\mathbf{S}$ \\
\hline
\end{tabular}


Table 5.10: Three Factor ANOVA Table for \% On Time Delivery in the Fab with PV=128 lots/year

\begin{tabular}{lrrrrrr}
\hline Source & DF & Seq SS & Adj SS & Adj MS & F & P \\
\hline PM & 2 & 407.1 & 407.1 & 203.6 & 1602.9 & 0.000 \\
DR & 6 & 1100.4 & 1100.4 & 183.4 & 1444.2 & 0.000 \\
DDT & 1 & 1262.5 & 1262.5 & 1262.5 & 9941.8 & 0.000 \\
PM*DR & 12 & 352.6 & 352.6 & 29.4 & 231.4 & 0.000 \\
PM*DDT & 2 & 387.9 & 387.9 & 193.9 & 1527.1 & 0.000 \\
DR*DDT & 6 & 1044.9 & 1044.9 & 174.2 & 1371.3 & 0.000 \\
PM*DR*DDT & 12 & 332.1 & 332.1 & 27.7 & 217.9 & 0.000 \\
Error & 84 & 10.7 & 10.7 & 0.1 & & \\
\hline Total & $\mathbf{1 2 5}$ & $\mathbf{4 8 9 8 . 2}$ & & & & \\
\hline
\end{tabular}

Table 5.11: Summary of Factors and Interactions for All Performance Measures for the Three Factor ANOVA with PV=128 lots/year (S-Significant, N-Not Significant, at $\alpha=0.05$ )

\begin{tabular}{|c|c|c|c|c|}
\hline $\begin{array}{l}\text { Effects and } \\
\text { Interactions }\end{array}$ & $\begin{array}{c}\% \text { On } \\
\text { Time } \\
\text { Delivery }\end{array}$ & $\begin{array}{c}\text { Average } \\
\text { Cycle } \\
\text { Time }\end{array}$ & $\begin{array}{c}\text { Std. Dev. } \\
\text { Of Cycle } \\
\text { Time }\end{array}$ & $\begin{array}{c}\text { Average } \\
\text { WIP }\end{array}$ \\
\hline PV & $\mathbf{S}$ & $\mathbf{S}$ & $\mathbf{S}$ & S \\
\hline DR & S & $\mathbf{S}$ & $\mathbf{S}$ & S \\
\hline DDT & $\mathbf{S}$ & $\mathbf{S}$ & $\mathbf{S}$ & $\mathbf{S}$ \\
\hline PM & $S$ & $\mathbf{S}$ & $\mathbf{S}$ & S \\
\hline PV*DR & S & $\mathbf{S}$ & $\mathbf{S}$ & $\mathbf{S}$ \\
\hline PV*DDT & S & $\mathbf{S}$ & $\mathbf{S}$ & $\mathbf{S}$ \\
\hline PV*PM & $\mathbf{S}$ & $\mathbf{S}$ & $\mathbf{S}$ & $\mathbf{S}$ \\
\hline DR*DDT & $\mathbf{S}$ & $\mathbf{S}$ & $\mathbf{S}$ & $\mathbf{S}$ \\
\hline DR*PM & $S$ & $\mathbf{S}$ & $\mathbf{S}$ & $\mathbf{S}$ \\
\hline DDT*PM & $\mathbf{S}$ & $\mathbf{N}$ & $\mathbf{N}$ & $\mathbf{N}$ \\
\hline PV*DR*DDT & $\mathbf{S}$ & $\mathbf{S}$ & $\mathbf{S}$ & $\mathbf{S}$ \\
\hline PV*DR*PM & $\mathbf{S}$ & $\mathbf{S}$ & $\mathbf{S}$ & $\mathbf{S}$ \\
\hline PV*DDT*PM & $\mathbf{S}$ & $\mathbf{S}$ & $\mathbf{S}$ & $\mathbf{S}$ \\
\hline DR*DDT*PM & $\mathbf{S}$ & $\mathbf{N}$ & $\mathbf{N}$ & $\mathbf{N}$ \\
\hline $\mathrm{PV}^{*} \mathrm{DR}^{*} \mathrm{DDT}^{*} \mathrm{PM}$ & $\mathbf{S}$ & $\mathbf{S}$ & $\mathbf{S}$ & $\mathbf{S}$ \\
\hline
\end{tabular}

\subsubsection{Analysis of Dispatching Rules and Due Date Tightness With Given Levels of Production Volume and Product Mix}

The three factor ANOVA results are used as the basis for conducting a two factor ANOVA with the factors being Dispatching Rules and Due Date Tightness for each Product Mix level at each production volume level. Table 5.12 shows that the for the percent on time delivery response, all factors and their interactions are significant at a confidence level of $95 \%$. All tables can be viewed in Appendix E. 
Table 5.12: ANOVA Table for \% On Time Delivery at PV=154 lots/year and PM = 25-25-50

\begin{tabular}{lrrrrrr}
\hline Source & DF & Seq SS & Adj SS & Adj MS & F & P \\
\hline DR & 6 & 23693.3 & 23693.3 & 3948.9 & 2648.6 & 0.000 \\
DDT & 1 & 2565.0 & 2565.0 & 2565.0 & 1720.4 & 0.000 \\
DR*DDT & 6 & 790.0 & 790.0 & 131.7 & 88.3 & 0.000 \\
Error & 28 & 41.7 & 41.7 & 1.5 & & \\
\hline Total & $\mathbf{4 1}$ & $\mathbf{2 7 0 9 0 . 0}$ & & & & \\
\hline
\end{tabular}

From the tables it can be concluded that the dispatching rules, due date tightness and their interactions are significant for the percent on time delivery response, for each production volume and product mix. Now, the combinations of the factors, those significantly perform the best need to be determined. Although the main effects individually may be significant, Tukey tests are not conducted on them unless the interaction itself is not significant. If the interaction is shown as not significant, a Tukey Test is only conducted on the dispatching rules, since the due date tightness has only two levels, which is below the minimum of three required to carry out a Tukey test.

The vertical lines in the significance column group the strategies that are not statistically different from each other. In Table 5.13, the FIFO and 15,20,25 combination is not statistically different from the LBA/FIFO and 15,20,25 combination but is statistically different from the HXT/FIFO and 15,20,25 combination. The Tukey tables for all the performance measures at all levels of production volume and product mix can be seen in Appendix F. 
Table 5.13: Tukey Pairwise Comparison Test for $\%$ On Time Delivery for $\mathrm{PV}=154$ lots/year and $\mathrm{PM}=25-25-50$

\begin{tabular}{|c|c|c|c|}
\hline $\begin{array}{c}\text { Dispatching } \\
\text { Rule }\end{array}$ & $\begin{array}{c}\text { Due Date } \\
\text { Tightness }(\mathrm{H}, \mathrm{M}, \mathrm{L})\end{array}$ & $\begin{array}{l}\% \text { on time } \\
\text { delivery }\end{array}$ & Sig. \\
\hline FIFO & $15,20,25$ & 86.343 & \\
\hline LBA/FIFO & $15,20,25$ & 85.205 & \\
\hline HXT/FIFO & $15,20,25$ & 71.125 & \\
\hline FIFO & $10,15,20$ & 66.052 & \\
\hline LBA/FIFO & $10,15,20$ & 64.61 & \\
\hline P/CR & $15,20,25$ & 50.311 & \\
\hline $\mathrm{P} / \mathrm{HXT}$ & $15,20,25$ & 50.109 & \\
\hline $\mathrm{P} / \mathrm{FIFO}$ & $15,20,25$ & 49.856 & \\
\hline $\mathrm{HXT} / \mathrm{FIFO}$ & $10,15,20$ & 41.303 & \\
\hline P/FIFO & $10,15,20$ & 39.406 & \\
\hline $\mathrm{P} / \mathrm{HXT}$ & $10,15,20$ & 37.252 & \\
\hline $\mathrm{P} / \mathrm{CR}$ & $10,15,20$ & 34.917 & \\
\hline CR/FIFO & $10,15,20$ & 0 & \\
\hline CR/FIFO & $15,20,25$ & 0 & \\
\hline
\end{tabular}

Table 5.13 shows the Tukey comparison for the combination of Dispatching Rules and Due Date Tightness for percent on time delivery. FIFO and LBA/FIFO at flow factors of 15,20 and 25 for the H, M and $\mathrm{N}$ lots perform well. After all the Tukey tests are conducted, the top groups of strategies for each performance measure are listed. This will also serve the purpose of establishing if a strategy is robust across production mixes at that level of production volume.

Table 5.14 lists the top groups combination of dispatching rules and due date tightness strategies at a production volume of 154 lots/year at the three levels of product mix. The FIFO and LBA/FIFO rules at both the levels of due date tightness seem to perform well and are in the top groups for all levels of product mix for all responses except for percent on time delivery for the lower proportions of medium and high priority-designated lots and for one level of product mix for standard deviation of cycle time. It is interesting to observe that for percent on time delivery, the CR/FIFO rule comes into play when the fab has relatively fewer medium and high priority-designated lots and does not make it in the top groups for any level of product mix for average cycle time. The CR rule is a due date based rule and is expected to perform well for the 
percent on time delivery and average cycle time performance measures. The due date based rules used in this research and their performances are discussed in a later section.

Table 5.15 lists the top groups combination of dispatching rules and due date tightness strategies at a production volume of 154 lots/year at the three levels of product mix. The due date based rules of CR/FIFO and P/CR at the second and more relaxed level of due date tightness find themselves in the top groups of all three levels of product mixes for the percent on time delivery response.

Table 5.14: Top Groups of Strategies for PV=154 lots/year

\begin{tabular}{|c|c|c|c|c|c|}
\hline PM & $\begin{array}{c}\% \\
\text { On Time Delivery }\end{array}$ & $\begin{array}{c}\text { Average } \\
\text { Cycle Time }\end{array}$ & $\begin{array}{l}\text { Std. Dev. } \\
\text { Of Cycle Time }\end{array}$ & $\begin{array}{l}\text { Average } \\
\text { WIP }\end{array}$ & $\begin{array}{c}\text { Robust Strategies } \\
\text { Across } \\
\text { Performance } \\
\text { Measures } \\
\end{array}$ \\
\hline $25-25-50$ & $\begin{array}{r}\text { FIFO } 15,20,25 \\
\text { LBA/FIFO } 15,20,25\end{array}$ & $\begin{array}{r}\text { FIFO } 10,15,20 \\
\text { FIFO } 15,20,25 \\
\text { LBA/FIFO } 10,15,20 \\
\text { LBA/FIFO } 15,20,25 \\
\text { HXT/FIFO } 10,15,20 \\
\text { HXT/FIFO } 15,20,25 \\
\text { P/HXT } 10,15,20 \\
\text { P/HXT } 15,20,25\end{array}$ & $\begin{array}{r}\text { HXT/FIFO } 10,15,20 \\
\text { HXT/FIFO } 15,20,25 \\
\text { FIFO } 10,15,20 \\
\text { FIFO } 15,20,25 \\
\text { LBA/FIFO } 10,15,20 \\
\text { LBA/FIFO } 15,20,25 \\
\text { CR/FIFO } 10,15,20 \\
\text { CR/FIFO } 15,20,25 \\
\text { P/HXT } 10,15,20 \\
\text { P/HXT } 15,20,25 \\
\end{array}$ & $\begin{array}{r}\text { FIFO } 10,15,20 \\
\text { FIFO 15,20,25 } \\
\text { LBA/FIFO 10,15,20 } \\
\text { LBA/FIFO 15,20,25 } \\
\text { HXT/FIFO } 10,15,20 \\
\text { HXT/FIFO 15,20,25 } \\
\text { P/HXT 10,15,20 } \\
\text { P/HXT 15,20,25 } \\
\text { CR/FIFO 10,15,20 } \\
\text { CR/FIFO 15,20,25 }\end{array}$ & $\begin{array}{r}\text { FIFO } 15,20,25 \\
\text { LBA/FIFO } 15,20,25\end{array}$ \\
\hline $15-15-70$ & $\begin{array}{r}\text { CR/FIFO } 15,20,25 \\
\text { P/FIFO } 15,20,25 \\
\text { P/HXT } 15,20,25\end{array}$ & $\begin{array}{r}\text { FIFO } 10,15,20 \\
\text { FIFO } 15,20,25 \\
\text { LBA/FIFO } 10,15,20 \\
\text { LBA/FIFO } 15,20,25 \\
\text { HXT/FIFO } 10,15,20 \\
\text { HXT/FIFO } 15,20,25 \\
\text { P/FIFO } 10,15,20 \\
\text { P/FIFO } 15,20,25\end{array}$ & $\begin{array}{r}\text { HXT/FIFO } 10,15,20 \\
\text { HXT/FIFO } 15,20,25 \\
\text { FIFO } 10,15,20 \\
\text { FIFO } 15,20,25 \\
\text { LBA/FIFO } 10,15,20 \\
\text { LBA/FIFO } 15,20,25\end{array}$ & $\begin{array}{r}\text { FIFO } 10,15,20 \\
\text { FIFO } 15,20,25 \\
\text { LBA/FIFO } 10,15,20 \\
\text { LBA/FIFO } 15,20,25 \\
\text { HXT/FIFO } 10,15,20 \\
\text { HXT/FIFO } 15,20,25 \\
\text { P/FIFO } 10,15,20 \\
\text { P/FIFO } 15,20,25\end{array}$ & P/FIFO 15,20,25 \\
\hline $5-5-90$ & $\begin{array}{r}\text { CR/FIFO } 15,20,25 \\
\text { P/FIFO } 15,20,25 \\
\text { P/HXT } 15,20,25\end{array}$ & $\begin{array}{r}\text { FIFO } 10,15,20 \\
\text { FIFO } 15,20,25 \\
\text { P/HXT } 10,15,20 \\
\text { P/HXT } 15,20,25 \\
\text { P/FIFO } 10,15,20 \\
\text { P/FIFO } 15,20,25 \\
\text { HXT/FIFO } 10,15,20 \\
\text { HXT/FIFO } 15,20,25 \\
\text { LBA/FIFO } 10,15,20 \\
\text { LBA/FIFO } 15,20,25\end{array}$ & $\begin{array}{l}\text { HXT/FIFO 10,15,20 } \\
\text { HXT/FIFO 15,20,25 }\end{array}$ & $\begin{array}{r}\text { FIFO 10,15,20 } \\
\text { FIFO 15,20,25 } \\
\text { P/HXT 10,15,20 } \\
\text { P/HXT 15,20,25 } \\
\text { P/FIFO 10,15,20 } \\
\text { P/FIFO 15,20,25 } \\
\text { HXT/FIFO 10,15,20 } \\
\text { HXT/FIFO 15,20,25 } \\
\text { LBA/FIFO 10,15,20 } \\
\text { LBA/FIFO 15,20,25 }\end{array}$ & $\begin{array}{r}\text { P/FIFO 15,20,25 } \\
\text { P/HXT 15,20,25 }\end{array}$ \\
\hline
\end{tabular}


Table 5.15: Top Groups of Strategies for PV=128 lots/year

\begin{tabular}{|c|c|c|c|c|c|}
\hline PM & $\begin{array}{c}\% \\
\text { On Time Delivery }\end{array}$ & $\begin{array}{c}\text { Average } \\
\text { Cycle Time }\end{array}$ & $\begin{array}{l}\text { Std. Dev. } \\
\text { Of Cycle Time }\end{array}$ & $\begin{array}{l}\text { Average } \\
\text { WIP }\end{array}$ & \begin{tabular}{|c|} 
Robust Strategies \\
Across \\
Performance \\
Measures \\
\end{tabular} \\
\hline $25-25-50$ & \begin{tabular}{|r} 
CR/FIFO $15,20,25$ \\
HXT/FIFO $15,20,25$ \\
P/CR 15,20,25 \\
P/FIFO 15,20,25 \\
P/HXT 15,20,25 \\
FIFO 15,20,25 \\
LBA/FIFO $15,20,25$
\end{tabular} & $\begin{array}{r}\text { P/FIFO 10,15,20 } \\
\text { P/FIFO 15,20,25 } \\
\text { P/HXT 10,15,20 } \\
\text { P/HXT 15,20,25 } \\
\text { FIFO 10,15,20 } \\
\text { FIFO 15,20,25 } \\
\text { P/CR 15,20,25 } \\
\text { P/CR 10,15,20 }\end{array}$ & HXT/FIFO 10,15,20 & $\begin{array}{r}\text { P/FIFO } 10,15,20 \\
\text { P/FIFO } 15,20,25 \\
\text { P/HXT } 10,15,20 \\
\text { P/HXT } 15,20,25 \\
\text { FIFO } 10,15,20 \\
\text { FIFO } 15,20,25 \\
\text { P/CR } 15,20,25 \\
\text { P/CR } 10,15,20\end{array}$ & $\begin{array}{r}\text { P/FIFO } 15,20,25 \\
\text { P/HXT 15,20,25 } \\
\text { FIFO 15,20,25 }\end{array}$ \\
\hline $15-15-70$ & $\begin{array}{r}\text { CR/FIFO } 15,20,25 \\
\text { HXT/FIFO } 15,20,25 \\
\text { P/CR } 15,20,25 \\
\text { P/FIFO } 15,20,25 \\
\text { P/HXT } 15,20,25 \\
\text { LBA/FIFO } 15,20,25 \\
\text { FIFO } 15,20,25 \\
\text { P/FIFO } 10,15,20 \\
\text { P/HXT } 10,15,20 \\
\text { P/CR } 10,15,20 \\
\end{array}$ & $\begin{array}{c}\text { P/HXT } \\
\text { FIFO } \\
\text { HXT/FIFO } \\
\text { LBA/FIFO } \\
\text { P/FIFO } \\
\\
\text { (@ both levels } \\
\text { of DDT) }\end{array}$ & $\begin{array}{l}\text { HXT/FIFO } 10,15,20 \\
\text { HXT/FIFO } 15,20,25\end{array}$ & $\begin{array}{c}\text { P/HXT } \\
\text { FIFO } \\
\text { HXT/FIFO } \\
\text { LBA/FIFO } \\
\text { P/FIFO } \\
\\
\text { (@ both levels } \\
\text { of DDT) }\end{array}$ & $\begin{array}{r}\text { P/FIFO 10,15,20 } \\
\text { P/FIFO 15,20,25 } \\
\text { P/HXT 10,15,20 } \\
\text { P/HXT 15,20,25 } \\
\text { LBA/FIFO } 15,20,25 \\
\text { FIFO } 15,20,25 \\
\text { HXT/FIFO } 15,20,25\end{array}$ \\
\hline 5-5-90 & \begin{tabular}{|r} 
CR/FIFO $15,20,25$ \\
HXT/FIFO $15,20,25$ \\
LBA/FIFO $15,20,25$ \\
P/CR $15,20,25$ \\
P/FIFO $15,20,25$ \\
P/HXT 15,20,25 \\
FIFO 15,20,25 \\
CR/FIFO 10,15,20 \\
P/CR 10,15,20 \\
P/HXT 10,15,20 \\
P/FIFO 10.15,20
\end{tabular} & $\begin{array}{r}\text { P/HXT 15,20,25 } \\
\text { HXT/FIFO 10,15,20 } \\
\text { HXT/FIFO 15,20,25 } \\
\text { P/HXT 10,15,20 } \\
\text { FIFO 10,15,20 } \\
\text { FIFO 15,20,25 } \\
\text { LBA/FIFO 10,15,20 } \\
\text { LBA/FIFO } 15,20,25\end{array}$ & $\begin{array}{r}\text { HXT/FIFO 10,15,20 } \\
\text { HXT/FIFO 15,20,25 } \\
\text { P/HXT 15,20,25 } \\
\\
\end{array}$ & $\begin{array}{r}\text { P/HXT } 15,20,25 \\
\text { HXT/FIFO } 10,15,20 \\
\text { HXT/FIFO } 15,20,25 \\
\text { P/HXT } 10,15,20 \\
\text { FIFO } 10,15,20 \\
\text { FIFO } 15,20,25 \\
\text { LBA/FIFO } 10,15,20 \\
\text { LBA/FIFO } 15,20,25\end{array}$ & \begin{tabular}{|l} 
HXT/FIFO $15,20,25$ \\
LBA/FIFO $15,20,25$ \\
P/HXT $10,15,20$ \\
P/HXT $15,20,25$ \\
FIFO $15,20,25$
\end{tabular} \\
\hline
\end{tabular}

\subsubsection{Using Due Date Tightness as a Controllable Factor}

By using due date tightness as a controllable factor, dispatching rules can be examined individually, as to what rules work best given a certain operating condition in the fab. In this case, the production volume, product mix and due date tightness are all used to generate 12 fab types. This is done to give fab managers a good indication as to what dispatching rules work best 
for given operating conditions. Table 5.16 lists the levels of production volume, due date tightness and product mix under which each fab operates.

Table 5.16: Fab Type by Operating Condition

\begin{tabular}{|c|c|c|c|}
\hline Fab Type & $\begin{array}{c}\text { Production } \\
\text { Volume } \\
\text { (lots per year) }\end{array}$ & $\begin{array}{c}\text { Due Date } \\
\text { Tightness } \\
\text { (multiples of raw } \\
\text { processing time } \\
\text { H,M,L) }\end{array}$ & $\begin{array}{c}\text { Product Mix } \\
\text { (lot start } \\
\text { percentages - } \\
\text { H-M-L) }\end{array}$ \\
\hline I & 154 & $10,15,20$ & $25-25-50$ \\
\hline II & 154 & $15,20,25$ & $15-15-70$ \\
\hline III & 154 & $10,15,20$ & $5-5-90$ \\
\hline IV & 154 & $15,20,25$ & $25-25-50$ \\
\hline V & 154 & $10,15,20$ & $15-15-70$ \\
\hline VI & 154 & $15,20,25$ & $5-5-90$ \\
\hline VII & 128 & $10,15,20$ & $25-25-50$ \\
\hline VIII & 128 & $15,20,25$ & $15-15-70$ \\
\hline IX & 128 & $10,15,20$ & $5-5-90$ \\
\hline $\mathbf{X}$ & 128 & $15,20,25$ & $25-25-50$ \\
\hline $\mathbf{X I}$ & 128 & $10,15,20$ & $15-15-70$ \\
\hline XII & 128 & $15,20,25$ & $5-5-90$ \\
\hline
\end{tabular}

ANOVA and Tukey tests are conducted for all 12 fab types for all four performance measures. ANOVA tables and Tukey tests conducted for each fab type can be seen in Appendix F.

Table 5.17 lists the top groups of dispatching rules for every fab type for every performance measure. The last column contains those rules that perform consistently well for a given fab type across all performance measures. The rules that have been named robust in most cases perform well for percent on time delivery, average cycle time and average WIP. The standard deviation of cycle time measure gives an indication as to how consistent the average 
cycle time of the lots in fab is. Hence rules find themselves as being robust even if they don't make it to the top group for the standard deviation of cycle time performance measure.

Table 5.17: Analysis of Dispatching Rules for the 12 Fab Types

\begin{tabular}{|c|c|c|c|c|c|}
\hline Fab Type & $\begin{array}{c}\% \\
\text { On Time } \\
\text { Delivery }\end{array}$ & $\begin{array}{c}\text { Average } \\
\text { Cycle Time }\end{array}$ & $\begin{array}{c}\text { Std. Dev. } \\
\text { Of Cycle Time }\end{array}$ & $\begin{array}{c}\text { Average } \\
\text { WIP }\end{array}$ & $\begin{array}{l}\text { Robust dispatching } \\
\text { rules }\end{array}$ \\
\hline I & $\begin{array}{c}\text { FIFO } \\
\text { LBA/FIFO }\end{array}$ & $\begin{array}{c}\text { FIFO } \\
\text { LBA/FIFO } \\
\text { HXT/FIFO } \\
\text { P/HXT } \\
\text { CR/FIFO } \\
\end{array}$ & $\begin{array}{c}\mathrm{HXT} / \mathrm{FIFO} \\
\text { FIFO } \\
\text { LBA/FIFO } \\
\text { CR/FIFO } \\
\text { P/HXT } \\
\end{array}$ & $\begin{array}{c}\text { FIFO } \\
\text { LBA/FIFO } \\
\text { HXT/FIFO } \\
\text { P/HXT } \\
\text { CR/FIFO } \\
\end{array}$ & $\begin{array}{c}\text { FIFO } \\
\text { LBA/FIFO }\end{array}$ \\
\hline II & $\begin{array}{c}\text { CR/FIFO } \\
\text { P/FIFO } \\
\text { P/HXT }\end{array}$ & $\begin{array}{c}\text { FIFO } \\
\text { LBA/FIFO } \\
\text { HXT/FIFO } \\
\text { P/FIFO }\end{array}$ & $\begin{array}{c}\text { HXT/FIFO } \\
\text { FIFO } \\
\text { LBA/FIFO }\end{array}$ & $\begin{array}{c}\text { FIFO } \\
\text { LBA/FIFO } \\
\text { HXT/FIFO } \\
\text { P/FIFO }\end{array}$ & P/FIFO \\
\hline III & $\begin{array}{l}\text { P/FIFO } \\
\text { P/HXT }\end{array}$ & $\begin{array}{c}\text { FIFO } \\
\text { P/HXT } \\
\text { P/FIFO } \\
\text { HXT/FIFO } \\
\text { LBA/FIFO }\end{array}$ & HXT/FIFO & $\begin{array}{c}\text { FIFO } \\
\text { P/HXT } \\
\text { P/FIFO } \\
\text { HXT/FIFO } \\
\text { LBA/FIFO }\end{array}$ & $\begin{array}{l}\text { P/FIFO } \\
\text { P/HXT }\end{array}$ \\
\hline IV & $\begin{array}{c}\text { FIFO } \\
\text { LBA/FIFO }\end{array}$ & $\begin{array}{c}\text { FIFO } \\
\text { LBA/FIFO } \\
\text { HXT/FIFO }\end{array}$ & $\begin{array}{c}\text { HXT/FIFO } \\
\text { FIFO } \\
\text { LBA/FIFO } \\
\text { CR/FIFO } \\
\end{array}$ & $\begin{array}{c}\text { FIFO } \\
\text { LBA/FIFO } \\
\text { HXT/FIFO }\end{array}$ & $\begin{array}{c}\text { FIFO } \\
\text { LBA/FIFO }\end{array}$ \\
\hline $\mathbf{V}$ & LBA/FIFO & $\begin{array}{c}\text { FIFO } \\
\text { LBA/FIFO } \\
\text { HXT/FIFO } \\
\text { P/FIFO } \\
\end{array}$ & $\begin{array}{c}\text { HXT/FIFO } \\
\text { FIFO } \\
\text { LBA/FIFO }\end{array}$ & $\begin{array}{c}\text { FIFO } \\
\text { LBA/FIFO } \\
\text { HXT/FIFO }\end{array}$ & LBA/FIFO \\
\hline VI & $\begin{array}{c}\text { CR/FIFO } \\
\text { P/FIFO } \\
\text { P/HXT }\end{array}$ & $\begin{array}{c}\text { FIFO } \\
\text { P/HXT } \\
\text { P/FIFO }\end{array}$ & HXT/FIFO & $\begin{array}{c}\text { FIFO } \\
\text { P/HXT } \\
\text { P/FIFO } \\
\text { HXT/FIFO }\end{array}$ & $\begin{array}{l}\text { P/FIFO } \\
\text { P/HXT }\end{array}$ \\
\hline VII & $\begin{array}{c}\text { P/FIFO } \\
\text { P/HXT } \\
\text { CR/FIFO } \\
\text { P/CR } \\
\end{array}$ & $\begin{array}{c}\text { P/FIFO } \\
\text { P/HXT } \\
\text { FIFO } \\
\text { P/CR } \\
\end{array}$ & HXT/FIFO & $\begin{array}{c}\text { P/FIFO } \\
\text { P/HXT } \\
\text { FIFO } \\
\text { P/CR } \\
\end{array}$ & $\begin{array}{c}\text { P/FIFO } \\
\text { P/HXT } \\
\text { P/CR }\end{array}$ \\
\hline VIII & $\begin{array}{c}\text { CR/FIFO } \\
\text { HXT/FIFO } \\
\text { P/CR } \\
\text { P/FIFO } \\
\text { P/HXT }\end{array}$ & $\begin{array}{c}\text { P/HXT } \\
\text { FIFO } \\
\text { HXT/FIFO } \\
\text { LBA/FIFO } \\
\text { P/FIFO }\end{array}$ & HXT/FIFO & $\begin{array}{c}\text { P/HXT } \\
\text { FIFO } \\
\text { HXT/FIFO } \\
\text { LBA/FIFO } \\
\text { P/FIFO }\end{array}$ & $\begin{array}{c}\text { HXT/FIFO } \\
\text { P/FIFO } \\
\text { P/HXT }\end{array}$ \\
\hline IX & $\begin{array}{c}\text { CR/FIFO } \\
\text { P/CR } \\
\text { P/HXT } \\
\text { P/FIFO } \\
\end{array}$ & $\begin{array}{c}\text { HXT/FIFO } \\
\text { P/HXT } \\
\text { FIFO } \\
\text { LBA/FIFO } \\
\end{array}$ & HXT/FIFO & $\begin{array}{c}\text { HXT/FIFO } \\
\text { P/HXT } \\
\text { FIFO } \\
\text { LBA/FIFO }\end{array}$ & P/HXT \\
\hline$X$ & $\begin{array}{c}\text { CR/FIFO } \\
\text { HXT/FIFO } \\
\text { P/CR } \\
\text { P/FIFO } \\
\text { P/HXT } \\
\text { FIFO }\end{array}$ & $\begin{array}{c}\text { P/FIFO } \\
\text { P/HXT } \\
\text { FIFO } \\
\text { P/CR }\end{array}$ & HXT/FIFO & $\begin{array}{c}\text { P/FIFO } \\
\text { P/HXT } \\
\text { FIFO } \\
\text { P/CR }\end{array}$ & $\begin{array}{c}\text { P/CR } \\
\text { P/FIFO } \\
\text { P/HXT }\end{array}$ \\
\hline XI & $\begin{array}{c}\text { P/FIFO } \\
\text { P/HXT } \\
\text { P/CR } \\
\text { CR/FIFO }\end{array}$ & $\begin{array}{c}\text { P/HXT } \\
\text { FIFO } \\
\text { HXT/FIFO } \\
\text { LBA/FIFO } \\
\text { P/FIFO }\end{array}$ & HXT/FIFO & $\begin{array}{c}\text { P/HXT } \\
\text { FIFO } \\
\text { HXT/FIFO } \\
\text { LBA/FIFO } \\
\text { P/FIFO }\end{array}$ & $\begin{array}{l}\text { P/FIFO } \\
\text { P/HXT }\end{array}$ \\
\hline XII & $\begin{array}{c}\text { CR/FIFO } \\
\text { HXT/FIFO } \\
\text { LBA/FIFO } \\
\text { P/CR } \\
\text { P/FIFO } \\
\text { P/HXT } \\
\end{array}$ & $\begin{array}{c}\text { P/HXT } \\
\text { HXT/FIFO } \\
\text { FIFO } \\
\text { LBA/FIFO }\end{array}$ & $\begin{array}{c}\text { HXT/FIFO } \\
\text { P/HXT }\end{array}$ & $\begin{array}{c}\text { P/HXT } \\
\text { HXT/FIFO } \\
\text { FIFO } \\
\text { LBA/FIFO }\end{array}$ & $\begin{array}{c}\text { HXT/FIFO } \\
\text { LBA/FIFO } \\
\text { P/HXT }\end{array}$ \\
\hline
\end{tabular}


For the levels of product mix with lower proportions of low priority designated lots, it is seen that the FIFO and LBA/FIFO rules perform the best. The P/FIFO and P/HXT rules perform better for the lower level of production volume and for product mixes with higher proportion of low priority-designated lots. It is interesting to note that the due date based rules, CR/FIFO finds it self in the top group of almost all fab types for the percent on time delivery but is not a robust rule across other performance measures. Similarly, the HXT/FIFO rule performs consistently well for the standard deviation of cycle time performance measure for most fab types but is a robust rule only for two fab types.

\subsubsection{Performance of the Due Date Based Rules}

Past research has shown that due date-based rules like Critical Ratio (CR) and Earliest Due Date (EDD) perform well for due date constrained scenarios (Rose, 2002). Taking into account the good performance of the due date based rules; the CR/FIFO and P/CR rules have been used as levels in the dispatching rule factor while conducting simulations.

From the results in Table 5.17, it is clear that the CR/FIFO rule does not perform well across all the performance measures. The CR/FIFO performs well for the percent on time delivery response but fails to perform consistently well over the other measures. The P/CR rule is a robust rule for only one of the twelve fab types. Figures 5.4 and 5.5 show column graphs comparing percent on time delivery and average cycle time respectively of the due date based rules $(\mathrm{CR} / \mathrm{FIFO}$ and $\mathrm{P} / \mathrm{CR})$ with those of the other robust rules $(\mathrm{P} / \mathrm{FIFO}, \mathrm{P} / \mathrm{HXT}, \mathrm{LBA} / \mathrm{FIFO}$ and FIFO). It is seen that the CR/FIFO rule has extremes when it comes to percent on time delivery with value of either $0 \%$ or grater than $96 \%$. The P/CR rule does not do very well when compared to the other rules. The $\mathrm{CR} / \mathrm{FIFO}$ rule performs better than the $\mathrm{P} / \mathrm{CR}$ rule for average cycle time but does poorly when compared to the other robust rules. 


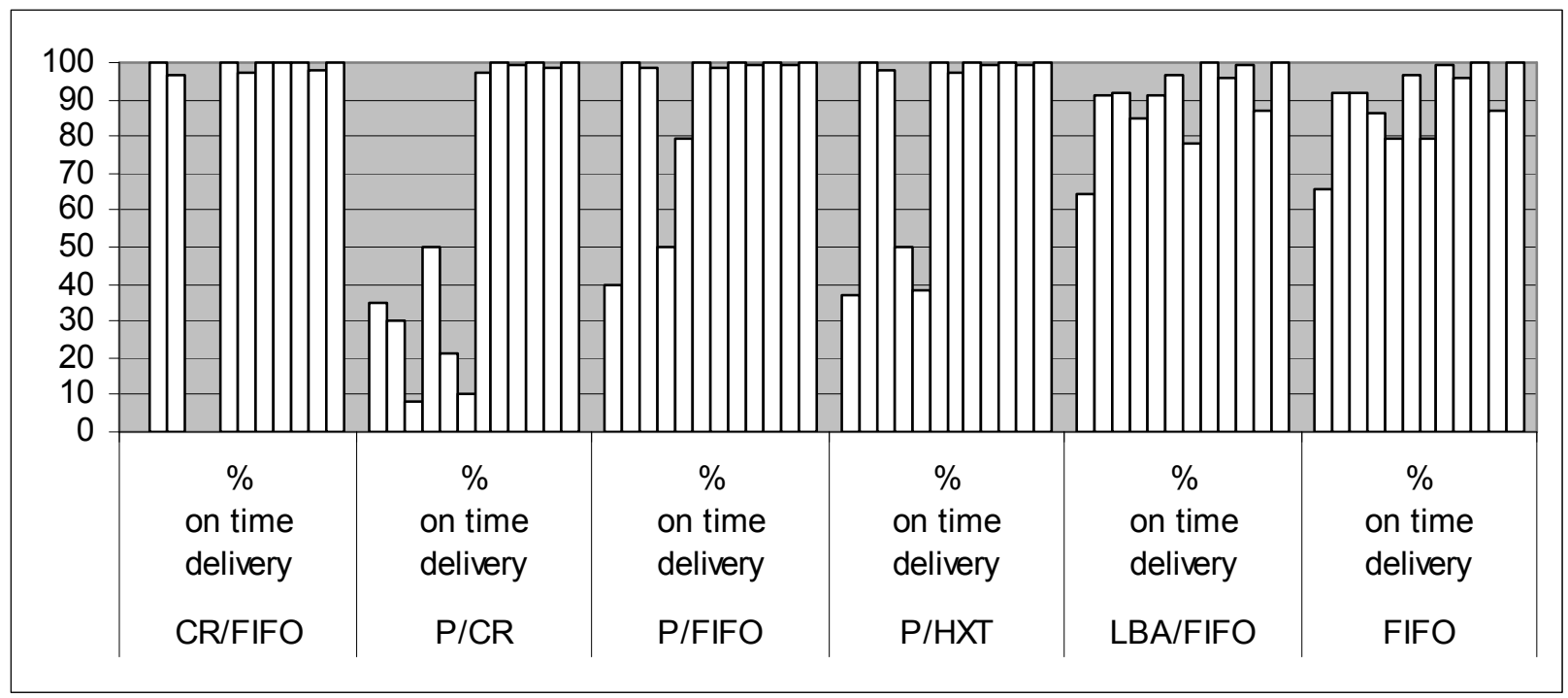

Figure 5.4: Comparison of \% On Time Delivery Between the Due Date Based Rules and Four Robust Rules, for the 12 Fab Types

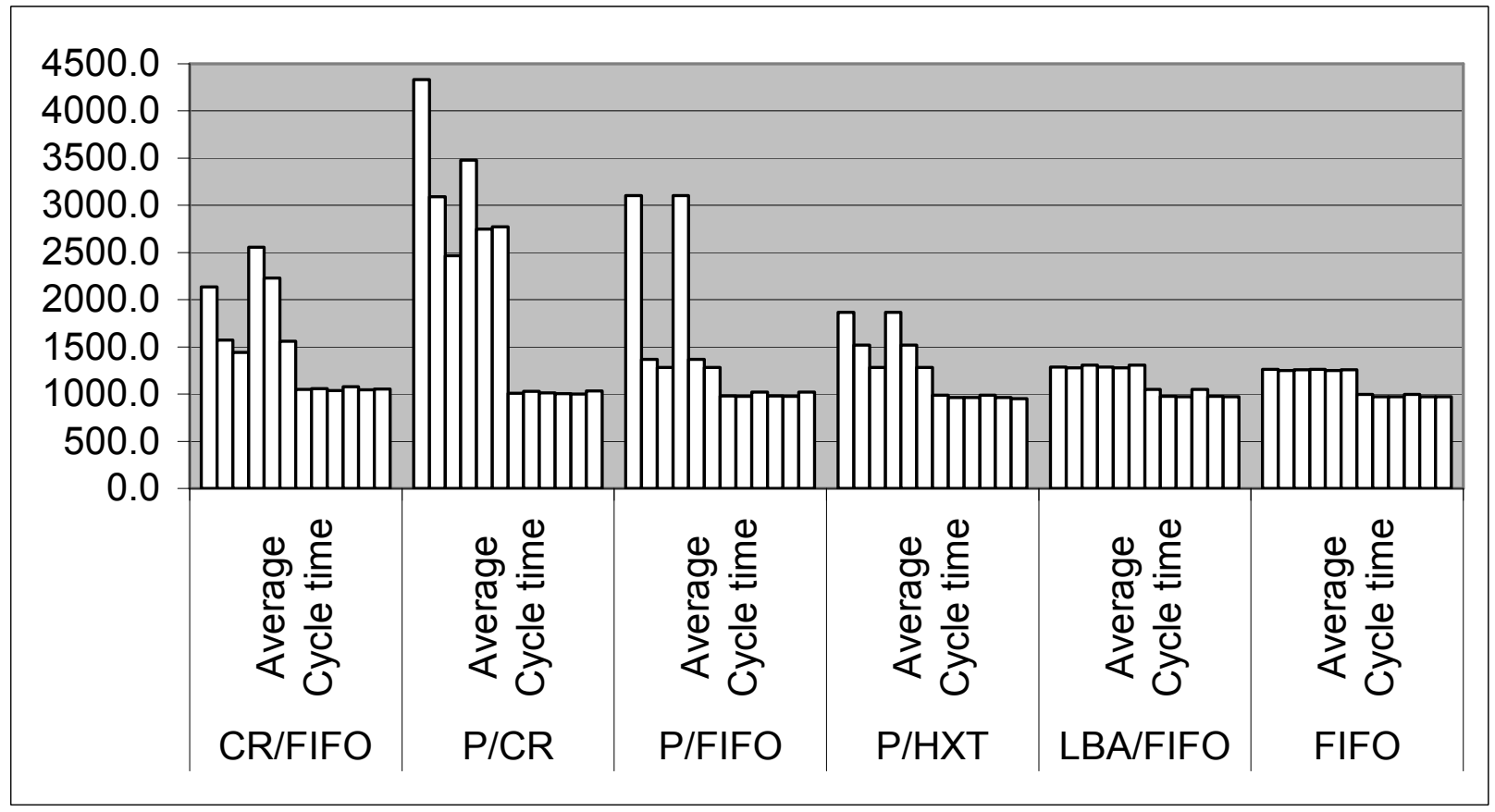

Figure 5.5: Comparison of Average Cycle Time Between the Due Date Based Rules and Four Robust Rules, for the 12 Fab Types 
A few reasons for this unexpected behavior of the due date based rules maybe:

- Lots with high slack remain at the bottom of resource worklists to give way to lots with lesser slack;

- Newer lots with high slack always give way to older lots with lesser slack;

- High numbers of reentrant steps, characteristic to semiconductor process routes hinder lot progress on account of slack and/or priority; and

- Due date based rules exclusively cater to giving precedence to lots with least slack and hence for higher volumes of production or higher proportions of one level of priority, lots will often have negative slack because of waiting on resource lists for processing. On the other hand, when due date based rules give good percent on time delivery values for certain fab scenarios, tend to balance out the average cycle time among the many products in the fab. These average cycle time values are not as high as some other rules. This is where the due date rules lose out on being robust because there is no good tradeoff between on time delivery and cycle time.

\subsubsection{Conclusions of Experiment 3}

A formally designed experiment tests the representative semiconductor research and development simulation model. The factors include production volume, primary/secondary dispatching rules, due date tightness and product mix. Fab behavior is quantified in performance measures including percent on time delivery, average cycle time, standard deviation of cycle time and average WIP. Statistical analyses are first conducted on all factors to check for significance of the factors for all performance measures. Subsequently production volume, product mix and due date tightness are used as blocking factors on the next three sets of statistical analyses. It is concluded that the dispatching rules, FIFO, LBA/FIFO, P/FIFO and 
$\mathrm{P} / \mathrm{HXT}$ are the most robust dispatching rules across performance measures. The due date based dispatching rules; $\mathrm{CR} / \mathrm{FIFO}$ and $\mathrm{P} / \mathrm{CR}$ do not perform with the expected consistency.

The results of the statistical analyses conducted in this section enable fab managers to employ dispatching rules according to the production volume and product mix present in the given R\&D fab. Also, if the fab managers have control of the due date of the products in the fab, they can employ the dispatching rules that perform the best, given the production volume and product mix. The use of these rules minimizes the time-to-market of these products.

\subsection{Summary of Experiments}

The experiments conducted and the results shown in this chapter deal with understanding the behavior of semiconductor R\&D fabs and quantifying performance statistically.

First, a simulation model of a representative $R \& D$ fab is built to understand the relationship between WIP, average cycle time and throughput. It is seen from the graphs that the average cycle time of lots progressively increases with increase in WIP and throughput increases with increase in WIP initially but remains constant at a maximum production level. A performance tradeoff metric is used to determine the WIP level at which there is a nominal tradeoff between average cycle time and throughput.

Second, a design of experiments is conducted where the WIP, number of tools and number of technical support personnel are tested at different levels by using a formally designed experiment. This tests the capacity of the modeled fab. Having redundancy of bottleneck tools, an extra technician and increasing the WIP on the fab floor see gains for throughput and cycle time.

Lastly, priority-designated lots are introduced in the fab and production strategies are compared. High, medium and low are the three levels of priority-designated lots introduced in the fab. A formally designed experiment tests levels of production volume, product mix, 
dispatching rules and due date tightness at different levels. The performance measures for production strategy evaluation are percent on time delivery, average cycle time, standard deviation of cycle time and average WIP. Production strategies are evaluated first by assigning production volume and product mix as controllable factors. It is observed that the due date based rule, $\mathrm{CR} / \mathrm{FIFO}$, performs well for product mixes where there are larger numbers of low prioritydesignated lots at a relaxed level of due date tightness. Although this rule does not find itself in the top groups for the average cycle time performance measure, it helps reduce the time to market for the fab products. Due date tightness then is assigned as a controllable factor and dispatching rules are evaluated according to 12 fab types with different levels of production volume, product mix and due date tightness. Again it is observed that the CR/FIFO rule performs well for fabs with lower proportions of medium and high priority-designated lots for the percent on time delivery performance measure. FIFO, LBA/FIFO, P/FIFO and P/HXT are observed to be the most robust dispatching rules across performance measures. Table 5.18 summarizes the best performance of these dispatching rules.

Table 5.18: Summary of Best Performing Rules

\begin{tabular}{|c|c|}
\hline Scenarios & $\begin{array}{c}\text { Robust Rules across performance } \\
\text { measures }\end{array}$ \\
\hline $\begin{array}{c}\text { High Production Volume level and high proportion of } \\
\text { high and medium priority-designated lots }\end{array}$ & $\begin{array}{c}\text { FIFO } \\
\text { LBA/FIFO }\end{array}$ \\
\hline $\begin{array}{c}\text { High Production Volume Level, relaxed due date and } \\
\text { lower proportion of high and medium priority- } \\
\text { designated lots }\end{array}$ & P/FIFO \\
\hline $\begin{array}{c}\text { High Production Volume level, tight due date and 70\% } \\
\text { low priority designated lots }\end{array}$ & LBA/FIFO \\
\hline $\begin{array}{c}\text { Both Production Volume levels, both due date levels } \\
\text { and lowest proportion of high and medium priority- } \\
\text { designated lots }\end{array}$ & P/FIFO \\
\hline $\begin{array}{c}\text { Low Production Volume level, both due date levels } \\
\text { and higher proportions of high and medium priority- } \\
\text { designated lots }\end{array}$ & P/HXT \\
\hline $\begin{array}{c}\text { Low Production Volume level, both due date levels } \\
\text { and lowest proportion of high and medium priority- } \\
\text { designated lots }\end{array}$ & P/HXT \\
\hline
\end{tabular}




\section{SEMICONDUCTOR RESEARCH AND DEVELOPMENT FAB CASE STUDY}

The Semiconductor and Microsystems Fabrication Laboratory (SMFL) at the Rochester Institute of Technology (RIT) is a semiconductor R\&D fab, which offers processing resources and technical expertise in the design and development of microsystems to industrial and academic customers (http://smfl.microe.rit.edu). Researchers use the fab facilities during day shifts with the lab closing at $6 \mathrm{pm}$. The researchers may be college students or outsiders paying to use fab time. Applying the production strategies to the SMFL tests the results from the statistical analyses conducted in the previous chapter.

\subsection{Simulation Model}

The simulation model used for this case study uses the same assumptions and setup as described in Simulation of Representative Semiconductor R\&D Fabs chapter (Chapter 4). A SubMicron CMOS recipe is chosen as the routing for the representative wafer lots. Tools are reserved for class labs according to the SMFL tool reservation timetable for the Fall quarter of 2003, see Figure 6.1. The researchers can use tools and other fab facilities during class lab hours except those that have been reserved during these hours. Five technicians work in the fab to repair tools that are down or to work on tools undergoing preventive maintenance events. The technicians and their tool certifications are as listed in Table 6.1. The primary technician has a higher processing efficiency than the secondary technician. The secondary technicians operate at $2 / 3$ times the efficiency as the primary technicians on the concerned tools. The secondary technician works on the tool only if the primary technician is busy or unavailable. 
Fall 2003 Quarter Lab Schedule

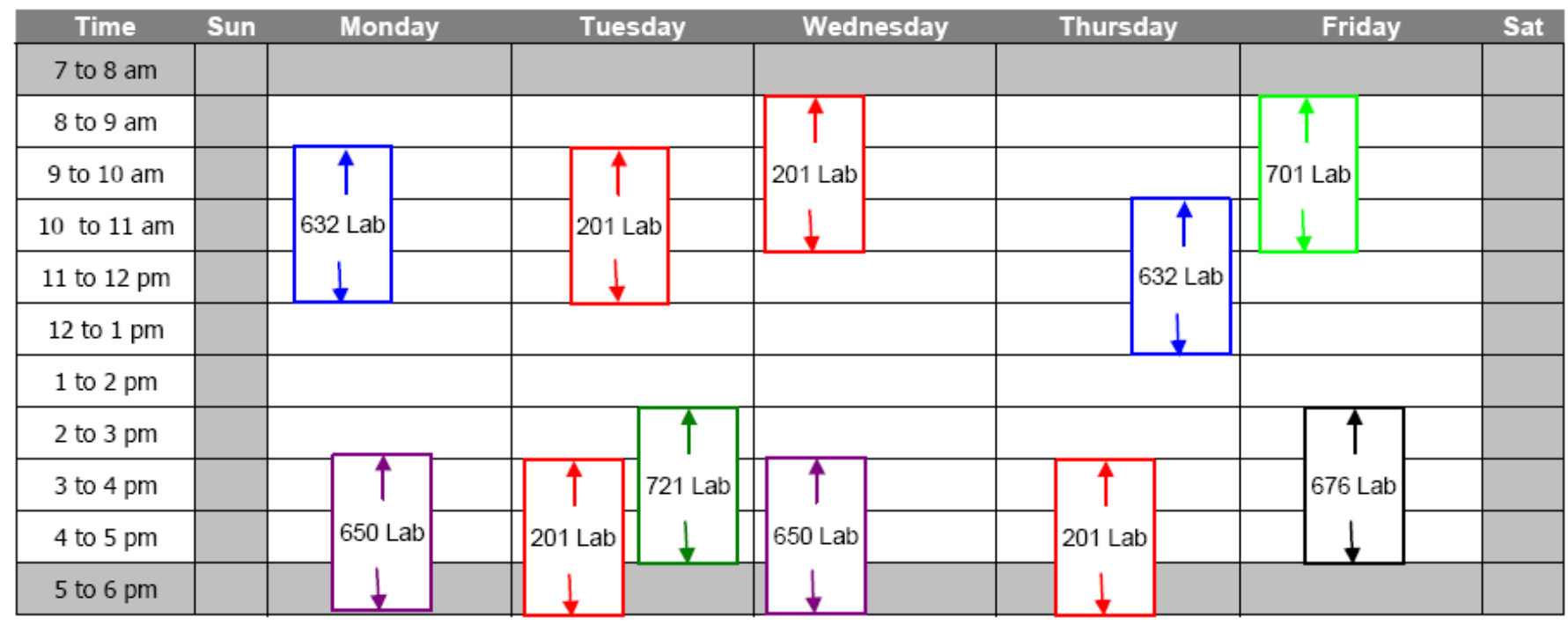

Figure 6.1: SMFL Tool Reservation Time Table

Table 6.1: SMFL Tool Ceritifications for Technicians

\begin{tabular}{|c|l|c|}
\hline $\begin{array}{c}\text { Technical } \\
\text { Support }\end{array}$ & \multicolumn{1}{|c|}{ Tool Certification } & $\begin{array}{c}\text { Processing } \\
\text { Efficiency }\end{array}$ \\
\hline \multirow{5}{*}{ Bruce } & ASM LPCVD & 1.00 \\
\cline { 2 - 3 } & Branson Asher & 0.66 \\
\cline { 2 - 3 } & Drytek RIE & 1.00 \\
\cline { 2 - 3 } & Bruce furnace tubes & 0.66 \\
\hline \multirow{3}{*}{ Rich } & LAM 490 Plasma etch & 1.00 \\
\cline { 2 - 3 } & Varian 350D Implanter & 1.00 \\
\cline { 2 - 3 } & CVC-601 Sputter & 1.00 \\
\hline \multirow{3}{*}{ Scott } & RCA Clean & 1.00 \\
\cline { 2 - 3 } & Canon \& GCA Steppers & 1.00 \\
\cline { 2 - 3 } & Bruce furnace tubes & 1.00 \\
\hline \multirow{3}{*}{ John } & RCA clean & 0.66 \\
\cline { 2 - 3 } & Branson Asher & 1.00 \\
\cline { 2 - 3 } & Varian 350D Implanter & 0.66 \\
\cline { 2 - 3 } & RCA clean & 0.66 \\
\cline { 2 - 3 } & Drytek RIE & 0.66 \\
\cline { 2 - 3 } & Varian 390 Plasma etch & 0.66 \\
\hline
\end{tabular}




\subsection{The Experimental Design}

The simulation model is tested at different levels of a formally designed experiment. The simulation model is run for a full-factorial design. Production volume (PV), dispatching rules (DR), due date tightness (DDT) and product mix (PM) are the factors and the performance measures are percent on time delivery and average cycle time. The levels of the designed experiment are shown in Table 6.2. PV is in lots per year, DDT is in terms of flow factors which are multiples of the raw processing time in the format $\mathrm{H}, \mathrm{M}, \mathrm{L}$, for the high, medium and low priority-designated lots respectively and PM is the percentage of high, medium and low prioritydesignated lots present in the fab, in the format H-M-L.

Table 6.2: Design of experiments for the SMFL

\begin{tabular}{|c|c|c|c|c|}
\hline Factors/Levels & $\mathbf{1}$ & $\mathbf{2}$ & $\mathbf{3}$ & $\mathbf{4}$ \\
\hline $\begin{array}{c}\text { Production Volume } \\
\text { (PV) }\end{array}$ & $\begin{array}{c}90 \text { lots } \\
\text { per year }\end{array}$ & $\begin{array}{c}70 \text { lots } \\
\text { per year }\end{array}$ & - & - \\
\hline $\begin{array}{c}\text { Dispatching Rules } \\
\text { (DR) }\end{array}$ & P/FIFO & CR/FIFO & P/HXT & LBA/FIFO \\
\hline $\begin{array}{c}\text { Due Date Tightness } \\
\text { (DDT) }\end{array}$ & $10,15,20$ & $15,20,25$ & - & - \\
\hline $\begin{array}{c}\text { Product Mix } \\
\text { (PM) }\end{array}$ & $25-25-50$ & $15-15-70$ & - & - \\
\hline
\end{tabular}

The dispatching rules used are CR/FIFO, LBA/FIFO, P/FIFO and P/HXT. LBA/FIFO, $\mathrm{P} / \mathrm{FIFO}$ and $\mathrm{P} / \mathrm{HXT}$ are the rules found to be the most robust across performance measures (See Table 5.18: Summary of Best Performing Rules in Chapter 5). CR/FIFO is used to check if its application continues to provide good values for the percent on time delivery performance measure. Primary/Secondary dispatching rules are tested under different scenarios, according to the different levels of PM, DDT and PV. The simulation model is run for eight such scenarios. Table 6.3 lists the operating conditions for these eight fab types. 
Table 6.3: Fab Types for the SMFL

\begin{tabular}{|c|c|c|c|}
\hline Fab Type & PV & DDT & PM \\
\hline I & 90 & $10,15,20$ & $25-25-50$ \\
\hline II & 90 & $15,20,25$ & $25-25-50$ \\
\hline III & 90 & $10,15,20$ & $15-15-70$ \\
\hline IV & 90 & $15,20,25$ & $15-15-70$ \\
\hline V & 70 & $10,15,20$ & $25-25-50$ \\
\hline VI & 70 & $15,20,25$ & $25-25-50$ \\
\hline VII & 70 & $10,15,20$ & $15-15-70$ \\
\hline VIII & 70 & $15,20,25$ & $15-15-70$ \\
\hline
\end{tabular}

\subsection{Results}

Table 6.4 lists the percent on time delivery and average cycle time values for the eight fab types by dispatching rule. The table also lists the dispatching rule that performs best as per the operating conditions of the fab type.

Table 6.4: Results from the Simulation Run of the SMFL

\begin{tabular}{|c|c|c|c|c|c|c|c|c|c|}
\hline \multirow[b]{2}{*}{ Fab Type } & \multicolumn{2}{|c|}{ CR/FIFO } & \multicolumn{2}{|c|}{ P/FIFO } & \multicolumn{2}{|c|}{$\mathrm{P} / \mathrm{HXT}$} & \multicolumn{2}{|c|}{ LBA/FIFO } & \multirow[b]{2}{*}{ Best Rule } \\
\hline & $\begin{array}{c}\% \\
\text { On Time } \\
\text { Delivery }\end{array}$ & $\begin{array}{c}\text { Average } \\
\text { Cycle } \\
\text { Time }\end{array}$ & $\begin{array}{c}\% \\
\text { On Time } \\
\text { Delivery }\end{array}$ & $\begin{array}{c}\text { Average } \\
\text { Cycle } \\
\text { Time }\end{array}$ & $\begin{array}{c}\% \\
\text { On Time } \\
\text { Delivery }\end{array}$ & $\begin{array}{c}\text { Average } \\
\text { Cycle } \\
\text { Time }\end{array}$ & $\begin{array}{c}\% \\
\text { On Time } \\
\text { Delivery }\end{array}$ & $\begin{array}{c}\text { Average } \\
\text { Cycle } \\
\text { Time }\end{array}$ & \\
\hline I & 5.34 & 2021.9 & 43.45 & 2034.6 & 39.203 & 2020.4 & 75.23 & 1198.3 & LBA/FIFO \\
\hline II & 7.29 & 1987.3 & 48.32 & 2034.6 & 59.64 & 2020.4 & 89.36 & 1198.3 & LBA/FIFO \\
\hline III & 7.76 & 1994.6 & 80.36 & 1649.2 & 41.39 & 1756.08 & 92.71 & 1020.45 & LBA/FIFO \\
\hline IV & 100 & 1809.5 & 99.75 & 1649.2 & 99.43 & 1756.08 & 94.23 & 1020.45 & P/FIFO \\
\hline V & 98.84 & 980.45 & 99.06 & 956.4 & 98.94 & 967.98 & 79.08 & 976.6 & P/FIFO \\
\hline VI & 100 & 993.67 & 100 & 956.4 & 100 & 967.98 & 98.43 & 976.6 & P/FIFO \\
\hline VII & 97.99 & 991.24 & 100 & 950.5 & 99.93 & 948.98 & 88.84 & 948.8 & P/HXT \\
\hline VIII & 100 & 997.65 & 100 & 950.5 & 100 & 948.98 & 96.78 & 948.8 & P/HXT \\
\hline
\end{tabular}

It can be seen that the CR/FIFO rule gives good percent on time delivery values for most

of the fab types, as seen earlier, but does not perform well for average cycle time. P/FIFO and P/HXT are robust across both performance measures for lower volumes of production. LBA/FIFO give good average cycle time values but fail to compete with the other rules for the percent on time delivery performance measure for lower production levels. 


\subsection{Conclusions of Case Study}

A simulation model of the SMFL is used as a case study to test the results obtained from experiments described in Chapter 5. The due date based rule, CR/FIFO, fails to perform as the best rule for any fab type. The LBA/FIFO rule performs well for low production volumes and the $\mathrm{P} / \mathrm{FIFO}$ and $\mathrm{P} / \mathrm{HXT}$ rules perform well for high volumes of production. These results are similar to the results obtained for the experiments conducted in Chapter 5 for representative semiconductor R\&D fabs. The results from this case study serve to successfully test the best performing dispatching rules, by operating scenarios and verify their performance. 


\section{CONCLUSIONS AND RECOMMENDATIONS FOR FUTURE RESEARCH}

\subsection{Conclusions}

Semiconductor Research and Development fabs feed the technology to semiconductor production fabs for commercial large-scale manufacturing. It is essential that this technology be transferred to the production fabs on time so as to be on par if not beat the competition. In other words, the time to market the technology has to be as short as possible. Previous research has touched on the prevalent conditions of semiconductor R\&D fabs and improvement from a project management approach but not focused on the important issue of analyzing production control methodologies and strategies for semiconductor R\&D fabs. This research involves understanding the behavior of semiconductor R\&D fabs and evaluating fab specific production control methods to increase productivity by shortening the time to market of the products.

Initial experiments conducted show that with increase in the number of lots in the fab, the average cycle time dramatically rises with the throughput remaining constant. Also, tool redundancy and numbers and certifications of technical personnel have a direct bearing on the average cycle time and throughput. It is also concluded that a representative product load works well to provide an appropriate production load for analysis and evaluation purposes and also accounts for the variety of research activities in the fab. This led to conducting a last set of experiments to test production control methods for the best percent on time delivery, average cycle time, standard deviation of cycle time and average work-in-process, with the presence of three levels of priority designated lots. Simulation models of research fabs with varying levels of production volumes, product mixes, dispatching rules and due date tightness are run. All these factors are shown to be significant for the performance measures in question. 
From the statistical analyses conducted from the simulation results, it is seen that the due date based rule CR/FIFO works well for the percent on time delivery response in most fab scenarios but fails to be a robust rule across all performance measures. The robust rules across performance measures are found to be the FIFO, LBA/FIFO, P/FIFO and P/HXT rules. The $\mathrm{CR} / \mathrm{FIFO}$ rule can still be used as an effective dispatching rule to get the best percent on time deliveries but at the cost of cycle time of the lots in the fab. It works best in scenarios where the proportion of low priority-designated lots outweighs the proportion of medium and high prioritydesignated lots. The P/FIFO and P/HXT rules work best for all performance measures except when there is a heavy volume of production. In such cases the FIFO and LBA/FIFO prove to be robust rules.

\subsection{Recommendations for Future Research}

The findings and conclusions from this research provide opportunities for further research in the same area. The areas for future research in improving productivity in semiconductor R\&D fabs can focus on alternative prioritization of lots, examining the effects of super-hot lots, further investigating the behavior of due date based rules and due date determination and selectively applying chosen dispatching rules

This research uses three levels of priority-designated lots. The dispatching rules that are not priority based like the CR, FIFO, HXT and LBA rules unless coupled with the priority rule as primary or secondary rules, do not acknowledge the priority of these lots. Further research can focus on giving some dispatching weight to according to the priority of the lots when using non-

priority based rules. This could be used to break ties in queues or give priority to lots having relatively lower slack.

This research tests the effects of priority-designated lots and their varying proportions to fab productivity. These priority-designated lots take precedence in resource worklists according 
to the level of priority associated with them but their presence does not warrant blocking tools downstream for processing purposes. Doing this ensures minimal waiting time for these lots and helps the average cycle time. This practice though, can prove disastrous for other lots in the fab and hold them up in worklists depending on the proportion of these lots in the fab. These lots are termed super hot lots and their effects to semiconductor R\&D fab productivity need to be evaluated and quantified.

The due dates for lots in this research are determined by assigning a lead-time to the lots that enter the fab (Rose, 2002). This lead-time is assigned by multiplying a flow factor to the raw processing time of the lot. The flow factor in this case depends on the priority associated with the lot, in which case the lots with the highest priority have earlier due dates than the other lots. Another approach to determining due dates can be researched if the raw data collected does not provide a value.

The primary and secondary dispatching rules applied in this research are applied to worklists of all resources. A selective application of these rules to bottleneck tools or otherwise can be investigated. Also applying more than one dispatching strategy and dynamically changing strategies in semiconductor R\&D fabs can be investigated. 


\section{BIBLIOGRAPHY}

Busch, M.L. (1999). Trade Warriors States, Firms, and Strategic-Trade Policy in HighTechnology Competition. Cambridge University Press.

Chikamura, A., Nakamae, K., \& Fujioka, H. (1999). Effect of express lots on production dispatching rule scheduling and cost in VLSI manufacturing final test process. IEICE Transactions on Electronics, v E82-C, n 1, 1999, 86-93.

DeJong, C.D., \& Wu, S.P. (2002). Simulating the Transport and Scheduling of Priority Lots in Semiconductor Factories. Proceedings of the 2002 Winter Simulation Conference, December 8-11, (pp. 1387-1391).

Domaschke, J., Brown, S., Robinson, J., \& Leibl, F. (1998). Effective Implementation of cycle time reduction strategies for semiconductor back-end manufacturing. Proceedings of the 1998 Winter Simulation Conference, December 13-16, (pp. 985-992)

Ehteshami, B., Petrakian, R.G., \& Shabe, P.M. (1992). Trade-offs In Cycle time Management: Hot Lots. IEEE Transactions on Semiconductor Manufacturing, 5(2), 101-106.

Fronckowiak, D., Peikert, A., \& Nishinohara, K. (1996). Using Discrete Event Simulation to Analyze the Impact of Job Priorities on Cycle Time in Semiconductor Manufacturing. Proceedings of the 1996 Advanced Semiconductor Manufacturing Conference and Workshop (ASMC 96), November 12-14, (pp. 151-155).

Green, E.M. (1996). Economic Security and High Technology Competition in an Age of Transition: The Case of the Semiconductor Industry. Praeger Publishers.

Hillis, M, \& Robinson, J (2002). Extremely Hot Lots: Super-Expediting in a 0.18 Micron Wafer Fab. Proceedings of the MASM 2002 Conference, April 10-12, (pp. 106-111).

Hira, R. (2003, August 4). Top 100 R\&D Spenders. IEEE Spectrum, pp. 33 - 36. 
Hung, Y-F., \& Chen, I-R. (1998). A Simulation Study of Dispatch Rules for Reducing Flow Times in Semiconductor Wafer Fabrication, 9(7), 714-722.

Jaegar, R.C. (2002). Introduction to Microelectronic Fabrication, Upper Saddle River: Prentice Hall.

Janakiram, M. (1996). Cycle Time Reduction at Motorola's ACT Fab. Proceedings of the 1996 Advanced Semiconductor Manufacturing Conference and Workshop (ASMC 96), November 12-14, (pp. 465 - 469).

Johal, S. (1998, April). Simulation reduces Product Cycle Time. Semiconductor International, 21(4), (pp. 101-102).

Kuhl, M.E., Hirschman, K.D., Ramamurthi, V., \& Laubisch, G.R. (2004). Capacity and Productivity Modeling for Research Laboratories Using a Representative Product Load. Proceedings of the 2004 Advanced Semiconductor Manufacturing Conference and Workshop (ASMC 04), May 4-6, (pp. 157-161).

Lee, L., Hsieh, K., Lin, M., Luoh, R., Ling, A., \& Huang, S. (2000). Super-Hot-Runs Management System. Proceedings of the Ninth International Symposium on Semiconductor Manufacturing, September 26-28, (pp. 363-366).

Liao, D-Y., Chang, S-C., Pei, K.W., \& Chang, C-M. (1996, November). Daily Scheduling for R\&D Semiconductor Fabrication. IEEE Transactions on Semiconductor Manufacturing, 9(4), 550-561.

Lu, S.C.H., Ramaswamy, D., \& Kumar, P.R. (1994). Efficient scheduling policies to reduce mean and variance of cycle-time in semiconductor manufacturing plants, IEEE Transactions on Semiconductor Manufacturing, 7(3), 374-385.

May, G.S., \& Sze, S.M. (2003). Fundamentals of Semiconductor Fabrication. Wiley Text Books. 
Narahari, Y., \& Khan, L.M. (1997, February). Modeling the Effect of Hot Lots in Semiconductor Manufacturing Systems. IEEE Transactions on Semiconductor Manufacturing, 10(1), $185-188$

Padillo, J.M., \& Meyersdorf, D. (1998, March). Strategic Domain: IE in the Semiconductor Industry. IIE Solutions, 30(3), 36-42.

Phillips, T. (1998). Autosched $\mathrm{AP}^{\mathrm{TM}}$ by Autosimulations. Proceedings of the 1998 Winter Simulation Conference, December 13-16, (pp. 219 -222).

Pierce, Neal G., \& Yost, Alan, 1995. Cycle Time Metrics for R\&D Semiconductor Wafer Fabrication. 1995 IEEE/SEMI Advanced Semiconductor Manufacturing Conference. 105 $-110$

Robinson, Jennifer K., Fowler, John W., \& Neacy, Eileen. "Capacity Loss Factors in Semiconductor Manufacturing." Working paper.

Research - Silicon - Moore's Law. Technology and Research at Intel. Retrieved December 14, 2004, from http://www.intel.com/research/silicon/mooreslaw.htm

Rose, O. (2002). Some Issues of The Critical Ratio Dispatch Rule in Semiconductor Manufacturing. Proceedings of the 2002 Winter Simulation Conference, December 8-11, (pp. 1401-1405).

Sada, T., Yuen, R.A., Ichikawa, M., Yamada, M., \& Kabata, K. (2001). Simple Tool of analysis for Cycle Time Reduction. Proceedings of the Tenth International Symposium on Semiconductor Manufacturing, October 8-10, (pp. 79-82).

Sha, D.Y., \& Hsu, S-Y. (2004). The effects of Rework on the Shopfloor Control in Wafer Fabrication. Journal of Manufacturing Technology Management, 15(2), 184-198. 
Shiu, J., Hwang, T-K., Huang, Y-W., Tsai, C-M., Su, W-M., Cheng, Y., Chang, S-C., Chien, CC. (1996). FASE: A Scheduling Environment For Semiconductor Fabrication. Proceedings of the Nineteenth IEEE/CPMT International Electronics Manufacturing Technology Symposium, October 14-16, (pp. 34-41).

Thompson, M. (1996, May). Simulation-based Scheduling: Meeting the Semiconductor Wafer Fabrication Challenge. IIE Solutions, 28(5), 30-34.

Tullis, B., Mehrotra, V., \& Zuanich, D. (1990). Successful Modeling of a Semiconductor R\&D Facility. International Semiconductor Manufacturing Science Symposium, May 21-23, (pp. 26-32).

Wein, L.M. (1988, August). Scheduling Semiconductor Wafer Fabrication. IEEE Transactions on Semiconductor Manufacturing, 1(3), 115-130.

Wolf, S., \& Tauber, R.N. (1986). Silicon Processing for the VLSI era Volume 1: Process Technology, Lattice Press.

Wolfe, R.M. (2002). U.S. Industry Sustains R\&D expenditures during 2001 despite decline in Performers' Aggregate Sales. Retrieved May 3, 2004 from http://www.nsf.gov/sbe/srs/infbrief/nsf03306/start.htm 


\section{APPENDICES}

The appendices contain raw data, process routings and statistical analyses conducted as part of this research. Every appendix is explained and contains labeled tables and figures.

\section{Appendix A. Data Averaged from Replications of Simulation Runs For Experiment 3}

This appendix has the data averaged from all the replications of all the runs of the designed experiment for Experiment 3. It is separated into two tables containing data from production levels of 154 and 128 lots/year respectively.

Table A.1: Data for Production Volume = 154 lots/year

\begin{tabular}{|c|c|c|c|c|c|c|}
\hline $\begin{array}{l}\text { Product Mix } \\
\text { (lot start } \\
\text { percentages, } \\
\text { H-M-L) }\end{array}$ & $\begin{array}{l}\text { Dispatching Rules } \\
\text { (Primary/Secondary) }\end{array}$ & \begin{tabular}{|c|} 
Due Date \\
Tightness(flow \\
factor - multiple \\
of raw \\
processing time, \\
H,M,L) \\
\end{tabular} & \begin{tabular}{|c} 
Average \\
$\%$ On Time \\
Delivery
\end{tabular} & $\begin{array}{c}\text { Average } \\
\text { Cycle Time } \\
\text { (hours) }\end{array}$ & $\begin{array}{l}\text { Std. Dev. } \\
\text { Of Cycle } \\
\text { Time } \\
\text { (hours) }\end{array}$ & $\begin{array}{l}\text { Average } \\
\text { WIP (lots) }\end{array}$ \\
\hline \multirow{14}{*}{$25-25-50$} & CR/FIFO & $10,15,20$ & 0.00 & 2136.12 & 322.77 & 37.48 \\
\hline & FIFO & $10,15,20$ & 66.05 & 1261.26 & 100.55 & 22.13 \\
\hline & HXT/FIFO & $10,15,20$ & 41.30 & 1567.65 & 90.03 & 27.50 \\
\hline & LBA/FIFO & $10,15,20$ & 64.61 & 1286.48 & 110.52 & 22.57 \\
\hline & $\mathrm{P} / \mathrm{CR}$ & $10,15,20$ & 34.92 & 4334.07 & 3393.54 & 77.07 \\
\hline & P/FIFO & $10,15,20$ & 39.41 & 3104.28 & 2132.61 & 54.36 \\
\hline & $\mathrm{P} / \mathrm{HXT}$ & $10,15,20$ & 37.25 & 1866.98 & 903.92 & 32.75 \\
\hline & CR/FIFO & $15,20,25$ & 0.00 & 2556.43 & 357.29 & 44.85 \\
\hline & FIFO & $15,20,25$ & 86.34 & 1261.26 & 100.55 & 22.13 \\
\hline & HXT/FIFO & $15,20,25$ & 71.12 & 1567.65 & 90.03 & 27.50 \\
\hline & LBA/FIFO & $15,20,25$ & 85.20 & 1286.48 & 110.52 & 22.57 \\
\hline & $\mathrm{P} / \mathrm{CR}$ & $15,20,25$ & 50.31 & 3477.67 & 2475.12 & 61.28 \\
\hline & P/FIFO & $15,20,25$ & 49.86 & 3104.28 & 2132.61 & 54.36 \\
\hline & $\mathrm{P} / \mathrm{HXT}$ & $15,20,25$ & 50.11 & 1866.98 & 903.92 & 32.75 \\
\hline \multirow{14}{*}{$15-15-70$} & CR/FIFO & $10,15,20$ & 0.00 & 2231.15 & 293.95 & 39.14 \\
\hline & FIFO & $10,15,20$ & 79.62 & 1247.73 & 95.52 & 21.89 \\
\hline & HXT/FIFO & $10,15,20$ & 72.01 & 1320.98 & 63.62 & 23.18 \\
\hline & LBA/FIFO & $10,15,20$ & 91.38 & 1276.10 & 115.64 & 22.39 \\
\hline & $\mathrm{P} / \mathrm{CR}$ & $10,15,20$ & 21.54 & 2747.41 & 1163.44 & 48.24 \\
\hline & P/FIFO & $10,15,20$ & 79.52 & 1369.50 & 319.67 & 24.03 \\
\hline & $\mathrm{P} / \mathrm{HXT}$ & $10,15,20$ & 38.30 & 1520.81 & 353.39 & 26.68 \\
\hline & CR/FIFO & $15,20,25$ & 100.00 & 1572.35 & 302.66 & 27.58 \\
\hline & FIFO & $15,20,25$ & 91.73 & 1247.73 & 95.52 & 21.89 \\
\hline & HXT/FIFO & $15,20,25$ & 86.59 & 1320.98 & 63.62 & 23.18 \\
\hline & LBA/FIFO & $15,20,25$ & 91.38 & 1276.10 & 115.64 & 22.39 \\
\hline & P/CR & $15,20,25$ & 29.91 & 3089.55 & 1379.88 & 54.16 \\
\hline & P/FIFO & $15,20,25$ & 99.96 & 1369.50 & 319.67 & 24.03 \\
\hline & $\mathrm{P} / \mathrm{HXT}$ & $15,20,25$ & 99.93 & 1520.81 & 353.39 & 26.68 \\
\hline \multirow{14}{*}{$5-5-90$} & CR/FIFO & $10,15,20$ & 96.52 & 1441.01 & 177.09 & 25.28 \\
\hline & FIFO & $10,15,20$ & 92.09 & 1255.87 & 103.51 & 22.03 \\
\hline & HXT/FIFO & $10,15,20$ & 90.65 & 1285.47 & 67.02 & 22.55 \\
\hline & LBA/FIFO & $10,15,20$ & 91.88 & 1306.48 & 121.81 & 22.92 \\
\hline & $\mathrm{P} / \mathrm{CR}$ & $10,15,20$ & 8.01 & 2464.66 & 526.51 & 43.24 \\
\hline & P/FIFO & $10,15,20$ & 98.52 & 1283.30 & 169.24 & 22.51 \\
\hline & $\mathrm{P} / \mathrm{HXT}$ & $10,15,20$ & 97.86 & 1281.73 & 143.01 & 22.49 \\
\hline & CR/FIFO & $15,20,25$ & 100.00 & 1560.85 & 207.74 & 27.38 \\
\hline & FIFO & $15,20,25$ & 96.52 & 1255.87 & 103.51 & 22.03 \\
\hline & HXT/FIFO & $15,20,25$ & 95.61 & 1285.47 & 67.02 & 22.55 \\
\hline & LBA/FIFO & $15,20,25$ & 96.63 & 1306.48 & 121.81 & 22.92 \\
\hline & P/CR & $15,20,25$ & 10.00 & 2774.09 & 622.60 & 48.66 \\
\hline & P/FIFO & $15,20,25$ & 100.00 & 1283.30 & 169.24 & 22.51 \\
\hline & $\mathrm{P} / \mathrm{HXT}$ & $15,20,25$ & 100.00 & \begin{tabular}{|c|}
1281.73 \\
\end{tabular} & 143.01 & 22.49 \\
\hline
\end{tabular}


Table A.2: Data for Production Volume $=128$ lots/year

\begin{tabular}{|c|c|c|c|c|c|c|}
\hline $\begin{array}{l}\text { Product Mix } \\
\text { (lot start } \\
\text { percentages, } \\
\text { H-M-L) }\end{array}$ & $\begin{array}{c}\text { Dispatching Rules } \\
\text { (Primary/Secondary) }\end{array}$ & $\begin{array}{c}\text { Due Date } \\
\text { Tightness(flow } \\
\text { factor - multiple } \\
\text { of raw } \\
\text { processing time, } \\
\text { H,M,L) }\end{array}$ & $\begin{array}{c}\text { Average } \\
\% \text { On Time } \\
\text { Delivery }\end{array}$ & $\begin{array}{c}\text { Average } \\
\text { Cycle Time } \\
\text { (hours) }\end{array}$ & $\begin{array}{l}\text { Std. Dev. } \\
\text { Of Cycle } \\
\text { Time } \\
\text { (hours) }\end{array}$ & $\begin{array}{c}\text { Average } \\
\text { WIP (lots) }\end{array}$ \\
\hline \multirow{14}{*}{$25-25-50$} & CR/FIFO & $10,15,20$ & 97.52 & 1050.05 & 195.93 & 15.35 \\
\hline & FIFO & $10,15,20$ & 79.25 & 995.36 & 97.99 & 14.56 \\
\hline & HXT/FIFO & $10,15,20$ & 76.18 & 1024.62 & 71.91 & 14.98 \\
\hline & LBA/FIFO & $10,15,20$ & 77.95 & 1049.12 & 116.03 & 15.34 \\
\hline & P/CR & $10,15,20$ & 97.43 & 1009.98 & 177.32 & 14.77 \\
\hline & P/FIFO & $10,15,20$ & 98.34 & 979.09 & 160.25 & 14.32 \\
\hline & $\mathrm{P} / \mathrm{HXT}$ & $10,15,20$ & 97.57 & 989.56 & 156.28 & 14.47 \\
\hline & CR/FIFO & $15,20,25$ & 100.00 & 1078.82 & 189.57 & 15.77 \\
\hline & FIFO & $15,20,25$ & 99.78 & 995.36 & 97.99 & 14.56 \\
\hline & HXT/FIFO & $15,20,25$ & 100.00 & 1024.62 & 71.91 & 14.98 \\
\hline & LBA/FIFO & $15,20,25$ & 99.39 & 1049.12 & 116.03 & 15.34 \\
\hline & P/CR & $15,20,25$ & 100.00 & 1002.60 & 190.03 & 14.66 \\
\hline & P/FIFO & $15,20,25$ & 100.00 & 979.09 & 160.25 & 14.32 \\
\hline & $\mathrm{P} / \mathrm{HXT}$ & $15,20,25$ & 100.00 & 989.56 & 156.28 & 14.47 \\
\hline \multirow{14}{*}{$15-15-70$} & CR/FIFO & $10,15,20$ & 97.74 & 1044.69 & 159.72 & 15.27 \\
\hline & FIFO & $10,15,20$ & 87.03 & 972.18 & 92.31 & 14.21 \\
\hline & HXT/FIFO & $10,15,20$ & 87.21 & 972.80 & 69.59 & 14.22 \\
\hline & LBA/FIFO & $10,15,20$ & 87.12 & 974.46 & 90.52 & 14.24 \\
\hline & P/CR & $10,15,20$ & 98.91 & 1000.23 & 149.80 & 14.62 \\
\hline & P/FIFO & $10,15,20$ & 99.26 & 975.18 & 136.38 & 14.26 \\
\hline & $\mathrm{P} / \mathrm{HXT}$ & $10,15,20$ & 99.00 & 965.37 & 114.84 & 14.11 \\
\hline & CR/FIFO & $15,20,25$ & 100.00 & 1058.18 & 166.58 & 15.47 \\
\hline & FIFO & $15,20,25$ & 99.65 & 972.18 & 92.31 & 14.21 \\
\hline & HXT/FIFO & $15,20,25$ & 100.00 & 972.80 & 69.59 & 14.22 \\
\hline & LBA/FIFO & $15,20,25$ & 99.83 & 974.46 & 90.52 & 14.24 \\
\hline & P/CR & $15,20,25$ & 100.00 & 1027.72 & 174.99 & 15.03 \\
\hline & P/FIFO & $15,20,25$ & 100.00 & 975.18 & 136.38 & 14.26 \\
\hline & $\mathrm{P} / \mathrm{HXT}$ & $15,20,25$ & 100.00 & 965.37 & 114.84 & 14.11 \\
\hline \multirow{14}{*}{$5-5-90$} & CR/FIFO & $10,15,20$ & 99.70 & 1036.60 & 132.25 & 15.15 \\
\hline & FIFO & $10,15,20$ & 95.95 & 970.34 & 88.37 & 14.19 \\
\hline & HXT/FIFO & $10,15,20$ & 95.43 & 960.27 & 66.97 & 14.04 \\
\hline & LBA/FIFO & $10,15,20$ & 95.78 & 972.74 & 92.39 & 14.22 \\
\hline & $\mathrm{P} / \mathrm{CR}$ & $10,15,20$ & 99.52 & 1010.82 & 127.16 & 14.77 \\
\hline & P/FIFO & $10,15,20$ & 99.30 & 1019.31 & 144.96 & 14.89 \\
\hline & $\mathrm{P} / \mathrm{HXT}$ & $10,15,20$ & 99.43 & 962.02 & 83.57 & 14.06 \\
\hline & CR/FIFO & $15,20,25$ & 100.00 & 1053.66 & 146.33 & 15.40 \\
\hline & FIFO & $15,20,25$ & 99.91 & 970.34 & 88.37 & 14.19 \\
\hline & HXT/FIFO & $15,20,25$ & 100.00 & 960.27 & 66.97 & 14.04 \\
\hline & LBA/FIFO & $15,20,25$ & 100.00 & 972.74 & 92.39 & 14.22 \\
\hline & $\mathrm{P} / \mathrm{CR}$ & $15,20,25$ & 100.00 & 1031.53 & 142.39 & 15.08 \\
\hline & P/FIFO & $15,20,25$ & 100.00 & 1019.31 & 144.96 & 14.89 \\
\hline & $\mathrm{P} / \mathrm{HXT}$ & $15,20,25$ & 100.00 & 952.44 & 79.62 & 13.93 \\
\hline
\end{tabular}




\section{Appendix B. Four Factor ANOVA Results}

This appendix lists the ANOVA tables for all four performance measures when all four factors are included. The p-value indicates the significance of the factors and the interactions.

Table B.1: Four Factor ANOVA Table for \% On Time Delivery

\begin{tabular}{|c|c|c|c|c|c|c|}
\hline Source & DF & Seq SS & Adj SS & Adj MS & $\mathbf{F}$ & $\mathbf{P}$ \\
\hline PV & 1 & 54166.7 & 54166.7 & 54166.7 & 55634.0 & 0.000 \\
\hline DR & 6 & 22321.7 & 22321.7 & 3720.3 & 3821.1 & 0.000 \\
\hline DDT & 1 & 8321.8 & 8321.8 & 8321.8 & 8547.3 & 0.000 \\
\hline PM & 2 & 17005.1 & 17005.1 & 8502.6 & 8732.9 & 0.000 \\
\hline PV*DR & 6 & 31966.2 & 31966.2 & 5327.7 & 5472.0 & 0.000 \\
\hline PV*DDT & 1 & 1678.9 & 1678.9 & 1678.9 & 1724.4 & 0.000 \\
\hline PV*PM & 2 & 10407.9 & 10407.9 & 5204.0 & 5344.9 & 0.000 \\
\hline DR*DDT & 6 & 1217.0 & 1217.0 & 202.8 & 208.3 & 0.000 \\
\hline DR*PM & 12 & 15021.8 & 15021.8 & 1251.8 & 1285.7 & 0.000 \\
\hline DDT*PM & 2 & 2736.0 & 2736.0 & 1368.0 & 1405.1 & 0.000 \\
\hline$P V * D R^{\star} D D T$ & 6 & 2452.3 & 2452.3 & 408.7 & 419.8 & 0.000 \\
\hline PV*DR*PM & 12 & 16546.0 & 16546.0 & 1378.8 & 1416.2 & 0.000 \\
\hline$P^{*}{ }^{*} D^{*} P M$ & 2 & 1696.7 & 1696.7 & 848.4 & 871.3 & 0.000 \\
\hline $\mathrm{DR}^{*} \mathrm{DDT}^{*} \mathrm{PM}$ & 12 & 5526.0 & 5526.0 & 460.5 & 473.0 & 0.000 \\
\hline $\mathrm{PV}^{*} \mathrm{DR}^{*} \mathrm{DDT}{ }^{*} \mathrm{PM}$ & 12 & 4855.2 & 4855.2 & 404.6 & 415.6 & 0.000 \\
\hline Error & 168 & 163.6 & 163.6 & 1.0 & & \\
\hline Total & 251 & 196082.9 & & & & \\
\hline
\end{tabular}

Table B.2: Four Factor ANOVA Table for Average Cycle Time

\begin{tabular}{|c|c|c|c|c|c|c|}
\hline Source & DF & Seq SS & Adj SS & Adj MS & $\mathbf{F}$ & $\mathbf{P}$ \\
\hline PV & 1 & 38644331.0 & 38644331.0 & 38644331.0 & 3137.4 & 0.000 \\
\hline DR & 6 & 24549724.0 & 24549724.0 & 4091621.0 & 332.2 & 0.000 \\
\hline DDT & 1 & 1938.0 & 1938.0 & 1938.0 & 0.2 & 0.692 \\
\hline PM & 2 & 5916571.0 & 5916571.0 & 2958286.0 & 240.2 & 0.000 \\
\hline$P V * D R$ & 6 & 22803778.0 & 22803778.0 & 3800630.0 & 308.6 & 0.000 \\
\hline PV*DDT & 1 & 6123.0 & 6123.0 & 6123.0 & 0.5 & 0.482 \\
\hline PV*PM & 2 & 5087377.0 & 5087377.0 & 2543689.0 & 206.5 & 0.000 \\
\hline DR*DDT & 6 & 5691.0 & 5691.0 & 949.0 & 0.1 & 0.998 \\
\hline DR*PM & 12 & 4868792.0 & 4868792.0 & 405733.0 & 32.9 & 0.000 \\
\hline DDT*PM & 2 & 47051.0 & 47051.0 & 23525.0 & 1.9 & 0.151 \\
\hline$P V * D R * D D T$ & 6 & 16905.0 & 16905.0 & 2818.0 & 0.2 & 0.967 \\
\hline PV*DR*PM & 12 & 5755096.0 & 5755096.0 & 479591.0 & 38.9 & 0.000 \\
\hline$P^{*}{ }^{*} T^{*} P M$ & 2 & 47241.0 & 47241.0 & 23620.0 & 1.9 & 0.150 \\
\hline DR*DDT*PM & 12 & 1166802.0 & 1166802.0 & 97233.0 & 7.9 & 0.000 \\
\hline $\mathrm{PV}^{*} \mathrm{DR}^{*} \mathrm{DDT}^{*} \mathrm{PM}$ & 12 & 1069073.0 & 1069073.0 & 89089.0 & 7.2 & 0.000 \\
\hline Error & 168 & 2069337.0 & 2069337.0 & 12317.0 & & \\
\hline Total & \multicolumn{6}{|c|}{251112055830.0} \\
\hline
\end{tabular}


Table B.3: Four Factor ANOVA Table for Std. Dev. Of Cycle Time

\begin{tabular}{|c|c|c|c|c|c|c|}
\hline Source & DF & Seq SS & Adj SS & Adj MS & $\mathbf{F}$ & $\mathbf{P}$ \\
\hline PV & 1 & 9017439.0 & 9017439.0 & 9017439.0 & 749.0 & 0.000 \\
\hline DR & 6 & 18475205.0 & 18475205.0 & 3079201.0 & 255.8 & 0.000 \\
\hline DDT & 1 & 7830.0 & 7830.0 & 7830.0 & 0.7 & 0.421 \\
\hline PM & 2 & 7063950.0 & 7063950.0 & 3531975.0 & 293.4 & 0.000 \\
\hline PV*DR & 6 & 15435132.0 & 15435132.0 & 2572522.0 & 213.7 & 0.000 \\
\hline$P V * D D T$ & 1 & 12678.0 & 12678.0 & 12678.0 & 1.1 & 0.306 \\
\hline$P V * P M$ & 2 & 5970461.0 & 5970461.0 & 2985230.0 & 248.0 & 0.000 \\
\hline$D R * D D T$ & 6 & 70511.0 & 70511.0 & 11752.0 & 1.0 & 0.443 \\
\hline DR*PM & 12 & 10580564.0 & 10580564.0 & 881714.0 & 73.2 & 0.000 \\
\hline DDT*PM & 2 & 84247.0 & 84247.0 & 42124.0 & 3.5 & 0.032 \\
\hline$P^{*}{ }^{*} R^{*} D D T$ & 6 & 96784.0 & 96784.0 & 16131.0 & 1.3 & 0.242 \\
\hline$P V^{*} D R^{*} P M$ & 12 & 10313784.0 & 10313784.0 & 859482.0 & 71.4 & 0.000 \\
\hline PV*DDT*PM & 2 & 77336.0 & 77336.0 & 38668.0 & 3.2 & 0.043 \\
\hline DR*DDT*PM & 12 & 508017.0 & 508017.0 & 42335.0 & 3.5 & 0.000 \\
\hline $\mathrm{PV}^{*} \mathrm{DR}^{*} \mathrm{DDT}{ }^{*} \mathrm{PM}$ & 12 & 497263.0 & 497263.0 & 41439.0 & 3.4 & 0.000 \\
\hline Error & 168 & 2022629.0 & 2022629.0 & 12039.0 & & \\
\hline Total & 251 & 80233829.0 & & & & \\
\hline
\end{tabular}

Table B.4: Four Factor ANOVA Table for Average WIP

\begin{tabular}{|c|c|c|c|c|c|c|}
\hline Source & DF & Seq SS & Adj SS & Adj MS & $\mathbf{F}$ & $\mathbf{P}$ \\
\hline PV & 1 & 17543.0 & 17543.0 & 17543.0 & 4512.3 & 0.000 \\
\hline DR & 6 & 7600.3 & 7600.3 & 1266.7 & 325.8 & 0.000 \\
\hline DDT & 1 & 1.0 & 1.0 & 1.0 & 0.3 & 0.619 \\
\hline PM & 2 & 1824.8 & 1824.8 & 912.4 & 234.7 & 0.000 \\
\hline PV*DR & 6 & 7151.8 & 7151.8 & 1192.0 & 306.6 & 0.000 \\
\hline PV*DDT & 1 & 2.2 & 2.2 & 2.2 & 0.6 & 0.452 \\
\hline PV*PM & 2 & 1608.1 & 1608.1 & 804.1 & 206.8 & 0.000 \\
\hline DR*DDT & 6 & 3.1 & 3.1 & 0.5 & 0.1 & 0.992 \\
\hline DR*PM & 12 & 1535.4 & 1535.4 & 128.0 & 32.9 & 0.000 \\
\hline DDT*PM & 2 & 15.5 & 15.5 & 7.8 & 2.0 & 0.139 \\
\hline$P V * D R * D D T$ & 6 & 6.4 & 6.4 & 1.1 & 0.3 & 0.949 \\
\hline$P V^{*} D R^{*} P M$ & 12 & 1764.2 & 1764.2 & 147.0 & 37.8 & 0.000 \\
\hline$P^{*}{ }^{*} D^{*} P M$ & 2 & 15.5 & 15.5 & 7.8 & 2.0 & 0.139 \\
\hline DR*DDT*PM & 12 & 371.1 & 371.1 & 30.9 & 8.0 & 0.000 \\
\hline $\mathrm{PV}^{*} \mathrm{DR}^{*} \mathrm{DDT}{ }^{*} \mathrm{PM}$ & 12 & 345.6 & 345.6 & 28.8 & 7.4 & 0.000 \\
\hline Error & 168 & 653.2 & 653.2 & 3.9 & & \\
\hline Total & 251 & 40441.2 & & & & \\
\hline
\end{tabular}




\section{Appendix C. Three Factor ANOVA Tables for Production Volume of 154 lots/year}

This appendix lists the ANOVA tables from the statistical analyses of runs with production level of 154 lots/year.

Table C.1: Three Factor ANOVA Table for $\%$ On Time Delivery

\begin{tabular}{lrrrrrr}
\hline Source & DF & Seq SS & Adj SS & Adj MS & F & P \\
\hline DR & 6 & 53187.5 & 53187.5 & 8864.6 & 4870.0 & 0.000 \\
DDT & 1 & 8738.2 & 8738.2 & 8738.2 & 4800.6 & 0.000 \\
PM & 2 & 27005.9 & 27005.9 & 13503.0 & 7418.3 & 0.000 \\
DR*DDT & 6 & 2624.4 & 2624.4 & 437.4 & 240.3 & 0.000 \\
DR*PM $^{*}$ & 12 & 31215.2 & 31215.2 & 2601.3 & 1429.1 & 0.000 \\
DDT*PM $^{*}$ DR $^{*}$ DDT*PM & 2 & 4044.9 & 4044.9 & 2022.4 & 1111.1 & 0.000 \\
Error & 12 & 10049.0 & 10049.0 & 837.4 & 460.1 & 0.000 \\
\hline Total & 84 & 152.9 & 152.9 & 1.8 & & \\
\hline
\end{tabular}

Table C.2: Three Factor ANOVA Table for Average Cycle Time

\begin{tabular}{lrrrrrr}
\hline Source & DF & Seq SS & Adj SS & Adj MS & F & P \\
\hline DR & 6 & 47270190.0 & 47270190.0 & 7878365.0 & 320.8 & 0.000 \\
DDT & 1 & 7475.0 & 7475.0 & 7475.0 & 0.3 & 0.583 \\
PM & 2 & 10986728.0 & 10986728.0 & 5493364.0 & 223.7 & 0.000 \\
DR*DDT & 6 & 20545.0 & 20545.0 & 3424.0 & 0.1 & 0.991 \\
DR*PM $^{*}$ & 12 & 10589608.0 & 10589608.0 & 882467.0 & 35.9 & 0.000 \\
DDT*PM $^{*}$ & 2 & 94249.0 & 94249.0 & 47124.0 & 1.9 & 0.153 \\
DR*DDT*PM $^{*}$ Dror & 12 & 2234608.0 & 2234608.0 & 186217.0 & 7.6 & 0.000 \\
Error & 84 & 2063177.0 & 2063177.0 & 24562.0 & & \\
\hline Total & $\mathbf{1 2 5}$ & $\mathbf{7 3 2 6 6 5 8 0 . 0}$ & & & & \\
\hline
\end{tabular}

Table C.3: Three Factor ANOVA Table for Std. Dev. Of Cycle Time

\begin{tabular}{lcrrrrr}
\hline Source & DF & Seq SS & Adj SS & Adj MS & F & P \\
\hline DR & 6 & 33764926.0 & 33764926.0 & 5627488.0 & 233.9 & 0.000 \\
DDT & 1 & 20217.0 & 20217.0 & 20217.0 & 0.8 & 0.362 \\
PM & 2 & 13010958.0 & 13010958.0 & 6505479.0 & 270.4 & 0.000 \\
DR*DDT & 6 & 166059.0 & 166059.0 & 27676.0 & 1.2 & 0.341 \\
DR*PM & 12 & 20880645.0 & 20880645.0 & 1740054.0 & 72.3 & 0.000 \\
DDT*PM $^{*}$ & 2 & 161507.0 & 161507.0 & 80753.0 & 3.4 & 0.040 \\
DR*DDT*PM & 12 & 1004887.0 & 1004887.0 & 83741.0 & 3.5 & 0.000 \\
Error & 84 & 2020807.0 & 2020807.0 & 24057.0 & & \\
\hline Total & $\mathbf{1 2 5}$ & $\mathbf{7 1 0 3 0 0 0 6 . 0}$ & & & & \\
\hline
\end{tabular}


Table C.4: Three Factor ANOVA Table for Average WIP

\begin{tabular}{|c|c|c|c|c|c|c|}
\hline \multirow{2}{*}{$\begin{array}{l}\text { Source } \\
\text { DR }\end{array}$} & \multicolumn{2}{|c|}{ Seq SS } & Adj SS & Adj MS & \multicolumn{2}{|c|}{$\mathbf{P}$} \\
\hline & 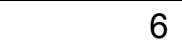 & 14734.4 & 14734.4 & 2455.7 & 316.5 & 0.000 \\
\hline DDT & 1 & 3.1 & 3.1 & 3.1 & 0.4 & 0.533 \\
\hline PM & 2 & 3429.1 & 3429.1 & 1714.6 & 221.0 & 0.000 \\
\hline DR*DDT & 6 & 9.0 & 9.0 & 1.5 & 0.2 & 0.978 \\
\hline DR*PM & 12 & 3292.3 & 3292.3 & 274.4 & 35.4 & 0.000 \\
\hline DDT*PM & 2 & 31.1 & 31.1 & 15.5 & 2.0 & 0.141 \\
\hline DR*DDT*PM & 12 & 716.4 & 716.4 & 59.7 & 7.7 & 0.000 \\
\hline Error & 84 & 651.8 & 651.8 & 7.8 & & \\
\hline Total & 125 & 22867.2 & & & & \\
\hline
\end{tabular}




\section{Appendix D. Three Factor ANOVA Tables for Production Volume of 128 lots/year}

This appendix lists the ANOVA tables from the statistical analyses of runs with production level of 128 lots/year.

Table D.1: Three Factor ANOVA Table for \% On Time Delivery

\begin{tabular}{lrrrrrr}
\hline Source & DF & Seq SS & Adj SS & Adj MS & F & P \\
\hline PM & 2 & 407.1 & 407.1 & 203.6 & 1602.9 & 0.000 \\
DR & 6 & 1100.4 & 1100.4 & 183.4 & 1444.2 & 0.000 \\
DDT & 1 & 1262.5 & 1262.5 & 1262.5 & 9941.8 & 0.000 \\
PM*DR & 12 & 352.6 & 352.6 & 29.4 & 231.4 & 0.000 \\
PM*DDT & 2 & 387.9 & 387.9 & 193.9 & 1527.1 & 0.000 \\
DR*DDT $^{*}$ & 6 & 1044.9 & 1044.9 & 174.2 & 1371.3 & 0.000 \\
PM$^{*}$ DR*DDT & 12 & 332.1 & 332.1 & 27.7 & 217.9 & 0.000 \\
Error & 84 & 10.7 & 10.7 & 0.1 & & \\
\hline Total & $\mathbf{1 2 5}$ & $\mathbf{4 8 9 8 . 2}$ & & & & \\
\hline
\end{tabular}

Table D.2: Three Factor ANOVA Table for Average Cycle Time

\begin{tabular}{lrrrrrr}
\hline Source & DF & Seq SS & Adj SS & Adj MS & F & P \\
\hline PM & 2 & 17221.0 & 17221.0 & 8610.5 & 117.4 & 0.000 \\
DR & 6 & 83312.1 & 83312.1 & 13885.3 & 189.4 & 0.000 \\
DDT & 1 & 585.8 & 585.8 & 585.8 & 8.0 & 0.006 \\
PM*DR & 12 & 34281.0 & 34281.0 & 2856.7 & 39.0 & 0.000 \\
PM*DDT & 2 & 42.4 & 42.4 & 21.2 & 0.3 & 0.749 \\
DR*DDT $^{*}$ & 6 & 2052.7 & 2052.7 & 342.1 & 4.7 & 0.000 \\
PM*DR*DDT & 12 & 1266.7 & 1266.7 & 105.6 & 1.4 & 0.164 \\
Error & 84 & 6158.7 & 6158.7 & 73.3 & & \\
\hline Total & $\mathbf{1 2 5}$ & $\mathbf{1 4 4 9 2 0 . 3}$ & & & & \\
\hline
\end{tabular}

Table D.3: Three Factor ANOVA Table for Std. Dev. Of Cycle Time

\begin{tabular}{|c|c|c|c|c|c|c|}
\hline Source & DF & Seq SS & Adj SS & Adj MS & $\mathbf{F}$ & $\mathbf{P}$ \\
\hline PM & 2 & 23453.4 & 23453.4 & 11726.7 & 540.6 & 0.000 \\
\hline DR & 6 & 145409.7 & 145409.7 & 24234.9 & 1117.2 & 0.000 \\
\hline DDT & 1 & 290.6 & 290.6 & 290.6 & 13.4 & 0.000 \\
\hline PM*DR & 12 & 13702.9 & 13702.9 & 1141.9 & 52.6 & 0.000 \\
\hline PM*DDT & 2 & 76.2 & 76.2 & 38.1 & 1.8 & 0.179 \\
\hline DR*DDT & 6 & 1235.6 & 1235.6 & 205.9 & 9.5 & 0.000 \\
\hline$P M * D R * D D T$ & 12 & 392.1 & 392.1 & 32.7 & 1.5 & 0.138 \\
\hline Error & 84 & 1822.2 & 1822.2 & 21.7 & & \\
\hline Total & 125 & 186382.7 & & & & \\
\hline
\end{tabular}


Table D.4: Three Factor ANOVA Table for Average WIP

\begin{tabular}{lrrrrrr}
\hline Source & DF & Seq SS & Adj SS & Adj MS & F & P \\
\hline PM & 2 & 3.8 & 3.8 & 1.9 & 120.0 & 0.000 \\
DR & 6 & 17.8 & 17.8 & 3.0 & 189.0 & 0.000 \\
DDT & 1 & 0.1 & 0.1 & 0.1 & 8.2 & 0.005 \\
PM*DR & 12 & 7.3 & 7.3 & 0.6 & 38.6 & 0.000 \\
PM*DDT & 2 & 0.0 & 0.0 & 0.0 & 0.3 & 0.739 \\
DR*DDT $^{*}$ & 6 & 0.4 & 0.4 & 0.1 & 4.7 & 0.000 \\
PM*DR*DDT & 12 & 0.3 & 0.3 & 0.0 & 1.4 & 0.175 \\
Error & 84 & 1.3 & 1.3 & 0.0 & & \\
\hline Total & $\mathbf{1 2 5}$ & $\mathbf{3 0 . 9}$ & & & & \\
\hline
\end{tabular}




\section{Appendix E. Two Factor ANOVA and Tukey Tables}

The appendices in this section have ANOVA and Tukey test tables for the two factor analyses conducted. Depending on whether the two factor interactions or the main effects are significant, Tukey pairwise comparison tests are done to determine which factor levels are statistically significant from each other. The Tukey family error rate is set at $5 \%$. The vertical lines in the significance column group the strategies that are not statistically different from each other.

Two Factor Analysis for Production Volume $=154$ lots $/$ year and Product Mix $=25-25-50$

Table E.1.A: Two Factor ANOVA Table for \% On Time Delivery

\begin{tabular}{lrrrrrr}
\hline Source & DF & Seq SS & Adj SS & Adj MS & F & P \\
\hline DR & 6 & 23693.3 & 23693.3 & 3948.9 & 2648.6 & 0.000 \\
DDT & 1 & 2565.0 & 2565.0 & 2565.0 & 1720.4 & 0.000 \\
DR*DDT & 6 & 790.0 & 790.0 & 131.7 & 88.3 & 0.000 \\
Error & 28 & 41.7 & 41.7 & 1.5 & & \\
\hline Total & $\mathbf{4 1}$ & $\mathbf{2 7 0 9 0 . 0}$ & & & & \\
\hline
\end{tabular}

Table E.1.B: Two Factor Tukey Table for $\%$ On Time Delivery

\begin{tabular}{|c|c|c|c|}
\hline $\begin{array}{c}\text { Dispatching } \\
\text { Rule }\end{array}$ & \begin{tabular}{|c|} 
Due Date \\
Tightness \\
$(\mathrm{H}, \mathrm{M}, \mathrm{L})$
\end{tabular} & $\begin{array}{c}\% \text { on time } \\
\text { delivery }\end{array}$ & Sig. \\
\hline FIFO & $15,20,25$ & 86.343 & \\
\hline LBA/FIFO & $15,20,25$ & 85.205 & \\
\hline HXT/FIFO & $15,20,25$ & 71.125 & \\
\hline FIFO & $10,15,20$ & 66.052 & \\
\hline LBA/FIFO & $10,15,20$ & 64.61 & \\
\hline $\mathrm{P} / \mathrm{CR}$ & $15,20,25$ & 50.311 & \\
\hline $\mathrm{P} / \mathrm{HXT}$ & $15,20,25$ & 50.109 & \\
\hline P/FIFO & $15,20,25$ & 49.856 & \\
\hline HXT/FIFO & $10,15,20$ & 41.303 & \\
\hline P/FIFO & $10,15,20$ & 39.406 & \\
\hline $\mathrm{P} / \mathrm{H} \times \mathrm{T}$ & $10,15,20$ & 37.252 & \\
\hline $\mathrm{P} / \mathrm{CR}$ & $10,15,20$ & 34.917 & \\
\hline CR/FIFO & $10,15,20$ & 0 & \\
\hline CR/FIFO & $15,20,25$ & 0 & \\
\hline
\end{tabular}


Table E.2.A: Two Factor ANOVA Table for Average Cycle Time

\begin{tabular}{lrrrrrr}
\hline Source & DF & Seq SS & Adj SS & Adj MS & F & P \\
\hline DR & 6 & 35850642.0 & 35850642.0 & 5975107.0 & 85.4 & 0.000 \\
DDT & 1 & 40752.0 & 40752.0 & 40752.0 & 0.6 & 0.452 \\
DR*DDT & 6 & 1324378.0 & 1324378.0 & 220730.0 & 3.2 & 0.017 \\
Error & 28 & 1959124.0 & 1959124.0 & 69969.0 & & \\
\hline Total & $\mathbf{4 1}$ & $\mathbf{3 9 1 7 4 8 9 7 . 0}$ & & & & \\
\hline
\end{tabular}

Table E.2.B: Two Factor Tukey Table for Average Cycle Time

\begin{tabular}{|c|c|c|c|}
\hline $\begin{array}{c}\text { Dispatching } \\
\text { Rule }\end{array}$ & $\begin{array}{c}\text { Due Date } \\
\text { Tightness }(\mathrm{H}, \mathrm{M}, \mathrm{L})\end{array}$ & $\begin{array}{c}\text { Avg. Cycle } \\
\text { Time } \\
\text { (hours) }\end{array}$ & Sig. \\
\hline FIFO & $10,15,20$ & 1261.3 & \\
\hline FIFO & $15,20,25$ & 1261.3 & \\
\hline LBA/FIFO & $10,15,20$ & 1286.5 & \\
\hline LBA/FIFO & $15,20,25$ & 1286.5 & \\
\hline $\mathrm{HXT/FIFO}$ & $10,15,20$ & 1567.7 & \\
\hline $\mathrm{HXT} / \mathrm{FIFO}$ & $15,20,25$ & 1567.7 & \\
\hline $\mathrm{P} / \mathrm{HXT}$ & $10,15,20$ & 1867 & \\
\hline $\mathrm{P} / \mathrm{HXT}$ & $15,20,25$ & 1867 & \\
\hline CR/FIFO & $10,15,20$ & 2136.1 & \\
\hline CR/FIFO & $15,20,25$ & 2556.4 & \\
\hline P/FIFO & $10,15,20$ & 3104.3 & \\
\hline P/FIFO & $15,20,25$ & 3104.3 & \\
\hline $\mathrm{P} / \mathrm{CR}$ & $15,20,25$ & 3477.7 & \\
\hline $\mathrm{P} / \mathrm{CR}$ & $10,15,20$ & 4334.1 & \\
\hline
\end{tabular}


Table E.3.A: Two Factor ANOVA Table for Std. Dev. Of Cycle Time

\begin{tabular}{|c|c|c|c|c|c|c|c|}
\hline Source & DF & & Seq SS & Adj SS & Adj MS & $\mathbf{F}$ & \\
\hline \multicolumn{2}{|l|}{ DR } & 6 & 47255809.0 & 47255809.0 & 7875968.0 & 111.2 & 0.000 \\
\hline \multicolumn{2}{|l|}{ DDT } & 1 & 167418.0 & 167418.0 & 167418.0 & 2.4 & 0.135 \\
\hline \multicolumn{2}{|l|}{$\mathrm{DR}^{\star} \mathrm{DDT}$} & 6 & 1099612.0 & 1099612.0 & 183269.0 & 2.6 & 0.040 \\
\hline \multicolumn{2}{|l|}{ Error } & 28 & 1983488.0 & 1983488.0 & 70839.0 & & \\
\hline Total & & 41 & 50506327.0 & & & & \\
\hline
\end{tabular}

Table E.3.B: Two Factor Tukey Table for Std. Dev. Of Cycle Time

\begin{tabular}{|l|l|r|r|}
\hline $\begin{array}{c}\text { Dispatching } \\
\text { Rule }\end{array}$ & \multicolumn{1}{|c|}{$\begin{array}{c}\text { Due Date } \\
\text { Tightness }(\mathbf{H , M , L )}\end{array}$} & $\begin{array}{r}\text { Std. Dev. } \\
\text { (hours) }\end{array}$ & \multicolumn{1}{|c|}{ Sig. } \\
\hline HXT/FIFO & $10,15,20$ & 90 & \\
\hline HXT/FIFO & $15,20,25$ & 90 \\
\hline FIFO & $10,15,20$ & 100.6 \\
\hline FIFO & $15,20,25$ & 100.6 \\
\hline LBA/FIFO & $10,15,20$ & 110.5 \\
\hline LBA/FIFO & $15,20,25$ & 110.5 \\
\hline CR/FIFO & $10,15,20$ & 322.8 \\
\hline CR/FIFO & $15,20,25$ & 357.3 \\
\hline P/HXT & $10,15,20$ & 903.9 \\
\hline P/HXT & $15,20,25$ & 903.9 & \\
\hline P/FIFO & $10,15,20$ & 2132.6 \\
\hline P/FIFO & $15,20,25$ & 2132.6 \\
\hline P/CR & $15,20,25$ & 2475.1 \\
\hline P/CR & $10,15,20$ & 3393.5 \\
\hline
\end{tabular}


Table E.4.A: Two Factor ANOVA Table for Average WIP

\begin{tabular}{lrrrrrr}
\hline Source & DF & Seq SS & Adj SS & Adj MS & F & P \\
\hline DR & 6 & 11253.6 & 11253.6 & 1875.6 & 84.8 & 0.000 \\
DDT & 1 & 15.2 & 15.2 & 15.2 & 0.7 & 0.414 \\
DR*DDT & 6 & 440.4 & 440.4 & 73.4 & 3.3 & 0.014 \\
Error & 28 & 619.4 & 619.4 & 22.1 & & \\
\hline Total & $\mathbf{4 1}$ & $\mathbf{1 2 3 2 8 . 5}$ & & & & \\
\hline
\end{tabular}

Table E.4.B: Two Factor Tukey Table for Average WIP

\begin{tabular}{|l|l|r|r|}
\hline $\begin{array}{c}\text { Dispatching } \\
\text { Rule }\end{array}$ & $\begin{array}{c}\text { Due Date } \\
\text { Tightness (H, } \mathbf{M}, \mathrm{L})\end{array}$ & Avg. WIP & Sig. \\
\hline FIFO & $10,15,20$ & 22.127 & \\
\hline FIFO & $15,20,25$ & 22.127 \\
\hline LBA/FIFO & $10,15,20$ & 22.57 \\
\hline LBA/FIFO & $15,20,25$ & 22.57 \\
\hline HXT/FIFO & $10,15,20$ & 27.5 \\
\hline HXT/FIFO & $15,20,25$ & 27.5 \\
\hline P/HXT & $10,15,20$ & 32.75 \\
\hline P/HXT & $15,20,25$ & 32.75 \\
\hline CR/FIFO & $10,15,20$ & 37.477 \\
\hline CR/FIFO & $15,20,25$ & 44.85 & $\mid$ \\
\hline P/FIFO & $10,15,20$ & 54.357 \\
\hline P/FIFO & $15,20,25$ & 54.357 \\
\hline P/CR & $15,20,25$ & 61.283 \\
\hline P/CR & $10,15,20$ & 77.073 & \\
\hline
\end{tabular}


Two Factor Analysis for Production Volume $=154$ lots $/$ year and Product Mix $=15-15-70$

Table E.5.A: Two Factor ANOVA Table for \% On Time Delivery

\begin{tabular}{lrrrrrr}
\hline Source & DF & Seq SS & Adj SS & Adj MS & F & P \\
\hline DR & 6 & 21238.7 & 21238.7 & 3539.8 & 928.5 & 0.000 \\
DDT & 1 & 10102.4 & 10102.4 & 10102.4 & 2649.9 & 0.000 \\
DR*DDT & 6 & 11864.6 & 11864.6 & 1977.4 & 518.7 & 0.000 \\
Error & 28 & 106.7 & 106.7 & 3.8 & & \\
\hline Total & $\mathbf{4 1}$ & $\mathbf{4 3 3 1 2 . 4}$ & & & & \\
\hline
\end{tabular}

Table E.5.A: Two Factor Tukey Table for \% On Time Delivery

\begin{tabular}{|c|c|c|c|}
\hline $\begin{array}{c}\text { Dispatching } \\
\text { Rule }\end{array}$ & $\begin{array}{c}\text { Due Date } \\
\text { Tightness }(\mathrm{H}, \mathrm{M}, \mathrm{L})\end{array}$ & $\begin{array}{l}\% \text { on time } \\
\text { delivery }\end{array}$ & Sig. \\
\hline CR/FIFO & $15,20,25$ & 100 & \multirow{14}{*}{$\left.\right|_{1}$} \\
\hline P/FIFO & $15,20,25$ & 99.96 & \\
\hline P/HXT & $15,20,25$ & 99.93 & \\
\hline FIFO & $15,20,25$ & 91.73 & \\
\hline LBA/FIFO & $10,15,20$ & 91.38 & \\
\hline LBA/FIFO & $15,20,25$ & 91.38 & \\
\hline HXT/FIFO & $15,20,25$ & 86.59 & \\
\hline FIFO & $10,15,20$ & 79.62 & \\
\hline P/FIFO & $10,15,20$ & 79.52 & \\
\hline HXT/FIFO & $10,15,20$ & 72.01 & \\
\hline $\mathrm{P} / \mathrm{H} \times \mathrm{T}$ & $10,15,20$ & 38.3 & \\
\hline $\mathrm{P} / \mathrm{CR}$ & $15,20,25$ & 29.91 & \\
\hline $\mathrm{P} / \mathrm{CR}$ & $10,15,20$ & 21.54 & \\
\hline CR/FIFO & $10,15,20$ & 0 & \\
\hline
\end{tabular}


Table E.6.A: Two Factor ANOVA Table for Average Cycle Time

\begin{tabular}{lrrrrrr}
\hline Source & DF & Seq SS & Adj SS & Adj MS & F & P \\
\hline DR & 6 & 13065988.0 & 13065988.0 & 2177665.0 & 661.5 & 0.000 \\
DDT & 1 & 21487.0 & 21487.0 & 21487.0 & 6.5 & 0.016 \\
DR*DDT & 6 & 805123.0 & 805123.0 & 134187.0 & 40.8 & 0.000 \\
Error & 28 & 92173.0 & 92173.0 & 3292.0 & & \\
\hline Total & $\mathbf{4 1} 13984771.0$ & & & &
\end{tabular}

Table E.6.B: Two Factor Tukey Table for Average Cycle Time

\begin{tabular}{|c|c|c|c|}
\hline $\begin{array}{c}\text { Dispatching } \\
\text { Rule }\end{array}$ & $\begin{array}{c}\text { Due Date } \\
\text { Tightness }(\mathrm{H}, \mathrm{M}, \mathrm{L})\end{array}$ & $\begin{array}{l}\text { Avg. Cycle } \\
\text { Time } \\
\text { (hours) }\end{array}$ & Sig. \\
\hline FIFO & $10,15,20$ & 1247.7 & \\
\hline FIFO & $15,20,25$ & 1247.7 & \\
\hline LBA/FIFO & $10,15,20$ & 1276.1 & \\
\hline LBAJFIFO & $15,20,25$ & 1276.1 & \\
\hline $\mathrm{HXT/FIFO}$ & $10,15,20$ & 1321 & \\
\hline $\mathrm{HXT} / \mathrm{FIFO}$ & $15,20,25$ & 1321 & \\
\hline P/FIFO & $10,15,20$ & 1369.5 & \\
\hline P/FIFO & $15,20,25$ & 1369.5 & \\
\hline $\mathrm{P} / \mathrm{HXT}$ & $10,15,20$ & 1520.8 & \\
\hline $\mathrm{P} / \mathrm{H} \times \mathrm{T}$ & $15,20,25$ & 1520.8 & \\
\hline CR/FIFO & $15,20,25$ & 1572.4 & \\
\hline CR/FIFO & $10,15,20$ & 2231.1 & \\
\hline $\mathrm{P} / \mathrm{CR}$ & $10,15,20$ & 2747.4 & \\
\hline $\mathrm{P} / \mathrm{CR}$ & $15,20,25$ & 3089.6 & \\
\hline
\end{tabular}


Table E.7.A: Two Factor ANOVA Table for Std. Dev. Of Cycle Time

\begin{tabular}{lrrrrrr}
\hline Source & DF & \multicolumn{1}{c}{ Seq SS } & Adj SS & Adj MS & F & P \\
\hline DR & 6 & 6324603.0 & 6324603.0 & 1054101.0 & 837.5 & 0.000 \\
DDT & 1 & 10862.0 & 10862.0 & 10862.0 & 8.6 & 0.007 \\
DR*DDT & 6 & 59521.0 & 59521.0 & 9920.0 & 7.9 & 0.000 \\
Error & 28 & 35242.0 & 35242.0 & 1259.0 & & \\
\hline Total & $\mathbf{4 1}$ & $\mathbf{6 4 3 0 2 2 9 . 0}$ & & & & \\
\hline
\end{tabular}

Table E.7.B: Two Factor Tukey Table for Std. Dev. Of Cycle Time

\begin{tabular}{|c|c|c|c|}
\hline $\begin{array}{c}\text { Dispatching } \\
\text { Rule }\end{array}$ & $\begin{array}{c}\text { Due Date } \\
\text { Tightness }(\mathrm{H}, \mathrm{M}, \mathrm{L})\end{array}$ & $\begin{array}{l}\text { Std. Dev. } \\
\text { (hours) }\end{array}$ & Sig. \\
\hline $\mathrm{HXT} / \mathrm{FIFO}$ & $10,15,20$ & 63.6 & \\
\hline $\mathrm{HXT/FIFO}$ & $15,20,25$ & 63.6 & \\
\hline FIFO & $10,15,20$ & 95.5 & \\
\hline FIFO & $15,20,25$ & 95.5 & \\
\hline LBAJFIFO & $10,15,20$ & 115.6 & \\
\hline LBA/FIFO & $15,20,25$ & 115.6 & \\
\hline $\mathrm{CR} / \mathrm{FIFO}$ & $10,15,20$ & 294 & \\
\hline CR/FIFO & $15,20,25$ & 302.7 & \\
\hline P/FIFO & $10,15,20$ & 319.7 & \\
\hline $\mathrm{P} / \mathrm{FIFO}$ & $15,20,25$ & 319.7 & \\
\hline $\mathrm{P} / \mathrm{HXT}$ & $10,15,20$ & 353.4 & \\
\hline $\mathrm{P} / \mathrm{HXT}$ & $15,20,25$ & 353.4 & \\
\hline $\mathrm{P} / \mathrm{CR}$ & $10,15,20$ & 1163.4 & \\
\hline $\mathrm{P} / \mathrm{CR}$ & $15,20,25$ & 1379.9 & \\
\hline
\end{tabular}


Table E.8.A: Two Factor ANOVA Table for Average WIP

\begin{tabular}{lrrrrrr}
\hline Source & DF & Seq SS & Adj SS & Adj MS & $\mathbf{F}$ & P \\
DR & 6 & 4020.8 & 4020.8 & 670.1 & 650.7 & 0.000 \\
DDT & 1 & 6.8 & 6.8 & 6.8 & 6.6 & 0.016 \\
DR*DDT & 6 & 246.5 & 246.5 & 41.1 & 39.9 & 0.000 \\
Error & 28 & 28.8 & 28.8 & 1.0 & & \\
\hline Total & $\mathbf{4 1}$ & $\mathbf{4 3 0 2 . 9}$ & & & & \\
\hline
\end{tabular}

Table E.8.B: Two Factor Tukey Table for Average WIP

\begin{tabular}{|c|c|c|c|}
\hline $\begin{array}{c}\text { Dispatching } \\
\text { Rule }\end{array}$ & $\begin{array}{c}\text { Due Date } \\
\text { Tightness (H,M,L) }\end{array}$ & Avg. WIP & Sig. \\
\hline FIFO & $10,15,20$ & 21.89 & \\
\hline FIFO & $15,20,25$ & 21.89 & \\
\hline LBA/FIFO & $10,15,20$ & 22.387 & \\
\hline LBA/FIFO & $15,20,25$ & 22.387 & \\
\hline $\mathrm{HXT} / \mathrm{FIFO}$ & $10,15,20$ & 23.177 & \\
\hline $\mathrm{HXT} / \mathrm{FIFO}$ & $15,20,25$ & 23.177 & \\
\hline P/FIFO & $10,15,20$ & 24.027 & \\
\hline $\mathrm{P} / \mathrm{FIFO}$ & $15,20,25$ & 24.027 & \\
\hline $\mathrm{P} / \mathrm{H} \times \mathrm{T}$ & $10,15,20$ & 26.68 & \\
\hline $\mathrm{P} / \mathrm{H} \times \mathrm{T}$ & $15,20,25$ & 26.68 & \\
\hline $\mathrm{CR} / \mathrm{FIFO}$ & $15,20,25$ & 27.577 & \\
\hline CR/FIFO & $10,15,20$ & 39.14 & \\
\hline $\mathrm{P} / \mathrm{CR}$ & $10,15,20$ & 48.237 & \\
\hline $\mathrm{P} / \mathrm{CR}$ & $15,20,25$ & 54.163 & \\
\hline
\end{tabular}


Two Factor Analysis for Production Volume = 154 lots/year and Product Mix = 5-5-90

Table E.9.A: Two Factor ANOVA Table for \% On Time Delivery

\begin{tabular}{lrrrrrr}
\hline Source & DF & Seq SS & Adj SS & Adj MS & F & P \\
\hline DR & 6 & 39470.7 & 39470.7 & 6578.5 & 41752.7 & 0.000 \\
DDT & 1 & 115.6 & 115.6 & 115.6 & 733.8 & 0.000 \\
DR ${ }^{*}$ DDT & 6 & 18.8 & 18.8 & 3.1 & 19.9 & 0.000 \\
Error & 28 & 4.4 & 4.4 & 0.2 & & \\
\hline Total & $\mathbf{4 1}$ & $\mathbf{3 9 6 0 9 . 5}$ & & & & \\
\hline
\end{tabular}

Table E.9.B: Two Factor Tukey Table for $\%$ On Time Delivery

\begin{tabular}{|c|c|c|c|}
\hline $\begin{array}{c}\text { Dispatching } \\
\text { Rule }\end{array}$ & $\begin{array}{c}\text { Due Date } \\
\text { Tightness }(\mathrm{H}, \mathrm{M}, \mathrm{L})\end{array}$ & $\begin{array}{l}\% \text { on time } \\
\text { delivery }\end{array}$ & Sig. \\
\hline CR/FIFO & $15,20,25$ & 100 & \\
\hline $\mathrm{P} / \mathrm{FIFO}$ & $15,20,25$ & 100 & \\
\hline $\mathrm{P} / \mathrm{HXT}$ & $15,20,25$ & 100 & \\
\hline P/FIFO & $10,15,20$ & 98.517 & \\
\hline $\mathrm{P} / \mathrm{HXT}$ & $10,15,20$ & 97.865 & \\
\hline LBA/FIFO & $15,20,25$ & 96.629 & \\
\hline CR/FIFO & $10,15,20$ & 96.52 & \\
\hline $\mathrm{FIFO}$ & $15,20,25$ & 96.516 & \\
\hline $\mathrm{HXT} / \mathrm{FIFO}$ & $15,20,25$ & 95.615 & \\
\hline FIFO & $10,15,20$ & 92.09 & \\
\hline LBA/FIFO & $10,15,20$ & 91.881 & \\
\hline HXT/FIFO & $10,15,20$ & 90.65 & \\
\hline $\mathrm{P} / \mathrm{CR}$ & $15,20,25$ & 9.997 & \\
\hline $\mathrm{P} / \mathrm{CR}$ & $10,15,20$ & 8.007 & \\
\hline
\end{tabular}


Table E.10.A: Two Factor ANOVA Table for Average Cycle Time

\begin{tabular}{lrrrrrr}
\hline Source & DF & Seq SS & Adj SS & Adj MS & F & P \\
\hline DR & 6 & 8943124.0 & 8943124.0 & 1490521.0 & 3508.8 & 0.000 \\
DDT & 1 & 39485.0 & 39485.0 & 39485.0 & 93.0 & 0.000 \\
DR ${ }^{*}$ DDT & 6 & 125670.0 & 125670.0 & 20945.0 & 49.3 & 0.000 \\
Error & 28 & 11894.0 & 11894.0 & 425.0 & & \\
\hline Total & $\mathbf{4 1}$ & $\mathbf{9 1 2 0 1 7 2 . 0}$ & & & &
\end{tabular}

Table E.10.B: Two Factor Tukey Table for Average Cycle Time

\begin{tabular}{|c|c|c|c|}
\hline $\begin{array}{c}\text { Dispatching } \\
\text { Rule }\end{array}$ & $\begin{array}{c}\text { Due Date } \\
\text { Tightness }(\mathrm{H}, \mathrm{M}, \mathrm{L})\end{array}$ & $\begin{array}{l}\text { Avg. Cycle } \\
\text { Time } \\
\text { (hours) }\end{array}$ & Sig. \\
\hline FIFO & $10,15,20$ & 1255.9 & \\
\hline FIFO & $15,20,25$ & 1255.9 & \\
\hline $\mathrm{P} / \mathrm{HXT}$ & $10,15,20$ & 1281.7 & \\
\hline $\mathrm{P} / \mathrm{HXT}$ & $15,20,25$ & 1281.7 & \\
\hline P/FIFO & $10,15,20$ & 1283.3 & \\
\hline P/FIFO & $15,20,25$ & 1283.3 & \\
\hline $\mathrm{HXT/FIFO}$ & $10,15,20$ & 1285.5 & \\
\hline $\mathrm{HXT/FIFO}$ & $15,20,25$ & 1285.5 & \\
\hline LBA/FIFO & $10,15,20$ & 1306.5 & \\
\hline LBA/FIFO & $15,20,25$ & 1306.5 & \\
\hline CR/FIFO & $10,15,20$ & 1441 & \\
\hline CR/FIFO & $15,20,25$ & 1560.8 & \\
\hline $\mathrm{P} / \mathrm{CR}$ & $10,15,20$ & 2464.7 & \\
\hline $\mathrm{P} / \mathrm{CR}$ & $15,20,25$ & 2774.1 & \\
\hline
\end{tabular}


Table E.11.A: Two Factor ANOVA Table for Std. Dev. Of Cycle Time

\begin{tabular}{lrrrrrr}
\hline Source & DF & Seq SS & Adj SS & Adj MS & F & P \\
\hline DR & 6 & 1065197.0 & 1065197.0 & 177533.0 & 2395.9 & 0.000 \\
DDT & 1 & 3442.0 & 3442.0 & 3442.0 & 46.5 & 0.000 \\
DR ${ }^{*}$ DDT & 6 & 11817.0 & 11817.0 & 1969.0 & 26.6 & 0.000 \\
Error & 28 & 2075.0 & 2075.0 & 74.0 & & \\
\hline Total & $\mathbf{4 1}$ & $\mathbf{1 0 8 2 5 3 0 . 0}$ & & & & \\
\hline
\end{tabular}

Table E.11.B: Two Factor Tukey Table for Std. Dev. Of Cycle Time

\begin{tabular}{|c|c|c|c|}
\hline $\begin{array}{c}\text { Dispatching } \\
\text { Rule }\end{array}$ & $\begin{array}{c}\text { Due Date } \\
\text { Tightness }(\mathrm{H}, \mathrm{M}, \mathrm{L})\end{array}$ & $\begin{array}{c}\text { Std. Dev. } \\
\text { (hours) }\end{array}$ & Sig. \\
\hline HXT/FIFO & $10,15,20$ & 67.02 & \\
\hline $\mathrm{HXT} / \mathrm{FIFO}$ & $15,20,25$ & 67.02 & \\
\hline $\mathrm{FIFO}$ & $10,15,20$ & 103.51 & \\
\hline FIFO & $15,20,25$ & 103.51 & \\
\hline LBA/FIFO & $10,15,20$ & 121.81 & \\
\hline LBA/FIFO & $15,20,25$ & 121.81 & \\
\hline $\mathrm{P} / \mathrm{H} \times \mathrm{T}$ & $10,15,20$ & 143.01 & \\
\hline $\mathrm{P} / \mathrm{HXT}$ & $15,20,25$ & 143.01 & \\
\hline P/FIFO & $10,15,20$ & 169.24 & \\
\hline $\mathrm{P} / \mathrm{FIFO}$ & $15,20,25$ & 169.24 & \\
\hline $\mathrm{CR} / \mathrm{FIFO}$ & $10,15,20$ & 177.09 & \\
\hline CR/FIFO & $15,20,25$ & 207.74 & \\
\hline $\mathrm{P} / \mathrm{CR}$ & $10,15,20$ & 526.51 & \\
\hline $\mathrm{P} / \mathrm{CR}$ & $15,20,25$ & 622.6 & \\
\hline
\end{tabular}


Table E.12.A: Two Factor ANOVA Table for Average WIP

\begin{tabular}{lrrrrrr}
\hline Source & DF & Seq SS & Adj SS & Adj MS & F & P \\
\hline DR & 6 & 2752.3 & 2752.3 & 458.7 & 3564.8 & 0.000 \\
DDT & 1 & 12.1 & 12.1 & 12.1 & 94.3 & 0.000 \\
DR ${ }^{*}$ DDT & 6 & 38.6 & 38.6 & 6.4 & 50.0 & 0.000 \\
Error & 28 & 3.6 & 3.6 & 0.1 & & \\
\hline Total & $\mathbf{4 1}$ & $\mathbf{2 8 0 6 . 7}$ & & & & \\
\hline
\end{tabular}

Table E.12.B: Two Factor Tukey Table for Average WIP

\begin{tabular}{|c|c|c|c|}
\hline $\begin{array}{c}\text { Dispatching } \\
\text { Rule }\end{array}$ & $\begin{array}{c}\text { Due Date } \\
\text { Tightness (H,M,L) }\end{array}$ & Avg. WIP & Sig. \\
\hline FIFO & $10,15,20$ & 22.033 & \\
\hline FIFO & $15,20,25$ & 22.033 & \\
\hline $\mathrm{P} / \mathrm{HXT}$ & $10,15,20$ & 22.487 & \\
\hline $\mathrm{P} / \mathrm{HXT}$ & $15,20,25$ & 22.487 & \\
\hline P/FIFO & $10,15,20$ & 22.51 & \\
\hline P/FIFO & $15,20,25$ & 22.51 & \\
\hline HXT/FIFO & $10,15,20$ & 22.55 & \\
\hline $\mathrm{HXT} / \mathrm{FIFO}$ & $15,20,25$ & 22.55 & \\
\hline LBA/FIFO & $10,15,20$ & 22.92 & \\
\hline LBA/FIFO & $15,20,25$ & 22.92 & \\
\hline CR/FIFO & $10,15,20$ & 25.283 & \\
\hline CR/FIFO & $15,20,25$ & 27.383 & \\
\hline $\mathrm{P} / \mathrm{CR}$ & $10,15,20$ & 43.24 & \\
\hline $\mathrm{P} / \mathrm{CR}$ & $15,20,25$ & 48.663 & \\
\hline
\end{tabular}


Two Factor Analysis for Production Volume $=128$ lots $/$ year and Product Mix $=$ 25-25-50

Table E.13.A: Two Factor ANOVA Table for \% On Time Delivery

\begin{tabular}{lrrrrrr}
\hline Source & DF & Seq SS & Adj SS & Adj MS & F & P \\
\hline DR & 6 & 1056.3 & 1056.3 & 176.1 & 997.6 & 0.000 \\
DDT & 1 & 1203.3 & 1203.3 & 1203.3 & 6818.3 & 0.000 \\
DR*DDT & 6 & 1002.2 & 1002.2 & 167.0 & 946.5 & 0.000 \\
Error & 28 & 4.9 & 4.9 & 0.2 & & \\
\hline Total & $\mathbf{4 1}$ & $\mathbf{3 2 6 6 . 8}$ & & & & \\
\hline
\end{tabular}

Table E.13.A: Two Factor Tukey Table for $\%$ On Time Delivery

\begin{tabular}{|c|c|c|c|}
\hline $\begin{array}{c}\text { Dispatching } \\
\text { Rule }\end{array}$ & $\begin{array}{c}\text { Due Date } \\
\text { Tightness }(\mathrm{H}, \mathrm{M}, \mathrm{L})\end{array}$ & $\begin{array}{l}\% \text { on time } \\
\text { delivery }\end{array}$ & Sig. \\
\hline $\mathrm{CR} / \mathrm{FIFO}$ & $15,20,25$ & 100 & \\
\hline $\mathrm{HXT/FIFO}$ & $15,20,25$ & 100 & \\
\hline $\mathrm{P} / \mathrm{CR}$ & $15,20,25$ & 100 & \\
\hline P/FIFO & $15,20,25$ & 100 & \\
\hline $\mathrm{P} / \mathrm{HXT}$ & $15,20,25$ & 100 & \\
\hline $\mathrm{FIFO}$ & $15,20,25$ & 99.782 & \\
\hline LBA/FIFO & $15,20,25$ & 99.391 & \\
\hline P/FIFO & $10,15,20$ & 98.344 & \\
\hline $\mathrm{P} / \mathrm{HXT}$ & $10,15,20$ & 97.567 & \\
\hline CR/FIFO & $10,15,20$ & 97.52 & \\
\hline $\mathrm{P} / \mathrm{CR}$ & $10,15,20$ & 97.432 & \\
\hline $\mathrm{FIFO}$ & $10,15,20$ & 79.251 & \\
\hline LBA/FIFO & $10,15,20$ & 77.947 & \\
\hline $\mathrm{HXT} / \mathrm{FIFO}$ & $10,15,20$ & 76.175 & \\
\hline
\end{tabular}


Table E.14.A: Two Factor ANOVA Table for Average Cycle Time

\begin{tabular}{lrrrrrr}
\hline Source & DF & Seq SS & Adj SS & Adj MS & F & P \\
\hline DR & 6 & 36581.6 & 36581.6 & 6096.9 & 81.4 & 0.000 \\
DDT & 1 & 98.0 & 98.0 & 98.0 & 1.3 & 0.262 \\
DR*DDT & 6 & 1225.2 & 1225.2 & 204.2 & 2.7 & 0.033 \\
Error & 28 & 2098.0 & 2098.0 & 74.9 & & \\
\hline Total & $\mathbf{4 1}$ & $\mathbf{4 0 0 0 2 . 8}$ & & & & \\
\hline
\end{tabular}

Table E.14.B: Two Factor Tukey Table for Average Cycle Time

\begin{tabular}{|c|c|c|c|}
\hline $\begin{array}{c}\text { Dispatching } \\
\text { Rule }\end{array}$ & $\begin{array}{c}\text { Due Date } \\
\text { Tightness (H,M,L) }\end{array}$ & $\begin{array}{c}\text { Avg. Cycle } \\
\text { Time } \\
\text { (hours) }\end{array}$ & Sig. \\
\hline P/FIFO & $10,15,20$ & 979.09 & \\
\hline P/FIFO & $15,20,25$ & 979.09 & \\
\hline $\mathrm{P} / \mathrm{HXT}$ & $10,15,20$ & 989.56 & \\
\hline $\mathrm{P} / \mathrm{HXT}$ & $15,20,25$ & 989.56 & \\
\hline FIFO & $10,15,20$ & 995.36 & \\
\hline FIFO & $15,20,25$ & 995.36 & \\
\hline $\mathrm{P} / \mathrm{CR}$ & $15,20,25$ & 1002.6 & \\
\hline $\mathrm{P} / \mathrm{CR}$ & $10,15,20$ & 1009.98 & \\
\hline $\mathrm{HXT/FIFO}$ & $10,15,20$ & 1024.62 & \\
\hline $\mathrm{HXT/FIFO}$ & $15,20,25$ & 1024.62 & \\
\hline LBAJFIFO & $10,15,20$ & 1049.12 & \\
\hline LBAJFIFO & $15,20,25$ & 1049.12 & \\
\hline CR/FIFO & $10,15,20$ & 1050.05 & \\
\hline CR/FIFO & $15,20,25$ & 1078.82 & \\
\hline
\end{tabular}


Table E.15.A: Two Factor ANOVA Table for Std. Dev. Of Cycle Time

\begin{tabular}{lrrrrrr}
\hline Source & DF & Seq SS & Adj SS & Adj MS & F & P \\
DR & 6 & 74047.4 & 74047.4 & 12341.2 & 596.5 & 0.000 \\
DDT & 1 & 8.7 & 8.7 & 8.7 & 0.4 & 0.523 \\
DR*DDT & 6 & 294.3 & 294.3 & 49.1 & 2.4 & 0.056 \\
Error & 28 & 579.3 & 579.3 & 20.7 & & \\
\hline Total & $\mathbf{4 1}$ & $\mathbf{7 4 9 2 9 . 8}$ & & & & \\
\hline
\end{tabular}

Table E.15.B: Two Factor Tukey Table for Std. Dev. Of Cycle Time

\begin{tabular}{|c|c|c|}
\hline $\begin{array}{c}\text { Dispatching } \\
\text { Rule }\end{array}$ & $\begin{array}{l}\text { Std. Dev. } \\
\text { (hours) }\end{array}$ & Sig. \\
\hline $\mathrm{HXT} / \mathrm{FIFO}$ & 71.91 & \\
\hline FIFO & 97.99 & \\
\hline LBA/FIFO & 116.03 & \\
\hline $\mathrm{P} / \mathrm{H} \times \mathrm{T}$ & 156.28 & \\
\hline P/FIFO & 160.25 & \\
\hline $\mathrm{P} / \mathrm{CR}$ & 183.68 & \\
\hline CR/FIFO & 192.75 & \\
\hline
\end{tabular}

Table E.16.A: Two Factor ANOVA Table for Average WIP

\begin{tabular}{lrrrrrr}
\hline Source & DF & Seq SS & Adj SS & Adj MS & F & P \\
\hline DR & 6 & 7.8 & 7.8 & 1.3 & 81.3 & 0.000 \\
DDT & 1 & 0.0 & 0.0 & 0.0 & 1.3 & 0.260 \\
DR*DDT & 6 & 0.3 & 0.3 & 0.0 & 2.7 & 0.036 \\
Error & 28 & 0.4 & 0.4 & 0.0 & & \\
\hline Total & $\mathbf{4 1}$ & $\mathbf{8 . 5}$ & & & & \\
\hline
\end{tabular}

Table E.16.B: Two Factor Tukey Table for Average WIP

\begin{tabular}{|l|l|r|r|}
\hline $\begin{array}{c}\text { Dispatching } \\
\text { Rule }\end{array}$ & $\begin{array}{c}\text { Due Date } \\
\text { Tightness (H,M,L) }\end{array}$ & Avg. WIP & Sig. \\
\hline P/FIFO & $10,15,20$ & 14.317 & \\
\hline P/FIFO & $15,20,25$ & 14.317 & \\
\hline P/HXT & $10,15,20$ & 14.47 & \\
\hline P/HXT & $15,20,25$ & 14.47 & \\
\hline FIFO & $10,15,20$ & 14.557 \\
\hline FIFO & $15,20,25$ & 14.557 & \\
\hline P/CR & $15,20,25$ & 14.663 & $\mid$ \\
\hline P/CR & $10,15,20$ & 14.767 & \\
\hline HXT/FIFO & $10,15,20$ & 14.98 \\
\hline HXT/FIFO & $15,20,25$ & 15.34 \\
\hline LBA/FIFO & $10,15,20$ & 15.34 \\
\hline LBA/FIFO & $15,20,25$ & 15.353 \\
\hline CR/FIFO & $10,15,20$ & 15.77 & \\
\hline CR/FIFO & $15,20,25$ & \\
\hline
\end{tabular}


Two Factor Analysis for Production Volume $=128$ lots $/$ year and Product Mix $=15-15-70$

Table E.17.A: Two Factor ANOVA Table for \% On Time Delivery

\begin{tabular}{lrrrrrr}
\hline Source & DF & Seq SS & Adj SS & Adj MS & F & P \\
\hline DR & 6 & 359.4 & 359.4 & 59.9 & 368.9 & 0.000 \\
DDT & 1 & 400.2 & 400.2 & 400.2 & 2464.9 & 0.000 \\
DR*DDT & 6 & 338.4 & 338.4 & 56.4 & 347.4 & 0.000 \\
Error & 28 & 4.5 & 4.5 & 0.2 & & \\
\hline Total & $\mathbf{4 1}$ & $\mathbf{1 1 0 2 . 5}$ & & & & \\
\hline
\end{tabular}

Table E.17.B: Two Factor Tukey Table for \% On Time Delivery

\begin{tabular}{|c|c|c|c|}
\hline $\begin{array}{c}\text { Dispatching } \\
\text { Rule }\end{array}$ & $\begin{array}{c}\text { Due Date } \\
\text { Tightness }(\mathrm{H}, \mathrm{M}, \mathrm{L})\end{array}$ & $\begin{array}{l}\% \text { on time } \\
\text { delivery }\end{array}$ & Sig. \\
\hline CR/FIFO & $15,20,25$ & 100 & \\
\hline $\mathrm{HXT} / \mathrm{FIFO}$ & $15,20,25$ & 100 & \\
\hline P/CR & $15,20,25$ & 100 & \\
\hline P/FIFO & $15,20,25$ & 100 & \\
\hline $\mathrm{P} / \mathrm{HXT}$ & $15,20,25$ & 100 & \\
\hline LBA/FIFO & $15,20,25$ & 99.826 & \\
\hline FIFO & $15,20,25$ & 99.652 & \\
\hline P/FIFO & $10,15,20$ & 99.261 & \\
\hline $\mathrm{P} / \mathrm{HXT}$ & $10,15,20$ & 98.999 & \\
\hline $\mathrm{P} / \mathrm{CR}$ & $10,15,20$ & 98.911 & \\
\hline CR/FIFO & $10,15,20$ & 97.74 & \\
\hline HXT/FIFO & $10,15,20$ & 87.207 & \\
\hline LBA/FIFO & $10,15,20$ & 87.119 & \\
\hline FIFO & $10,15,20$ & 87.027 & \\
\hline
\end{tabular}


Table E.18.A: Two Factor ANOVA Table for Average Cycle Time

\begin{tabular}{lrrrrrr}
\hline Source & DF & Seq SS & Adj SS & Adj MS & F & P \\
DR & 6 & 36163.4 & 36163.4 & 6027.2 & 81.1 & 0.000 \\
DDT & 1 & 360.0 & 360.0 & 360.0 & 4.8 & 0.036 \\
DR*DDT & 6 & 1047.0 & 1047.0 & 174.5 & 2.4 & 0.058 \\
Error & 28 & 2080.9 & 2080.9 & 74.3 & & \\
\hline Total & $\mathbf{4 1}$ & $\mathbf{3 9 6 5 1 . 3}$ & & & & \\
\hline
\end{tabular}

Table E.18.B: Two Factor Tukey Table for Average Cycle Time

\begin{tabular}{|l|r|r|}
\hline $\begin{array}{c}\text { Dispatching } \\
\text { Rule }\end{array}$ & $\begin{array}{c}\text { Avg. Cycle } \\
\text { Time } \\
\text { (hours) }\end{array}$ & \multicolumn{1}{|c|}{ Sig. } \\
\hline P/HXT & 965.37 & \\
\hline FIFO & 972.18 & \\
\hline HXT/FIFO & 972.8 & \\
\hline LBA/FIFO & 974.46 & \\
\hline P/FIFO & 975.18 & \\
\hline P/CR & 1013.97 & \multicolumn{1}{|c|}{$\mid$} \\
\hline CR/FIFO & 1051.44 & \\
\hline
\end{tabular}

Table E.19.A: Two Factor ANOVA Table for Std. Dev. Of Cycle Time

\begin{tabular}{lrrrrrr}
\hline Source & DF & Seq SS & Adj SS & Adj MS & F & P \\
\hline DR & 6 & 48684.6 & 48684.6 & 8114.1 & 507.9 & 0.000 \\
DDT & 1 & 220.2 & 220.2 & 220.2 & 13.8 & 0.001 \\
DR*DDT & 6 & 802.3 & 802.3 & 133.7 & 8.4 & 0.000 \\
Error & 28 & 447.3 & 447.3 & 16.0 & & \\
\hline Total & $\mathbf{4 1}$ & $\mathbf{5 0 1 5 4 . 4}$ & & & & \\
\hline
\end{tabular}

Table E.19.B: Two Factor Tukey Table for Std. Dev. Of Cycle Time

\begin{tabular}{|c|c|c|c|}
\hline $\begin{array}{c}\text { Dispatching } \\
\text { Rule }\end{array}$ & $\begin{array}{c}\text { Due Date } \\
\text { Tightness }(\mathrm{H}, \mathrm{M}, \mathrm{L})\end{array}$ & $\begin{array}{l}\text { Std. Dev. } \\
\text { (hours) }\end{array}$ & Sig. \\
\hline $\mathrm{HXT} / \mathrm{FIFO}$ & $10,15,20$ & 69.59 & \\
\hline $\mathrm{HXT/FIFO}$ & $15,20,25$ & 69.59 & \\
\hline LBA/FIFO & $10,15,20$ & 90.52 & \\
\hline LBA/FIFO & $15,20,25$ & 90.52 & \\
\hline FIFO & $10,15,20$ & 92.31 & \\
\hline $\mathrm{FIFO}$ & $15,20,25$ & 92.31 & \\
\hline $\mathrm{P} / \mathrm{HXT}$ & $10,15,20$ & 114.84 & \\
\hline $\mathrm{P} / \mathrm{HXT}$ & $15,20,25$ & 114.84 & \\
\hline P/FIFO & $10,15,20$ & 136.38 & \\
\hline P/FIFO & $15,20,25$ & 136.38 & \\
\hline $\mathrm{P} / \mathrm{CR}$ & $10,15,20$ & 149.8 & \\
\hline CR/FIFO & $10,15,20$ & 159.72 & \\
\hline CR/FIFO & $15,20,25$ & 166.58 & \\
\hline $\mathrm{P} / \mathrm{CR}$ & $15,20,25$ & 174.99 & \\
\hline
\end{tabular}


Table E.20.A: Two Factor ANOVA Table for Average WIP

\begin{tabular}{lrrrrrr}
\hline Source & DF & Seq SS & Adj SS & Adj MS & F & P \\
\hline DR & 6 & 7.7 & 7.7 & 1.3 & 80.4 & 0.000 \\
DDT & 1 & 0.1 & 0.1 & 0.1 & 4.9 & 0.035 \\
DR*DDT & 6 & 0.2 & 0.2 & 0.0 & 2.4 & 0.055 \\
Error & 28 & 0.4 & 0.4 & 0.0 & & \\
\hline Total & $\mathbf{4 1}$ & $\mathbf{8 . 5}$ & & & & \\
\hline
\end{tabular}

Table E.20.B: Two Factor Tukey Table for Average WIP

\begin{tabular}{|c|c|c|}
\hline $\begin{array}{c}\text { Dispatching } \\
\text { Rule }\end{array}$ & Avg. WIP & Sig. \\
\hline $\mathrm{P} / \mathrm{H} \times \mathrm{T}$ & 14.113 & \\
\hline $\mathrm{FIFO}$ & 14.21 & \\
\hline $\mathrm{HXT/FIFO}$ & 14.223 & \\
\hline LBA/FIFO & 14.243 & \\
\hline $\mathrm{P} / \mathrm{FIFO}$ & 14.257 & \\
\hline $\mathrm{P} / \mathrm{CR}$ & 14.823 & \\
\hline CR/FIFO & 15.37 & \\
\hline
\end{tabular}


Two Factor Analysis for Production Volume = 128 lots/year and Product Mix = 5-5-90

Table E.21.A: Two Factor ANOVA Table for \% On Time Delivery

\begin{tabular}{lrrrrrr}
\hline Source & DF & Seq SS & Adj SS & Adj MS & F & P \\
\hline DR & 6 & 37.4 & 37.4 & 6.2 & 147.8 & 0.000 \\
DDT & 1 & 46.9 & 46.9 & 46.9 & 1113.4 & 0.000 \\
DR*DDT & 6 & 36.4 & 36.4 & 6.1 & 143.9 & 0.000 \\
Error & 28 & 1.2 & 1.2 & 0.0 & & \\
\hline Total & $\mathbf{4 1}$ & $\mathbf{1 2 1 . 9}$ & & & & \\
\hline
\end{tabular}

Table E.21.B: Two Factor Tukey Table for \% On Time Delivery

\begin{tabular}{|c|c|c|c|}
\hline $\begin{array}{l}\text { Dispatching } \\
\text { Rule }\end{array}$ & $\begin{array}{c}\text { Due Date } \\
\text { Tightness (H,M,L) }\end{array}$ & $\begin{array}{c}\% \text { on time } \\
\text { delivery }\end{array}$ & Sig. \\
\hline CR/FIFO & $15,20,25$ & 100 & \\
\hline $\mathrm{HXT/FIFO}$ & $15,20,25$ & 100 & \\
\hline LBAJFIFO & $15,20,25$ & 100 & \\
\hline P/CR & $15,20,25$ & 100 & \\
\hline P/FIFO & $15,20,25$ & 100 & \\
\hline $\mathrm{P} / \mathrm{HXT}$ & $15,20,25$ & 100 & \\
\hline $\mathrm{FIFO}$ & $15,20,25$ & 99.913 & \\
\hline CR/FIFO & $10,15,20$ & 99.696 & \\
\hline P/CR & $10,15,20$ & 99.522 & \\
\hline $\mathrm{P} / \mathrm{HXT}$ & $10,15,20$ & 99.433 & \\
\hline P/FIFO & $10,15,20$ & 99.304 & \\
\hline FIFO & $10,15,20$ & 95.954 & \\
\hline LBA/FIFO & $10,15,20$ & 95.777 & \\
\hline $\mathrm{HXT} / \mathrm{FIFO}$ & $10,15,20$ & 95.426 & \\
\hline
\end{tabular}


Table E.22.A: Two Factor ANOVA Table for Average Cycle Time

\begin{tabular}{lrrrrrr}
\hline Source & DF & Seq SS & Adj SS & Adj MS & F & P \\
\hline DR & 6 & 44848.1 & 44848.1 & 7474.7 & 105.7 & 0.000 \\
DDT & 1 & 170.2 & 170.2 & 170.2 & 2.4 & 0.132 \\
DR*DDT & 6 & 1047.2 & 1047.2 & 174.5 & 2.5 & 0.048 \\
Error & 28 & 1979.8 & 1979.8 & 70.7 & & \\
\hline Total & $\mathbf{4 1}$ & $\mathbf{4 8 0 4 5 . 2}$ & & & & \\
\hline
\end{tabular}

Table E.22.B: Two Factor Tukey Table for Average Cycle Time

\begin{tabular}{|l|l|r|r|}
\hline $\begin{array}{c}\text { Dispatching } \\
\text { Rule }\end{array}$ & \multicolumn{1}{|c|}{$\begin{array}{c}\text { Due Date } \\
\text { Tightness }(\mathbf{H , M , L )}\end{array}$} & $\begin{array}{c}\text { Avg. Cycle } \\
\text { Time } \\
\text { (hours) }\end{array}$ & Sig. \\
\hline P/HXT & $15,20,25$ & 952.44 & \\
\hline HXT/FIFO & $10,15,20$ & 960.27 & \\
\hline HXT/FIFO & $15,20,25$ & 960.27 & 962.02 \\
\hline P/HXT & $10,15,20$ & 970.34 \\
\hline FIFO & $10,15,20$ & 970.34 \\
\hline FIFO & $15,20,25$ & 972.74 \\
\hline LBA/FIFO & $10,15,20$ & 972.74 \\
\hline LBA/FIFO & $15,20,25$ & 1010.82 \\
\hline P/CR & $10,15,20$ & 1019.31 \\
\hline P/FIFO & $10,15,20$ & 1019.31 \\
\hline P/FIFO & $15,20,25$ & 1031.53 \\
\hline P/CR & $15,20,25$ & 1036.6 \\
\hline CR/FIFO & $10,15,20$ & 1053.66 \\
\hline CR/FIFO & $15,20,25$ & \\
\hline
\end{tabular}


Table E.23.A: Two Factor ANOVA Table for Std. Dev. Of Cycle Time

\begin{tabular}{lrrrrrr}
\hline Source & DF & Seq SS & Adj SS & Adj MS & F & P \\
DR & 6 & 36380.5 & 36380.5 & 6063.4 & 213.4 & 0.000 \\
DDT & 1 & 137.9 & 137.9 & 137.9 & 4.9 & 0.036 \\
DR*DDT & 6 & 531.1 & 531.1 & 88.5 & 3.1 & 0.018 \\
Error & 28 & 795.6 & 795.6 & 28.4 & & \\
\hline Total & $\mathbf{4 1}$ & $\mathbf{3 7 8 4 5 . 1}$ & & & & \\
\hline
\end{tabular}

Table E.23.B: Two Factor Tukey Table for Std. Dev. Of Cycle Time

\begin{tabular}{|l|l|r|r|}
\hline $\begin{array}{c}\text { Dispatching } \\
\text { Rule }\end{array}$ & \multicolumn{1}{|c|}{$\begin{array}{c}\text { Due Date } \\
\text { Tightness }(\mathrm{H}, \mathrm{M}, \mathrm{L})\end{array}$} & $\begin{array}{r}\text { Std. Dev. } \\
\text { (hours) }\end{array}$ & \multicolumn{1}{|c|}{ Sig. } \\
\hline HXT/FIFO & $10,15,20$ & 66.97 & \\
\hline HXT/FIFO & $15,20,25$ & 66.97 \\
\hline P/HXT & $15,20,25$ & 79.62 & $\mid$ \\
\hline P/HXT & $10,15,20$ & 83.57 \\
\hline FIFO & $10,15,20$ & 88.37 \\
\hline FIFO & $15,20,25$ & 88.37 \\
\hline LEA/FIFO & $10,15,20$ & 92.39 \\
\hline LBA/FIFO & $15,20,25$ & 92.39 \\
\hline P/CR & $10,15,20$ & 127.16 \\
\hline CR/FIFO & $10,15,20$ & 132.25 \\
\hline P/CR & $15,20,25$ & 142.39 \\
\hline P/FIFO & $10,15,20$ & 144.96 \\
\hline P/FIFO & $15,20,25$ & 144.96 \\
\hline CR/FIFO & $15,20,25$ & 146.33 \\
\hline
\end{tabular}


Table E.24.A: Two Factor ANOVA Table for Average WIP

\begin{tabular}{lrrrrrr}
\hline Source & DF & Seq SS & Adj SS & Adj MS & F & P \\
\hline DR & 6 & 9.5 & 9.5 & 1.6 & 105.5 & 0.000 \\
DDT & 1 & 0.0 & 0.0 & 0.0 & 2.5 & 0.127 \\
DR*DDT & 6 & 0.2 & 0.2 & 0.0 & 2.5 & 0.048 \\
Error & 28 & 0.4 & 0.4 & 0.0 & & \\
\hline Total & $\mathbf{4 1}$ & $\mathbf{1 0 . 2}$ & & & & \\
\hline
\end{tabular}

Table E.24.B: Two Factor Tukey Table for Average WIP

\begin{tabular}{|l|l|r|r|}
\hline $\begin{array}{c}\text { Dispatching } \\
\text { Rule }\end{array}$ & \multicolumn{1}{|c|}{$\begin{array}{c}\text { Due Date } \\
\text { Tightness }(\mathbf{H , M , L )}\end{array}$} & Avg. WIP & Sig. \\
\hline P/HXT & $15,20,25$ & 13.927 & \\
\hline HXT/FIFO & $10,15,20$ & 14.04 & \\
\hline HXT/FIFO & $15,20,25$ & 14.04 & \\
\hline P/HXT & $10,15,20$ & 14.063 \\
\hline FIFO & $10,15,20$ & 14.187 \\
\hline FIFO & $15,20,25$ & 14.187 \\
\hline LBA/FIFO & $10,15,20$ & 14.22 \\
\hline LBA/FIFO & $15,20,25$ & 14.22 \\
\hline P/CR & $10,15,20$ & 14.773 \\
\hline P/FIFO & $10,15,20$ & 14.893 \\
\hline P/FIFO & $15,20,25$ & 14.893 \\
\hline P/CR & $15,20,25$ & 15.077 \\
\hline CR/FIFO & $10,15,20$ & 15.153 \\
\hline CR/FIFO & $15,20,25$ & 15.403 & \\
\hline
\end{tabular}




\section{Appendix F. Analysis of Dispatching Rules With Given Levels of Production Volume, Product Mix and Due Date Tightness}

The appendices in this section have ANOVA and Tukey test tables for the analysis of dispatching rules with given levels of production volume, product mix and due date tightness. Twelve fab types are analyzed and depending on whether the dispatching rule is significant, Tukey pairwise comparison tests are done to determine which rules are statistically significant from each other. The Tukey family error rate is set at 5 . The vertical lines in the significance column group the strategies that are not statistically different from each other. The levels in the fab types are listed in Table F.

Table F: Fab Types

\begin{tabular}{|c|c|c|r|}
\hline Fab Type & $\begin{array}{c}\text { Production } \\
\text { Volume } \\
\text { (lots/year) }\end{array}$ & $\begin{array}{c}\text { Due Date } \\
\text { Tightness } \\
\text { (H,M,L) }\end{array}$ & $\begin{array}{c}\text { Product } \\
\text { Mix } \\
\text { (H-M-L) }\end{array}$ \\
\hline I & 154 & $20,15,10$ & $25-25-50$ \\
\hline II & 154 & $25,20,15$ & $15-15-70$ \\
\hline III & 154 & $20,15,10$ & $5-5-90$ \\
\hline IV & 154 & $25,20,15$ & $25-25-50$ \\
\hline V & 154 & $20,15,10$ & $15-15-70$ \\
\hline VI & 154 & $25,20,15$ & $5-5-90$ \\
\hline VII & 128 & $20,15,10$ & $25-25-50$ \\
\hline VIII & 128 & $25,20,15$ & $15-15-70$ \\
\hline IX & 128 & $20,15,10$ & $5-5-90$ \\
\hline $\mathbf{X}$ & 128 & $25,20,15$ & $25-25-50$ \\
\hline $\mathbf{X I}$ & 128 & $20,15,10$ & $15-15-70$ \\
\hline $\mathbf{X I I}$ & 128 & $25,20,15$ & $5-5-90$ \\
\hline
\end{tabular}




\section{Analysis of Fab Type I}

Table F.1.1: ANOVA and Tukey Tables for $\%$ On Time Delivery

\begin{tabular}{lrrrrr}
\hline Source & DF & SS & MS & F & P \\
\hline DR & 6 & 8754.1 & 1459.0 & 700.5 & 0.000 \\
Error & 14 & 29.2 & 2.1 & & \\
\hline Total & $\mathbf{2 0}$ & $\mathbf{8 7 8 3 . 2}$ & & & \\
\hline
\end{tabular}

\begin{tabular}{|c|c|c|}
\hline Dispatching Rule & $\begin{array}{l}\% \text { on time } \\
\text { delivery }\end{array}$ & Sig. \\
\hline FIFO & 66.052 & \\
\hline LBA/FIFO & 64.61 & \\
\hline $\mathrm{HXT/FIFO}$ & 41.303 & \\
\hline P/FIFO & 39.406 & \\
\hline $\mathrm{P} / \mathrm{H} \times \mathrm{T}$ & 37.252 & \\
\hline $\mathrm{P} / \mathrm{CR}$ & 34.917 & \\
\hline CR/FIFO & 0 & \\
\hline
\end{tabular}

Table F.1.2: ANOVA and Tukey Tables for Average Cycle Time

\begin{tabular}{lrrrrr}
\hline Source & DF & SS & MS & F & P \\
\hline DR & 6 & 22797200.0 & 3799540.0 & 34.9 & 0.000 \\
Error & 14 & 1525580.0 & 108969.8 & & \\
\hline Total & $\mathbf{2 0}$ & $\mathbf{2 4 3 2 2 8 0 0 . 0}$ & & \\
\hline
\end{tabular}

\begin{tabular}{|l|r|r|}
\hline \multicolumn{1}{|c|}{ Dispatching Rule } & $\begin{array}{r}\text { Avg. Cycle } \\
\text { Time (hours) }\end{array}$ & Sig. \\
\hline FIFO & 1261.3 & \\
\hline LBA/FIFO & 1286.5 & \\
\hline HXT/FIFO & 1567.7 & \\
\hline P/HXT & 1867 & \\
\hline CR/FIFO & 2136.1 & \multicolumn{1}{|c|}{$\mid$} \\
\hline P/FIFO & 3104.3 \\
\hline P/CR & 4334.1 & \\
\hline
\end{tabular}

Table F.1.3: ANOVA and Tukey Tables for Std. Dev. Of Cycle Time

\begin{tabular}{lrrrrr}
\hline Source & DF & SS & MS & F & P \\
\hline DR & 6 & 29722600.04953770 .0 & 45.6 & 0.000 \\
Error & 14 & 1520440.0 & 108603.0 & & \\
\hline Total & $\mathbf{2 0}$ & $\mathbf{3 1 2 4 3 1 0 0 . 0}$ & & & \\
\hline
\end{tabular}

\begin{tabular}{|l|r|r|}
\hline \multicolumn{1}{|c|}{ Dispatching Rule } & \multicolumn{1}{c|}{$\begin{array}{c}\text { Std. Dev. } \\
\text { (hours) }\end{array}$} & Sig. \\
\hline HXT/FIFO & 90 & \\
\hline FIFO & 100.6 & \\
\hline LBA/FIFO & 110.5 & \\
\hline CR/FIFO & 322.8 & \\
\hline P/HXT & 903.9 & \\
\hline P/FIFO & 2132.6 & \multicolumn{1}{|c|}{} \\
\hline P/CR & 3393.5 & \\
\hline
\end{tabular}

Table F.1.4: ANOVA and Tukey Tables for Average WIP

\begin{tabular}{lrrrrr}
\hline Source & DF & SS & MS & F & P \\
\hline DR & 6 & 7240.8 & 1206.8 & 35.1 & 0.000 \\
Error & 14 & 482.0 & 34.4 & & \\
\hline Total & $\mathbf{2 0}$ & $\mathbf{7 7 2 2 . 7}$ & & & \\
\hline
\end{tabular}

\begin{tabular}{|l|r|r|}
\hline \multicolumn{1}{|c|}{ Dispatching Rule } & Avg. WIP & Sig. \\
\hline FIFO & 22.127 & \\
\hline LBA/FIFO & 22.57 & \\
\hline HXT/FIFO & 27.5 & \\
\hline P/HXT & 32.75 & \\
\hline CR/FIFO & 37.477 & \multirow{2}{|}{$\mid$} \\
\hline P/FIFO & 54.357 & \\
\hline P/CR & 77.073 & \\
\hline
\end{tabular}




\section{Analysis of Fab Type II}

Table F.2.1: ANOVA and Tukey Tables for $\%$ On Time Delivery

\begin{tabular}{lrrrrr}
\hline Source & DF & SS & MS & F & P \\
\hline DR & 6 & 11375.5 & 1895.9 & 2712.5 & 0.000 \\
Error & 14 & 9.8 & 0.7 & & \\
\hline Total & $\mathbf{2 0}$ & $\mathbf{1 1 3 8 5 . 2}$ & & & \\
\hline
\end{tabular}

\begin{tabular}{|c|c|c|}
\hline $\begin{array}{c}\text { Dispatching } \\
\text { Rule }\end{array}$ & $\begin{array}{l}\% \text { on time } \\
\text { delivery }\end{array}$ & Sig. \\
\hline CR/FIFO & 100 & \\
\hline P/FIFO & 99.964 & \\
\hline $\mathrm{P} / \mathrm{H} \times \mathrm{T}$ & 99.927 & \\
\hline FIFO & 91.73 & \\
\hline LBA/FIFO & 91.379 & \\
\hline HXT/FIFO & 86.585 & \\
\hline $\mathrm{P} / \mathrm{CR}$ & 29.914 & \\
\hline
\end{tabular}

Table F.2.2: ANOVA and Tukey Tables for Average Cycle Time

\begin{tabular}{lrrrrr}
\hline Source & DF & SS & MS & F & P \\
\hline DR & 6 & 7740730.01290120 .0 & 498.9 & 0.000 \\
Error & 14 & 36201.4 & 2585.8 & & \\
\hline Total & $\mathbf{2 0}$ & $\mathbf{7 7 7 6 9 3 0 . 0}$ & & & \\
\hline
\end{tabular}

\begin{tabular}{|l|r|r|}
\hline \multicolumn{1}{|c|}{$\begin{array}{c}\text { Dispatching } \\
\text { Rule }\end{array}$} & $\begin{array}{c}\text { Avg. Cycle } \\
\text { Time (hours) }\end{array}$ & Sig. \\
\hline FIFO & 1247.7 & \\
\hline LBA/FIFO & 1276.1 & \\
\hline HXT/FIFO & 1321 & \\
\hline P/FIFO & 1369.5 & \multicolumn{1}{|l}{$\mid$} \\
\hline P/HXT & 1520.8 & \multicolumn{1}{|l}{$\mid$} \\
\hline CR/FIFO & 1572.4 & \\
\hline P/CR & 3089.6 & \\
\hline
\end{tabular}

Table F.2.3: ANOVA and Tukey Tables for Std. Dev. Of Cycle Time

\begin{tabular}{lrrrrr}
\hline Source & DF & SS & MS & F & P \\
\hline DR & 6 & 3782620.0630437 .0 & 481.8 & 0.000 \\
Error & 14 & 18319.7 & 1308.6 & & \\
\hline Total & $\mathbf{2 0}$ & $\mathbf{3 8 0 0 9 4 0 . 0}$ & & & \\
\hline
\end{tabular}

\begin{tabular}{|c|c|c|}
\hline $\begin{array}{c}\text { Dispatching } \\
\text { Rule }\end{array}$ & $\begin{array}{c}\text { Std. Dev. } \\
\text { (hours) }\end{array}$ & Sig. \\
\hline HXT/FIFO & 63.6 & \\
\hline FIFO & 95.5 & \\
\hline LBA/FIFO & 115.6 & \\
\hline CR/FIFO & 302.7 & \\
\hline P/FIFO & 319.7 & \\
\hline $\mathrm{P} / \mathrm{HXT}$ & 353.4 & \\
\hline $\mathrm{P} / \mathrm{CR}$ & 1379.9 & \\
\hline
\end{tabular}

Table F.2.4: ANOVA and Tukey Tables for Average WIP

\begin{tabular}{lrrrrr}
\hline Source & DF & SS & MS & F & P \\
\hline DR & 6 & 2376.5 & 396.1 & 467.6 & 0.000 \\
Error & 14 & 11.9 & 0.8 & & \\
\hline Total & $\mathbf{2 0}$ & $\mathbf{2 3 8 8 . 3}$ & & & \\
\hline
\end{tabular}

\begin{tabular}{|l|r|r|}
\hline \multicolumn{1}{|c|}{$\begin{array}{c}\text { Dispatching } \\
\text { Rule }\end{array}$} & Avg. WIP & Sig. \\
\hline FIFO & 21.89 & \\
\hline LBA/FIFO & 22.387 & \\
\hline HXT/FIFO & 23.177 & \\
\hline P/FIFO & 24.027 & \multicolumn{1}{|l}{$\mid$} \\
\hline P/HXT & 26.68 & \multicolumn{1}{|l}{$\mid$} \\
\hline CR/FIFO & 27.577 & \\
\hline P/CR & 54.163 & \\
\hline
\end{tabular}




\section{Analysis of Fab Type III}

Table F.3.1: ANOVA and Tukey Tables for \% On Time Delivery

\begin{tabular}{lrrcrr}
\hline Source & DF & SS & MS & F & P \\
\hline DR & 6 & 19452.5 & 3242.113345 .1 & 0.000 \\
Error & 14 & 3.4 & 0.2 & & \\
\hline Total & $\mathbf{2 0}$ & $\mathbf{1 9 4 5 5 . 9}$ & & & \\
\hline
\end{tabular}

\begin{tabular}{|c|c|c|}
\hline $\begin{array}{c}\text { Dispatching } \\
\text { Rule }\end{array}$ & $\begin{array}{l}\% \text { on time } \\
\text { delivery }\end{array}$ & Sig. \\
\hline P/FIFO & 98.517 & \\
\hline $\mathrm{P} / \mathrm{HXT}$ & 97.865 & \\
\hline CR/FIFO & 96.52 & \\
\hline FIFO & 92.09 & \\
\hline LBA/FIFO & 91.881 & \\
\hline $\mathrm{HXT} / \mathrm{FIFO}$ & 90.65 & \\
\hline P/CR & 8.007 & \\
\hline
\end{tabular}

Table F.3.2: ANOVA and Tukey Tables for Average Cycle Time

\begin{tabular}{lrcrrr}
\hline Source & DF & SS & MS & F & P \\
\hline DR & 6 & 3501080.0583513 .0 & 1016.8 & 0.000 \\
Error & 14 & 8033.9 & 573.8 & & \\
\hline Total & $\mathbf{2 0}$ & $\mathbf{3 5 0 9 1 1 0 . 0}$ & & & \\
\hline
\end{tabular}

\begin{tabular}{|c|c|c|}
\hline $\begin{array}{c}\text { Dispatching } \\
\text { Rule }\end{array}$ & $\begin{array}{l}\text { Avg. Cycle } \\
\text { Time (hours) }\end{array}$ & Sig. \\
\hline FIFO & 1255.9 & \\
\hline $\mathrm{P} / \mathrm{HXT}$ & 1281.7 & \\
\hline P/FIFO & 1283.3 & \\
\hline $\mathrm{HXT} / \mathrm{FIFO}$ & 1285.5 & \\
\hline LBA/FIFO & 1306.5 & \\
\hline $\mathrm{CR} / \mathrm{FIFO}$ & 1441 & \\
\hline $\mathrm{P} / \mathrm{CR}$ & 2464.7 & \\
\hline
\end{tabular}

Table F.3.3: ANOVA and Tukey Tables for Std. Dev. Of Cycle Time

\begin{tabular}{lrrrrr}
\hline Source & DF & SS & MS & F & P \\
\hline DR & \multicolumn{6}{c}{6429687.671614 .6} & 752.2 & 0.000 \\
Error & 14 & 1332.8 & 95.2 & & \\
\hline Total & $\mathbf{2 0 4 3 1 0 2 0 . 4}$ & & & \\
\hline
\end{tabular}

\begin{tabular}{|c|c|c|}
\hline $\begin{array}{c}\text { Dispatching } \\
\text { Rule }\end{array}$ & $\begin{array}{c}\text { Std. Dev. } \\
\text { (hours) }\end{array}$ & Sig. \\
\hline $\mathrm{HXT} / \mathrm{FIFO}$ & 67.02 & \\
\hline FIFO & 103.51 & \\
\hline LBA/FIFO & 121.81 & \\
\hline $\mathrm{P} / \mathrm{HXT}$ & 143.01 & \\
\hline P/FIFO & 169.24 & \\
\hline CR/FIFO & 177.09 & \\
\hline $\mathrm{P} / \mathrm{CR}$ & 526.51 & \\
\hline
\end{tabular}

Table F.3.4: ANOVA and Tukey Tables for Average WIP

\begin{tabular}{lrrrrr}
\hline Source & DF & SS & MS & F & P \\
\hline DR & 6 & 1077.7 & 179.6 & 1026.0 & 0.000 \\
Error & 14 & 2.5 & 0.2 & & \\
\hline Total & $\mathbf{2 0}$ & $\mathbf{1 0 8 0 . 2}$ & & & \\
\hline
\end{tabular}

\begin{tabular}{|c|c|c|}
\hline $\begin{array}{c}\text { Dispatching } \\
\text { Rule }\end{array}$ & Avg. WIP & Sig. \\
\hline FIFO & 22.033 & \\
\hline $\mathrm{P} / \mathrm{HXT}$ & 22.487 & \\
\hline P/FIFO & 22.51 & \\
\hline HXT/FIFO & 22.55 & \\
\hline LBA/FIFO & 22.92 & \\
\hline $\mathrm{CR} / \mathrm{FIFO}$ & 25.283 & \\
\hline $\mathrm{P} / \mathrm{CR}$ & 43.24 & \\
\hline
\end{tabular}




\section{Analysis of Fab Type IV}

Table F.4.1: ANOVA and Tukey Tables for $\%$ On Time Delivery

\begin{tabular}{lrrrrr}
\hline Source & DF & SS & MS & F & P \\
\hline DR & 6 & 15729.2 & 2621.5 & 2916.0 & 0.000 \\
Error & 14 & 12.6 & 0.9 & & \\
\hline Total & $\mathbf{2 0}$ & $\mathbf{1 5 7 4 1 . 7}$ & & & \\
\hline
\end{tabular}

\begin{tabular}{|c|c|c|}
\hline $\begin{array}{c}\text { Dispatching } \\
\text { Rule }\end{array}$ & $\begin{array}{l}\% \text { on time } \\
\text { delivery }\end{array}$ & Sig. \\
\hline FIFO & 86.343 & \\
\hline LBA/FIFO & 85.205 & \\
\hline $\mathrm{HXT} / \mathrm{FIFO}$ & 71.125 & \\
\hline P/CR & 50.311 & \\
\hline $\mathrm{P} / \mathrm{HXT}$ & 50.109 & \\
\hline P/FIFO & 49.856 & \\
\hline CR/FIFO & 0 & \\
\hline
\end{tabular}

Table F.4.2: ANOVA and Tukey Tables for Average Cycle Time

\begin{tabular}{lrrrrr}
\hline Source & DF & SS & MS & F & P \\
\hline DR & 614377800.02396300 .0 & 77.4 & 0.000 \\
Error & 14 & 433546.7 & 30967.6 & & \\
\hline Total & $\mathbf{2 0 1 4 8 1 1 3 0 0 . 0}$ & & & \\
\hline
\end{tabular}

\begin{tabular}{|c|c|c|}
\hline $\begin{array}{c}\text { Dispatching } \\
\text { Rule }\end{array}$ & \begin{tabular}{|c|} 
Avg. Cycle \\
Time (hours)
\end{tabular} & Sig. \\
\hline FIFO & 1261.3 & \\
\hline LBA/FIFO & 1286.5 & \\
\hline HXT/FIFO & 1567.7 & \\
\hline $\mathrm{P} / \mathrm{HXT}$ & 1867 & \\
\hline CR/FIFO & 2556.4 & T \\
\hline P/FIFO & 3104.3 & \\
\hline $\mathrm{P} / \mathrm{CR}$ & 3477.7 & \\
\hline
\end{tabular}

Table F.4.3: ANOVA and Tukey Tables for Std. Dev. Of Cycle Time

\begin{tabular}{lrrrrr}
\hline Source & DF & SS & MS & F & P \\
\hline DR & 618632800.03105470 .0 & 93.9 & 0.000 \\
Error & 14 & 463046.5 & 33074.7 & & \\
\hline Total & $\mathbf{2 0 1 9 0 9 5 8 0 0 . 0}$ & & & \\
\hline
\end{tabular}

\begin{tabular}{|l|r|r|}
\hline \multicolumn{1}{|c|}{$\begin{array}{c}\text { Dispatching } \\
\text { Rule }\end{array}$} & $\begin{array}{c}\text { Std. Dev. } \\
\text { (hours) }\end{array}$ & Sig. \\
\hline HXT/FIFO & 90 & \\
\hline FIFO & 100.6 & \\
\hline LBA/FIFO & 110.5 & \\
\hline CR/FIFO & 357.3 & \\
\hline P/HXT & 903.9 & \multicolumn{1}{|c|}{$\mid$} \\
\hline P/FIFO & 2132.6 & \multicolumn{1}{|c|}{$\mid$} \\
\hline P/CR & 2475.1 & \\
\hline
\end{tabular}

Table F.4.4: ANOVA and Tukey Tables for Average WIP

\begin{tabular}{lrrrrr}
\hline Source & DF & SS & MS & F & P \\
\hline DR & 6 & 4453.2 & 742.2 & 75.6 & 0.000 \\
Error & 14 & 137.4 & 9.8 & & \\
\hline Total & $\mathbf{2 0}$ & $\mathbf{4 5 9 0 . 6}$ & & & \\
\hline
\end{tabular}

\begin{tabular}{|c|c|c|}
\hline $\begin{array}{c}\text { Dispatching } \\
\text { Rule }\end{array}$ & Avg. WIP & Sig. \\
\hline FIFO & 22.127 & \\
\hline LBA/FIFO & 22.57 & \\
\hline HXT/FIFO & 27.5 & \\
\hline $\mathrm{P} / \mathrm{HXT}$ & 32.75 & \\
\hline CR/FIFO & 44.85 & 1 \\
\hline P/FIFO & 54.357 & \\
\hline $\mathrm{P} / \mathrm{CR}$ & 61.283 & \\
\hline
\end{tabular}




\section{Analysis of Fab Type V}

Table F.5.1: ANOVA and Tukey Tables for \% On Time Delivery

\begin{tabular}{lrrrrr}
\hline Source & DF & SS & MS & F & P \\
\hline DR & 6 & 21727.8 & 3621.3 & 522.9 & 0.000 \\
Error & 14 & 97.0 & 6.9 & & \\
\hline Total & $\mathbf{2 0}$ & $\mathbf{2 1 8 2 4 . 8}$ & & & \\
\hline
\end{tabular}

\begin{tabular}{|c|c|c|}
\hline $\begin{array}{c}\text { Dispatching } \\
\text { Rule }\end{array}$ & $\begin{array}{c}\% \text { on time } \\
\text { delivery }\end{array}$ & Sig. \\
\hline LBA/FIFO & 91.379 & \\
\hline FIFO & 79.615 & \\
\hline P/FIFO & 79.524 & \\
\hline $\mathrm{HXT} / \mathrm{FIFO}$ & 72.011 & | \\
\hline $\mathrm{P} / \mathrm{H} \mathrm{TT}$ & 38.303 & \\
\hline $\mathrm{P} / \mathrm{CR}$ & 21.539 & \\
\hline CR/FIFO & 0 & \\
\hline
\end{tabular}

Table F.5.2: ANOVA and Tukey Tables for Average Cycle Time

\begin{tabular}{lrrrrr}
\hline Source & DF & SS & MS & F & P \\
\hline DR & 66130380.01021730 .0 & 255.6 & 0.000 \\
Error & 14 & 55971.5 & 3998.0 & & \\
\hline Total & $\mathbf{2 0 6 1 8 6 3 6 0 . 0}$ & & & \\
\hline
\end{tabular}

\begin{tabular}{|c|c|c|}
\hline $\begin{array}{c}\text { Dispatching } \\
\text { Rule }\end{array}$ & $\begin{array}{l}\text { Avg. Cycle } \\
\text { Time (hours) }\end{array}$ & Sig. \\
\hline FIFO & 1247.7 & \\
\hline LBA/FIFO & 1276.1 & \\
\hline HXT/FIFO & 1321 & \\
\hline P/FIFO & 1369.5 & \\
\hline $\mathrm{P} / \mathrm{H} \times \mathrm{T}$ & 1520.8 & \\
\hline CR/FIFO & 2231.1 & \\
\hline $\mathrm{P} / \mathrm{CR}$ & 2747.4 & \\
\hline
\end{tabular}

Table F.5.3: ANOVA and Tukey Tables for Std. Dev. Of Cycle Time

\begin{tabular}{lrrrrr}
\hline Source & DF & SS & MS & F & P \\
\hline DR & 62601500.0433583 .8 & 358.7 & 0.000 \\
Error & 14 & 16922.7 & 1208.8 & & \\
\hline Total & $\mathbf{2 0 2 6 1 8 4 3 0 . 0}$ & & & \\
\hline
\end{tabular}

\begin{tabular}{|l|r|l|}
\hline $\begin{array}{c}\text { Dispatching } \\
\text { Rule }\end{array}$ & $\begin{array}{c}\text { Std. Dev. } \\
\text { (hours) }\end{array}$ & Sig. \\
\hline HXT/FIFO & 63.6 & \\
\hline FIFO & 95.5 & \\
\hline LBA/FIFO & 115.6 & \multicolumn{1}{|c|}{$\mid$} \\
\hline CR/FIFO & 294 & \\
\hline P/FIFO & 319.7 & \\
\hline P/HXT & 353.4 & \multicolumn{1}{|l}{$\mid$} \\
\hline P/CR & 1163.4 & \\
\hline
\end{tabular}

Table F.5.4: ANOVA and Tukey Tables for Average WIP

\begin{tabular}{lrrrrr}
\hline Source & DF & SS & MS & F & P \\
\hline DR & 6 & 1890.8 & 315.1 & 259.9 & 0.000 \\
Error & 14 & 17.0 & 1.2 & & \\
\hline Total & $\mathbf{2 0}$ & $\mathbf{1 9 0 7 . 8}$ & & & \\
\hline
\end{tabular}

\begin{tabular}{|c|c|c|}
\hline $\begin{array}{c}\text { Dispatching } \\
\text { Rule }\end{array}$ & Avg. WIP & Sig. \\
\hline FIFO & 21.89 & \\
\hline LBAJFIFO & 22.387 & \\
\hline $\mathrm{HXT} / \mathrm{FIFO}$ & 23.177 & \\
\hline $\mathrm{P} / \mathrm{FIFO}$ & 24.027 & \\
\hline $\mathrm{P} / \mathrm{H} \times \mathrm{T}$ & 26.68 & \\
\hline CR/FIFO & 39.14 & | \\
\hline $\mathrm{P} / \mathrm{CR}$ & 48.237 & \\
\hline
\end{tabular}




\section{Analysis of Fab Type VI}

Table F.6.1: ANOVA and Tukey Tables for $\%$ On Time Delivery

\begin{tabular}{lrrcrr}
\hline Source & DF & SS & MS & F & P \\
\hline DR & 6 & 20037.0 & 3339.546271 .3 & 0.000 \\
Error & 14 & 1.0 & 0.1 & \\
\hline Total & $\mathbf{2 0}$ & $\mathbf{2 0 0 3 8 . 1}$ & & & \\
\hline
\end{tabular}

\begin{tabular}{|c|c|c|}
\hline $\begin{array}{c}\text { Dispatching } \\
\text { Rule }\end{array}$ & $\begin{array}{c}\% \text { on time } \\
\text { delivery }\end{array}$ & Sig. \\
\hline $\mathrm{CR} / \mathrm{FIFO}$ & 100 & \\
\hline $\mathrm{P} / \mathrm{FIFO}$ & 100 & \\
\hline $\mathrm{P} / \mathrm{HXT}$ & 100 & \\
\hline LBAJFIFO & 96.629 & \\
\hline FIFO & 96.516 & \\
\hline $\mathrm{HXT} / \mathrm{FIFO}$ & 95.615 & \\
\hline $\mathrm{P} / \mathrm{CR}$ & 9.997 & \\
\hline
\end{tabular}

Table F.6.2: ANOVA and Tukey Tables for Average Cycle Time

\begin{tabular}{lrrrrr}
\hline Source & DF & SS & MS & F & P \\
\hline DR & \multicolumn{6}{c}{65567710.0927952 .5} & 3365.2 & 0.000 \\
Error & 14 & 3860.5 & 275.8 & & \\
\hline Total & $\mathbf{2 0 5 5 7 1 5 8 0 . 0}$ & & & \\
\hline
\end{tabular}

\begin{tabular}{|c|c|c|}
\hline $\begin{array}{c}\text { Dispatching } \\
\text { Rule }\end{array}$ & $\begin{array}{c}\text { Avg. Cycle } \\
\text { Time } \\
\text { (hours) }\end{array}$ & Sig. \\
\hline FIFO & 1255.9 & \\
\hline $\mathrm{P} / \mathrm{HXT}$ & 1281.7 & \\
\hline P/FIFO & 1283.3 & \\
\hline $\mathrm{HXT} / \mathrm{FIFO}$ & 1285.5 & \\
\hline LBA/FIFO & 1306.5 & \\
\hline CR/FIFO & 1560.8 & \\
\hline $\mathrm{P} / \mathrm{CR}$ & 2774.1 & \\
\hline
\end{tabular}

Table F.6.3: ANOVA and Tukey Tables for Std. Dev. Of Cycle Time

\begin{tabular}{lrrrrr}
\hline Source & DF & SS & MS & F & P \\
\hline DR & 6647326.2107887 .7 & 2035.7 & 0.000 \\
Error & 14 & 742.0 & 53.0 & & \\
\hline Total & $\mathbf{2 0 6 4 8 0 6 8 . 2}$ & & & \\
\hline
\end{tabular}

\begin{tabular}{|c|c|c|}
\hline $\begin{array}{c}\text { Dispatching } \\
\text { Rule }\end{array}$ & $\begin{array}{c}\text { Std. Dev. } \\
\text { (hours) }\end{array}$ & Sig. \\
\hline HXT/FIFO & 67.02 & \\
\hline FIFO & 103.51 & \\
\hline LBA/FIFO & 121.81 & \\
\hline $\mathrm{P} / \mathrm{HXT}$ & 143.01 & \\
\hline P/FIFO & 169.24 & $\mid$ \\
\hline CR/FIFO & 207.74 & \\
\hline $\mathrm{P} / \mathrm{CR}$ & 622.6 & \\
\hline
\end{tabular}

Table F.6.4: ANOVA and Tukey Tables for Average WIP

\begin{tabular}{lrrrrr}
\hline Source & DF & SS & MS & F & P \\
\hline DR & 6 & 1713.2 & 285.5 & 3469.8 & 0.000 \\
Error & 14 & 1.2 & 0.1 & & \\
\hline Total & $\mathbf{2 0}$ & $\mathbf{1 7 1 4 . 3}$ & & & \\
\hline
\end{tabular}

\begin{tabular}{|c|c|c|}
\hline $\begin{array}{c}\text { Dispatching } \\
\text { Rule }\end{array}$ & Avg. WIP & Sig. \\
\hline FIFO & 22.033 & \\
\hline $\mathrm{P} / \mathrm{HXT}$ & 22.487 & \\
\hline P/FIFO & 22.51 & \\
\hline $\mathrm{HXT} / \mathrm{FIFO}$ & 22.55 & \\
\hline LBA/FIFO & 22.92 & \\
\hline CR/FIFO & 27.383 & | \\
\hline $\mathrm{P} / \mathrm{CR}$ & 48.663 & \\
\hline
\end{tabular}




\section{Analysis of Fab Type VII}

Table F.7.1: ANOVA and Tukey Tables for \% On Time Delivery

\begin{tabular}{lrrrrr}
\hline Source & DF & SS & MS & F & P \\
\hline DR & 6 & 2057.6 & 342.9 & 1011.4 & 0.000 \\
Error & 14 & 4.7 & 0.3 & & \\
\hline Total & $\mathbf{2 0}$ & $\mathbf{2 0 6 2 . 3}$ & & & \\
\hline
\end{tabular}

\begin{tabular}{|c|c|c|}
\hline $\begin{array}{c}\text { Dispatching } \\
\text { Rule }\end{array}$ & $\begin{array}{c}\% \text { on time } \\
\text { delivery }\end{array}$ & Sig. \\
\hline $\mathrm{P} / \mathrm{FIFO}$ & 98.344 & \\
\hline $\mathrm{P} / \mathrm{HXT}$ & 97.567 & \\
\hline CR/FIFO & 97.52 & \\
\hline $\mathrm{P} / \mathrm{CR}$ & 97.432 & \\
\hline FIFO & 79.251 & \\
\hline LBAJFIFO & 77.947 & \\
\hline $\mathrm{HXT} / \mathrm{FIFO}$ & 76.175 & \\
\hline
\end{tabular}

Table F.7.2: ANOVA and Tukey Tables for Average Cycle Time

\begin{tabular}{lrrrrr}
\hline Source & DF & SS & MS & F & P \\
\hline DR & 614475.8 & 2412.6 & 38.9 & 0.000 \\
Error & 14 & 867.8 & 62.0 & & \\
\hline Total & $\mathbf{2 0} 15343.6$ & & & \\
\hline
\end{tabular}

\begin{tabular}{|c|c|c|}
\hline $\begin{array}{c}\text { Dispatching } \\
\text { Rule }\end{array}$ & $\begin{array}{c}\text { Avg. Cycle } \\
\text { Time } \\
\text { (hours) }\end{array}$ & Sig. \\
\hline $\begin{array}{l}\text { P/FIFO } \\
\end{array}$ & 979.09 & \\
\hline $\mathrm{P} / \mathrm{HXT}$ & 989.56 & \\
\hline $\mathrm{FIFO}$ & 995.36 & \\
\hline $\mathrm{P} / \mathrm{CR}$ & 1009.98 & \\
\hline $\mathrm{HXT} / \mathrm{FIFO}$ & 1024.62 & \\
\hline LBA/FIFO & 1049.12 & \\
\hline CR/FIFO & 1050.05 & \\
\hline
\end{tabular}

Table F.7.3: ANOVA and Tukey Tables for Std. Dev. Of Cycle Time

\begin{tabular}{lrrrrr}
\hline Source & DF & SS & MS & F & P \\
\hline DR & 636507.4 & 6084.6 & 319.5 & 0.000 \\
Error & 14 & 266.6 & 19.0 & & \\
\hline Total & $\mathbf{2 0 3 6 7 7 4 . 0}$ & & & \\
\hline
\end{tabular}

\begin{tabular}{|c|c|c|}
\hline $\begin{array}{c}\text { Dispatching } \\
\text { Rule }\end{array}$ & $\begin{array}{c}\text { Std. Dev. } \\
\text { (hours) }\end{array}$ & Sig. \\
\hline HXT/FIFO & 71.91 & \\
\hline FIFO & 97.99 & \\
\hline LBA/FIFO & 116.03 & \\
\hline $\mathrm{P} / \mathrm{HXT}$ & 156.28 & \\
\hline P/FIFO & 160.25 & \\
\hline $\mathrm{P} / \mathrm{CR}$ & 177.32 & \\
\hline CR/FIFO & 195.93 & \\
\hline
\end{tabular}

Table F.7.4: ANOVA and Tukey Tables for Average WIP

\begin{tabular}{lrrrrr}
\hline Source & DF & SS & MS & F & P \\
\hline DR & 6 & 3.1 & 0.5 & 39.3 & 0.000 \\
Error & 14 & 0.2 & 0.0 & & \\
\hline Total & $\mathbf{2 0}$ & $\mathbf{3 . 3}$ & & & \\
\hline
\end{tabular}

\begin{tabular}{|l|r||r|}
\hline $\begin{array}{c}\text { Dispatching } \\
\text { Rule }\end{array}$ & Avg. WIP & Sig. \\
\hline P/FIFO & 14.317 & \\
\hline P/HXT & 14.47 & \\
\hline FIFO & 14.557 & \multicolumn{1}{|c|}{$\mid$} \\
\hline P/CR & 14.767 & \\
\hline HXT/FIFO & 14.98 & \multicolumn{1}{|l}{$\mid$} \\
\hline LBA/FIFO & 15.34 \\
\hline CR/FIFO & 15.353 & \\
\hline
\end{tabular}




\section{Analysis of Fab Type VIII}

Table F.8.1: ANOVA and Tukey Tables for $\%$ On Time Delivery

\begin{tabular}{lrrrrr}
\hline Source & DF & SS & MS & F & P \\
\hline DR & 6 & 0.3 & 0.1 & 4.1 & 0.014 \\
Error & 14 & 0.2 & 0.0 & & \\
\hline Total & $\mathbf{2 0}$ & $\mathbf{0 . 5}$ & & & \\
\hline
\end{tabular}

\begin{tabular}{|l|r||r|}
\hline $\begin{array}{c}\text { Dispatching } \\
\text { Rule }\end{array}$ & $\begin{array}{r}\% \text { on time } \\
\text { delivery }\end{array}$ & Sig. \\
\hline CR/FIFO & 100 & \\
\hline HXT/FIFO & 100 & \\
\hline P/CR & 100 & \\
\hline P/FIFO & 100 & \\
\hline P/HXT & 100 & \multicolumn{1}{|c|}{$\mid$} \\
\hline LBA/FIFO & 99.826 \\
\hline FIFO & 99.652 & \\
\hline
\end{tabular}

Table F.8.2: ANOVA and Tukey Tables for Average Cycle Time

\begin{tabular}{lrrrrr}
\hline Source & DF & SS & MS & F & P \\
\hline DR & 623150.3 & 3858.4 & 57.5 & 0.000 \\
Error & 14 & 939.6 & 67.1 & & \\
\hline Total & $\mathbf{2 0 2 4 0 8 9 . 9}$ & & & \\
\hline
\end{tabular}

\begin{tabular}{|l|r|r|}
\hline $\begin{array}{c}\text { Dispatching } \\
\text { Rule }\end{array}$ & $\begin{array}{c}\text { Avg. Cycle } \\
\text { Time (hours) }\end{array}$ & Sig. \\
\hline P/HXT & 965.37 & \\
\hline FIFO & 972.18 & \\
\hline HXT/FIFO & 972.8 & \\
\hline LBA/FIFO & 974.46 & \\
\hline P/FIFO & 975.18 & \multicolumn{1}{|l}{$\mid$} \\
\hline P/CR & 1027.72 & \\
\hline CR/FIFO & 1058.18 & \\
\hline
\end{tabular}

Table F.8.3: ANOVA and Tukey Tables for Std. Dev. Of Cycle Time

\begin{tabular}{lrrrrr}
\hline Source & DF & SS & MS & F & P \\
\hline DR & 628984.2 & 4830.7 & 255.8 & 0.000 \\
Error & 14 & 264.4 & 18.9 & & \\
\hline Total & $\mathbf{2 0} 29248.6$ & & & \\
\hline
\end{tabular}

\begin{tabular}{|c|c|c|}
\hline $\begin{array}{c}\text { Dispatching } \\
\text { Rule }\end{array}$ & $\begin{array}{l}\text { Std. Dev. } \\
\text { (hours) }\end{array}$ & Sig. \\
\hline $\mathrm{HXT} / \mathrm{FIFO}$ & 69.59 & \\
\hline LBA/FIFO & 90.52 & \\
\hline FIFO & 92.31 & \\
\hline $\mathrm{P} / \mathrm{HXT}$ & 114.84 & \\
\hline P/FIFO & 136.38 & \\
\hline CR/FIFO & 166.58 & \\
\hline $\mathrm{P} / \mathrm{CR}$ & 174.99 & \\
\hline
\end{tabular}

Table F.8.4: ANOVA and Tukey Tables for Average WIP

\begin{tabular}{lrrrrr}
\hline Source & DF & SS & MS & F & P \\
\hline DR & 6 & 5.0 & 0.8 & 56.9 & 0.000 \\
Error & 14 & 0.2 & 0.0 & & \\
\hline Total & $\mathbf{2 0}$ & $\mathbf{5 . 2}$ & & & \\
\hline
\end{tabular}

\begin{tabular}{|l|r||c|}
\hline $\begin{array}{c}\text { Dispatching } \\
\text { Rule }\end{array}$ & Avg. WIP & Sig. \\
\hline P/HXT & 14.113 & \\
\hline FIFO & 14.21 & \\
\hline HXT/FIFO & 14.223 & \\
\hline LBA/FIFO & 14.243 & \multicolumn{1}{|c|}{$\mid$} \\
\hline P/FIFO & 14.257 & \multicolumn{1}{|c|}{$\mid$} \\
\hline P/CR & 15.027 & \\
\hline CR/FIFO & 15.47 & \\
\hline
\end{tabular}




\section{Analysis of Fab Type IX}

Table F.9.1: ANOVA and Tukey Tables for $\%$ On Time Delivery

\begin{tabular}{lrrrrr}
\hline Source & DF & SS & MS & F & P \\
\hline DR & 6 & 73.8 & 12.3 & 147.2 & 0.000 \\
Error & 14 & 1.2 & 0.1 & & \\
\hline Total & $\mathbf{2 0}$ & $\mathbf{7 4 . 9}$ & & & \\
\hline
\end{tabular}

\begin{tabular}{|l|r|r|}
\hline $\begin{array}{c}\text { Dispatching } \\
\text { Rule }\end{array}$ & $\begin{array}{r}\text { \% on time } \\
\text { delivery }\end{array}$ & Sig. \\
\hline CR/FIFO & 99.696 & \\
\hline P/CR & 99.522 & \\
\hline P/HXT & 99.433 & \\
\hline P/FIFO & 99.304 & \multicolumn{1}{|c|}{$\mid$} \\
\hline FIFO & 95.954 & \\
\hline LBA/FIFO & 95.777 & \\
\hline HXT/FIFO & 95.426 & \\
\hline
\end{tabular}

Table F.9.2: ANOVA and Tukey Tables for Average Cycle Time

\begin{tabular}{lrrrrr}
\hline Source & DF & SS & MS & F & P \\
\hline DR & 617443.9 & 2907.3 & 53.1 & 0.000 \\
Error & 14 & 766.9 & 54.8 & & \\
\hline Total & $\mathbf{2 0 1 8 2 1 0 . 8}$ & & & \\
\hline
\end{tabular}

\begin{tabular}{|l|r|r|}
\hline $\begin{array}{c}\text { Dispatching } \\
\text { Rule }\end{array}$ & $\begin{array}{r}\text { Avg. Cycle } \\
\text { Time (hours) }\end{array}$ & Sig. \\
\hline HXT/FIFO & 960.27 & \\
\hline P/HXT & 962.02 & \\
\hline FIFO & 970.34 & \\
\hline LBA/FIFO & 972.74 & \multicolumn{1}{|c|}{$\mid$} \\
\hline P/CR & 1010.82 \\
\hline P/FIFO & 1019.31 \\
\hline CR/FIFO & 1036.6 & \\
\hline
\end{tabular}

Table F.9.3: ANOVA and Tukey Tables for Std. Dev. Of Cycle Time

\begin{tabular}{lrrrrr}
\hline Source & DF & SS & MS & F & P \\
\hline DR & 615514.2 & 2585.7 & 95.5 & 0.000 \\
Error & 14 & 379.2 & 27.1 & & \\
\hline Total & $\mathbf{2 0 1 5 8 9 3 . 4}$ & & & \\
\hline
\end{tabular}

\begin{tabular}{|c|c|c|}
\hline $\begin{array}{c}\text { Dispatching } \\
\text { Rule }\end{array}$ & $\begin{array}{l}\text { Std. Dev. } \\
\text { (hours) }\end{array}$ & Sig. \\
\hline $\mathrm{HXT} / \mathrm{FIFO}$ & 66.97 & \\
\hline $\mathrm{P} / \mathrm{H} \times \mathrm{T}$ & 83.57 & \\
\hline FIFO & 88.37 & \\
\hline LBA/FIFO & 92.39 & \\
\hline $\mathrm{P} / \mathrm{CR}$ & 127.16 & \\
\hline CR/FIFO & 132.25 & \\
\hline $\mathrm{P} / \mathrm{FIFO}$ & 144.96 & \\
\hline
\end{tabular}

Table F.9.4: ANOVA and Tukey Tables for Average WIP

\begin{tabular}{lrrrrr}
\hline Source & DF & SS & MS & F & P \\
\hline DR & 6 & 3.7 & 0.6 & 50.9 & 0.000 \\
Error & 14 & 0.2 & 0.0 & & \\
\hline Total & $\mathbf{2 0}$ & $\mathbf{3 . 9}$ & & & \\
\hline
\end{tabular}

\begin{tabular}{|l|r|c|}
\hline $\begin{array}{c}\text { Dispatching } \\
\text { Rule }\end{array}$ & Avg. WIP & Sig. \\
\hline HXT/FIFO & 14.04 & \\
\hline P/HXT & 14.063 & \\
\hline FIFO & 14.187 & \\
\hline LBA/FIFO & 14.22 & \multicolumn{1}{|c|}{$\mid$} \\
\hline P/CR & 14.773 & \multicolumn{1}{|c|}{$\mid$} \\
\hline P/FIFO & 14.893 & \multicolumn{1}{|c|}{$\mid$} \\
\hline CR/FIFO & 15.153 & \\
\hline
\end{tabular}




\section{Analysis of Fab Type X}

Table F.10.1: ANOVA and Tukey Tables for $\%$ On Time Delivery

\begin{tabular}{lrrrrr}
\hline Source & DF & SS & MS & F & P \\
\hline DR & 6 & 1.0 & 0.2 & 11.5 & 0.000 \\
Error & 14 & 0.2 & 0.0 & & \\
\hline Total & $\mathbf{2 0}$ & $\mathbf{1 . 2}$ & & & \\
\hline
\end{tabular}

\begin{tabular}{|l|r|r|}
\hline $\begin{array}{c}\text { Dispatching } \\
\text { Rule }\end{array}$ & $\begin{array}{c}\text { \% on time } \\
\text { delivery }\end{array}$ & Sig. \\
\hline CR/FIFO & 100 & \\
\hline HXT/FIFO & 100 & \\
\hline P/CR & 100 & \\
\hline P/FIFO & 100 & \\
\hline P/HXT & 100 & \\
\hline FIFO & 99.782 & \multicolumn{1}{|c|}{$\mid$} \\
\hline LBA/FIFO & 99.391 & \\
\hline
\end{tabular}

Table F.10.2: ANOVA and Tukey Tables for Average Cycle Time

\begin{tabular}{lrrrrr}
\hline Source & DF & SS & MS & F & P \\
\hline DR & 623331.0 & 3888.5 & 44.3 & 0.000 \\
Error & 14 & 1230.2 & 87.9 & & \\
\hline Total & $\mathbf{2 0 2 4 5 6 1 . 1}$ & & & \\
\hline
\end{tabular}

\begin{tabular}{|l|r|r|}
\hline $\begin{array}{c}\text { Dispatching } \\
\text { Rule }\end{array}$ & $\begin{array}{r}\text { Avg. Cycle } \\
\text { Time (hours) }\end{array}$ & Sig. \\
\hline P/FIFO & 979.09 & \\
\hline P/HXT & 989.56 & \\
\hline FIFO & 995.36 & \\
\hline P/CR & 1002.6 & \multicolumn{1}{|c|}{$\mid$} \\
\hline HXT/FIFO & 1024.62 \\
\hline LBA/FIFO & 1049.12 \\
\hline CR/FIFO & 1078.82 & \\
\hline
\end{tabular}

Table F.10.3: ANOVA and Tukey Tables for Std. Dev. Of Cycle Time

\begin{tabular}{lrrrrr}
\hline Source & DF & SS & MS & F & P \\
\hline DR & 637834.3 & 6305.7 & 282.3 & 0.000 \\
Error & 14 & 312.7 & 22.3 & & \\
\hline Total & $\mathbf{2 0 3 8 1 4 7 . 1}$ & & & \\
\hline
\end{tabular}

\begin{tabular}{|c|c|c|}
\hline $\begin{array}{c}\text { Dispatching } \\
\text { Rule }\end{array}$ & $\begin{array}{c}\text { Std. Dev. } \\
\text { (hours) }\end{array}$ & Sig. \\
\hline $\mathrm{HXT} / \mathrm{FIFO}$ & 71.91 & \\
\hline FIFO & 97.99 & 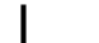 \\
\hline LBA/FIFO & 116.03 & \\
\hline $\mathrm{P} / \mathrm{HXT}$ & 156.28 & \\
\hline P/FIFO & 160.25 & \\
\hline CR/FIFO & 189.57 & \\
\hline $\mathrm{P} / \mathrm{CR}$ & 190.03 & \\
\hline
\end{tabular}

Table F.10.4: ANOVA and Tukey Tables for Average WIP

\begin{tabular}{lrrrrr}
\hline Source & DF & SS & MS & F & P \\
\hline DR & 6 & 5.0 & 0.8 & 43.9 & 0.000 \\
Error & 14 & 0.3 & 0.0 & & \\
\hline Total & $\mathbf{2 0}$ & $\mathbf{5 . 2}$ & & & \\
\hline
\end{tabular}

\begin{tabular}{|l|r|r|}
\hline $\begin{array}{c}\text { Dispatching } \\
\text { Rule }\end{array}$ & Avg. WIP & Sig. \\
\hline P/FIFO & 14.317 & \\
\hline P/HXT & 14.47 & \\
\hline FIFO & 14.557 & \\
\hline P/CR & 14.663 & \multicolumn{1}{|c|}{$\mid$} \\
\hline HXT/FIFO & 14.98 & \\
\hline LBA/FIFO & 15.34 & \\
\hline CR/FIFO & 15.77 & \\
\hline
\end{tabular}




\section{Analysis of Fab Type XI}

Table F.11.1: ANOVA and Tukey Tables for $\%$ On Time Delivery

\begin{tabular}{lrrrrr}
\hline Source & DF & SS & MS & F & P \\
\hline DR & 6 & 697.4 & 116.2 & 373.8 & 0.000 \\
Error & 14 & 4.4 & 0.3 & & \\
\hline Total & $\mathbf{2 0}$ & $\mathbf{7 0 1 . 8}$ & & & \\
\hline
\end{tabular}

\begin{tabular}{|l|r|r|}
\hline $\begin{array}{c}\text { Dispatching } \\
\text { Rule }\end{array}$ & $\begin{array}{c}\text { \% on time } \\
\text { delivery }\end{array}$ & \multicolumn{1}{c|}{ Sig. } \\
\hline P/FIFO & 99.261 & \\
\hline P/HXT & 98.999 & \\
\hline P/CR & 98.911 & \\
\hline CR/FIFO & 97.74 & \multicolumn{1}{|c|}{$\mid$} \\
\hline HXT/FIFO & 87.207 & \\
\hline LBA/FIFO & 87.119 & \\
\hline FIFO & 87.027 & \\
\hline
\end{tabular}

Table F.11.2: ANOVA and Tukey Tables for Average Cycle Time

\begin{tabular}{lrrrrr}
\hline Source & DF & SS & MS & F & P \\
\hline DR & 6 & 14060.1 & 2343.4 & 28.7 & 0.000 \\
Error & 14 & 1141.3 & 81.5 & & \\
\hline Total & $\mathbf{2 0} 15201.4$ & & & \\
\hline
\end{tabular}

\begin{tabular}{|l|r|r|}
\hline $\begin{array}{c}\text { Dispatching } \\
\text { Rule }\end{array}$ & $\begin{array}{c}\text { Avg. Cycle } \\
\text { Time (hours) }\end{array}$ & Sig. \\
\hline P/HXT & 965.37 & \\
\hline FIFO & 972.18 & \\
\hline HXT/FIFO & 972.8 & \\
\hline LBA/FIFO & 974.46 & \multicolumn{1}{|c|}{$\mid$} \\
\hline P/FIFO & 975.18 & \\
\hline P/CR & 1000.23 & \multicolumn{1}{|c|}{$\mid$} \\
\hline CR/FIFO & 1044.69 & \\
\hline
\end{tabular}

Table F.11.3: ANOVA and Tukey Tables for Std. Dev. Of Cycle Time

\begin{tabular}{lrrrrr}
\hline Source & DF & SS & MS & F & P \\
\hline DR & 620502.8 & 3417.1 & 261.6 & 0.000 \\
Error & 14 & 182.9 & 13.1 & & \\
\hline Total & $\mathbf{2 0 2 0 6 8 5 . 7}$ & & & \\
\hline
\end{tabular}

\begin{tabular}{|l|r||c|}
\hline $\begin{array}{c}\text { Dispatching } \\
\text { Rule }\end{array}$ & $\begin{array}{c}\text { Std. Dev. } \\
\text { (hours) }\end{array}$ & Sig. \\
\hline HXT/FIFO & 69.59 & \multicolumn{1}{|c|}{$\mid$} \\
\hline LBA/FIFO & 90.52 & \\
\hline FIFO & 92.31 & \multicolumn{1}{|c|}{$\mid$} \\
\hline P/HXT & 114.84 & \\
\hline P/FIFO & 136.38 & \\
\hline P/CR & 149.8 \\
\hline CR/FIFO & 159.72 & \\
\hline
\end{tabular}

Table F.11.4: ANOVA and Tukey Tables for Average WIP

\begin{tabular}{lrrrrr}
\hline Source & DF & SS & MS & F & P \\
\hline DR & 6 & 3.0 & 0.5 & 28.6 & 0.000 \\
Error & 14 & 0.2 & 0.0 & & \\
\hline Total & $\mathbf{2 0}$ & $\mathbf{3 . 2}$ & & & \\
\hline
\end{tabular}

\begin{tabular}{|c|c|c|}
\hline $\begin{array}{c}\text { Dispatching } \\
\text { Rule }\end{array}$ & Avg. WIP & Sig. \\
\hline $\mathrm{P} / \mathrm{HXT}$ & 14.113 & \\
\hline FIFO & 14.21 & \\
\hline $\mathrm{HXT} / \mathrm{FIFO}$ & 14.223 & \\
\hline LBA/FIFO & 14.243 & \\
\hline P/FIFO & 14.257 & \\
\hline $\mathrm{P} / \mathrm{CR}$ & 14.62 & \\
\hline CR/FIFO & 15.27 & \\
\hline
\end{tabular}




\section{Analysis of Fab Type XII}

Table F.12.1: ANOVA and Tukey Tables for $\%$ On Time Delivery

\begin{tabular}{lrrrrr}
\hline Source & DF & SS & MS & F & P \\
\hline DR & 6 & 0.0 & 0.0 & 4.0 & 0.015 \\
Error & 14 & 0.0 & 0.0 & & \\
\hline Total & $\mathbf{2 0}$ & $\mathbf{0 . 0}$ & & & \\
\hline
\end{tabular}

\begin{tabular}{|l|r|r|}
\hline $\begin{array}{c}\text { Dispatching } \\
\text { Rule }\end{array}$ & $\begin{array}{r}\% \text { on time } \\
\text { delivery }\end{array}$ & Sig. \\
\hline CR/FIFO & 100 & \\
\hline HXT/FIFO & 100 & \\
\hline LBA/FIFO & 100 & \\
\hline P/CR & 100 & \\
\hline P/FIFO & 100 & \\
\hline P/HXT & 100 & \multicolumn{1}{|c|}{} \\
\hline FIFO & 99.913 & \\
\hline
\end{tabular}

Table F.12.2: ANOVA and Tukey Tables for Average Cycle Time

\begin{tabular}{lrrrrr}
\hline Source & DF & SS & MS & F & P \\
\hline DR & 628451.3 & 4741.9 & 54.7 & 0.000 \\
Error & 14 & 1212.9 & 86.6 & & \\
\hline Total & $\mathbf{2 0 2 9 6 6 4 . 3}$ & & & \\
\hline
\end{tabular}

\begin{tabular}{|l|r|c|}
\hline $\begin{array}{c}\text { Dispatching } \\
\text { Rule }\end{array}$ & $\begin{array}{r}\text { Avg. Cycle } \\
\text { Time (hours) }\end{array}$ & Sig. \\
\hline P/HXT & 952.44 & \\
\hline HXT/FIFO & 960.27 & \\
\hline FIFO & 970.34 & \\
\hline LBA/FIFO & 972.74 & \multicolumn{1}{|c|}{$\mid$} \\
\hline P/FIFO & 1019.31 & \multicolumn{1}{|c|}{$\mid$} \\
\hline P/CR & 1031.53 & $\mid$ \\
\hline CR/FIFO & 1053.66 & \\
\hline
\end{tabular}

Table F.12.3: ANOVA and Tukey Tables for Std. Dev. Of Cycle Time

\begin{tabular}{lrrrrr}
\hline Source & DF & SS & MS & F & P \\
\hline DR & 621397.4 & 3566.2 & 119.9 & 0.000 \\
Error & 14 & 416.4 & 29.7 & & \\
\hline Total & $\mathbf{2 0 2 1 8 1 3 . 9}$ & & & \\
\hline
\end{tabular}

\begin{tabular}{|c|c|c|}
\hline $\begin{array}{c}\text { Dispatching } \\
\text { Rule }\end{array}$ & $\begin{array}{c}\text { Std. Dev. } \\
\text { (hours) }\end{array}$ & Sig. \\
\hline $\mathrm{HXT} / \mathrm{FIFO}$ & 66.97 & \\
\hline $\mathrm{P} / \mathrm{HXT}$ & 79.62 & \\
\hline FIFO & 88.37 & \\
\hline LBA/FIFO & 92.39 & \\
\hline $\mathrm{P} / \mathrm{CR}$ & 142.39 & \\
\hline P/FIFO & 144.96 & \\
\hline CR/FIFO & 146.33 & \\
\hline
\end{tabular}

Table F.12.4: ANOVA and Tukey Tables for Average WIP

\begin{tabular}{lrrrrr}
\hline Source & DF & SS & MS & F & P \\
\hline DR & 6 & 6.0 & 1.0 & 56.1 & 0.000 \\
Error & 14 & 0.3 & 0.0 & & \\
\hline Total & $\mathbf{2 0}$ & $\mathbf{6 . 3}$ & & & \\
\hline
\end{tabular}

\begin{tabular}{|l|r||c|}
\hline $\begin{array}{c}\text { Dispatching } \\
\text { Rule }\end{array}$ & Avg. WIP & Sig. \\
\hline P/HXT & 13.927 & \\
\hline HXT/FIFO & 14.04 & \\
\hline FIFO & 14.187 & \\
\hline LBA/FIFO & 14.22 & \multicolumn{1}{|c|}{$\mid$} \\
\hline P/FIFO & 14.893 & \multirow{2}{*}{$\mid$} \\
\hline P/CR & 15.077 & \\
\hline CR/FIFO & 15.403 & \\
\hline
\end{tabular}




\section{Appendix G. Simulation Models of Semiconductor Research and Development Fabs and Results for Experiments 1, 2 and 3 on CD}

This appendix contains a brief description of the simulation models used in Experiments 1, 2 and 3 and results from these experiments. The data used for the modeling and the results can be found in excel workbooks on a CD attached to the back cover of the bound thesis. The Excel workbooks are named "Experiment 1 and Experiment 2.xls", "Experiment 3.xls" and "Results.xls". The first workbook is used to simulate models for Experiments 1 and 2 and the second to simulate models for Experiment 3. The third workbook contains results from the simulations of all three experiments.

Table G.1 briefly describes the contents of the spreadsheets of the workbooks containing data for the simulation models. Detailed instructions on changing WIP levels, dispatching rules, production volumes, technical support, tools quantities, product mix and lead time can be found in the spreadsheets of the workbooks.

Table G.1: Contents of Spreadsheets of Workbooks Titled "Experiment 1 and Experiment 2.xls" and "Experiment 3.xls"

\begin{tabular}{|c|l|}
\hline Spreadsheet Name & \\
\hline part.txt & lists the parts and lots used in the model \\
\hline order.txt & lists the interarrival rate for lots introduced in the fab \\
\hline stn.txt & contains data on tool quantities, capacities, load times and associated storages \\
\hline kanban.txt & contains genres to control WIP in the system \\
\hline oper.txt & $\begin{array}{l}\text { lists the operators available to process lots at tools/stations and technical operators } \\
\text { to repair down tools }\end{array}$ \\
\hline attach.txt & assigns schedules to resources (tools and operators) \\
\hline kanbandevilloop.txt & contains actionlists for lots to trigger down and PM events \\
\hline devilPMloop.txt & contains actionlists for lots to trigger PM events at the respective tools \\
\hline devildownloop.txt & contains actionlists for lots to trigger down events based on statistical distributions \\
\hline subcmos.txt & $\begin{array}{l}\text { contains actionlists for representative lots when they visit tools that require specific } \\
\text { actions in their routes }\end{array}$ \\
\hline pmroutes.txt & lists routes for lots that trigger PM events \\
\hline downroutes.txt & lists routes for lots that trigger down events \\
\hline route2.txt/reproute.txt & $\begin{array}{l}\text { details the steps in the representative route, specifying the tool, the operator, the } \\
\text { setup and the actionlist required }\end{array}$ \\
\hline storage.txt & specifies storages for tools \\
\hline setup.txt & specifies setup times for tools \\
\hline shiftcal.txt & specifies schedules for the operators in the fab \\
\hline techcal.txt & specifies schedules for the technical support group \\
\hline shiftSTNcal.txt & specifies schedules for tools including tool reservations and off times \\
\hline shiftrepdummycal.txt & $\begin{array}{l}\text { specifies schedules for the control operators who leave before the designated } \\
\text { window for their completion until the end of shift of the designated operator }\end{array}$ \\
\hline
\end{tabular}


Table G.2 contains a description of the contents of the spreadsheet in the workbook having results and graphs from the three experiments.

Table G.2: Contents of Spreadsheets of Workbooks Titled "Results.xls"

\begin{tabular}{|c|l|}
\hline Spreadsheet Name & \multicolumn{1}{|c|}{ Contents } \\
\hline Experiment 1 Results & contains results from the experimental design conducted for Experiment 1 \\
\hline Experiment 1 Graph & contains graphs for average cycle time, throughput and tradeoff for Experiment 1 \\
\hline Experiment 2 Results & contains results from the experimental design conducted for Experiment 2 \\
\hline Experiment 3 Raw Data & contains raw data from the experimental design conducted for Experiment 3 \\
\hline
\end{tabular}

